\title{
Um Framework para criação e simulação de Redes Neurais Artificiais utilizando Component Object Model $^{1}$
}

\section{Humberto Costa de Sousa}

Orientador: Prof. Dr. André Carlos P. de Leon F. de Carvalho

Dissertação apresentada ao Instituto de Ciências Matemáticas e de Computação - ICMC-USP, como parte dos requisitos para obtenção do título de Mestre em Ciências de Computação e Matemática Computacional. 
"Ao grande amor da minha vida, Elaine." 


\section{Agradecimentos}

Aos meus pais pelo apoio, compreensão e carinho que sempre demonstraram durante toda a minha vida, principalmente nestes dois anos em que estive ausente, sempre lembrando da grande importância da família em todas as conquistas.

Ao Prof. Dr. André de Carvalho, que mais que um orientador, sempre foi um grande amigo que acompanhou constantemente o desenvolvimento deste trabalho, mesmo durante grandes mudanças na sua vida.

À Prof. Dra. Solange Rezende, que como um anjo da guarda sempre esteve presente, ajudando e aconselhando nos momentos mais difíceis.

À minha adorada esposa Elaine pela imensa contribuição na redação deste texto, e mais ainda por compartilhar seus problemas e conquistas, sempre com as palavras certas de incentivo que me permitiram concluir este trabalho.

Ao meu amigo, colega e verdadeiro guru da programação Ernesto, que me convenceu a reaprender orientação a objetos, sempre estando por perto para me tirar dos apuros.

Ao novo amigo Luis, pela indispensável ajuda e com quem tive o prazer de dividir algumas das tarefas mais árduas deste trabalho.

À Laura, Beth, Marília, Sandra e Adriana, que habilmente resolveram todas as dificuldades burocráticas que inevitavelmente surgiram nestes dois anos.

Aos amigos Walter, Robson e Chandler que me ajudaram a dominar o Latex, pelo menos o suficiente para escrever este texto, embora não tenham me ensinado a "abrir aspas".

Aos amigos e professores do Labic, pela ajuda direta ou indireta a este trabalho.

A FAPESP e CAPES pelo auxílio financeiro fornecido ao longo deste trabalho. 


\section{Resumo}

Tarefas envolvendo Reconhecimento de Padrões vêm se tornando mais freqüentes em diferentes domínios de aplicação. A maioria destas tarefas tem sido eficientemente tratada através da utilização de Redes Neurais Artificiais. Entre os modelos de Redes Neurais mais difundidos, destaca-se o modelo Perceptron Multi-Camadas (Multi-Layer Perceptron ou MLP). Entretanto, o desempenho de uma Rede Neural MLP em um determinado problema depende diretamente da topologia adotada, que deve ser determinada no início do processo de treinamento. A escolha da topologia de uma Rede Neural não é trivial, normalmente resultando em uma busca exaustiva pela configuração mais apropriada.

Com o objetivo de auxiliar a determinação da topologia de uma Rede Neural, vários métodos foram desenvolvidos para a automação deste processo, entre os quais encontram-se as Redes Neurais Construtivas. Estas redes utilizam Algoritmos Construtivos que, a partir de uma rede mínima, inserem gradualmente novos neurônios e conexões durante o treinamento, procurando melhorar o desempenho da mesma. Contudo, a avaliação da melhor aplicação de diferentes Algoritmos Construtivos em um mesmo problema depende da homogeneidade do seu ambiente de treinamento.

Este trabalho fornece a definição de um conjunto de classes abstratas para permitir que diferentes algoritmos de treinamento, incluindo Algoritmos Construtivos, sejam criados como componentes com acesso estritamente definido para futura utilização em diferentes aplicações. Através do uso destes componentes em uma nova versão do Simulador para Redes Neurais Artificiais Kipu, a análise da eficiência de Redes Neurais Construtivas em tarefas reais de Reconhecimento de Padrões teve início. 


\section{Abstract}

Tasks involving Pattern Recognition are becoming more frequent in many applications. Most of these tasks have been efficiently handled by Artificial Neural Networks. One of the most common models used is the MLP (Multi-Layer Perceptron), though its performance is directly dependent on the chosen topology, which it must be set in the beginning of the training process. The choice of a Neural Network topology is not trivial, and usually becomes an exhaustive search for the most appropriate configuration.

Several methods have been developed to automatically find a suitable Neural Network topology, including Constructive Neural Networks. These networks are trained by Constructive Algorithms which, starting from a minimal topology, gradually insert new neurons and connections, aming to improve the network's performance. Nevertheless, the evaluation of the best use of such algorithms in a given task depends on the homogeneity of the training environment.

This work provides the definition of a set of abstract classes which allow different training algorithms, including Constructive Algorithms, to be built as components with strictly defined access in order to be used in different applications. By using these components in a new version of the Kipu Neural Network Simulator, it is possible to begin analyzing the efficiency of Constructive Neural Networks in real Pattern Recognition tasks. 


\section{Conteúdo}

1 Introduçāo

1.1 Considerações Iniciais . . . . . . . . . . . . . . . . . . 2

1.2 Motivação e Objetivo . . . . . . . . . . . . . . . . 4

1.3 Organização do Trabalho . . . . . . . . . . . . . . . . 5

2 Redes Neurais Artificiais e Reconhecimento de Padrões $\quad 7$

2.1 Introdução . . . . . . . . . . . . . . . . . . . 7

2.2 Redes Neurais Artificiais . . . . . . . . . . . . . . . . 8

2.3 Reconhecimento de Padrões . . . . . . . . . . . . . . . . 12

2.4 Consideraçōes Finais . . . . . . . . . . . . . . . . . . . . . 14

3 Redes Neurais Construtivas - $\quad 15$

3.1 Introdução . . . . . . . . . . . . . . . . . . . 15

3.2 Algoritmos Construtivos . . . . . . . . . . . . . . . . 17

3.2 .1 Cascade Correlation . . . . . . . . . . . . . 17

3.2 .2 Tower e Pyramid . . . . . . . . . . . . . . . 21

3.2 .3 Upstart . . . . . . . . . . . . . . . . . . . 24

3.2 .4 Perceptron Cascade . . . . . . . . . . . . . . 27

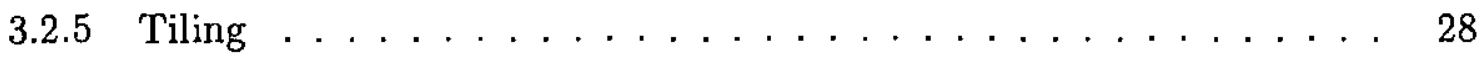

3.3 Taxonomia para Redes Neurais Construtivas . . . . . . . . . . . . . . . 31

3.4 Consideraçōes Finais . . . . . . . . . . . . . . . . . . . 32

4 Kipu - Um Simulador para Redes Neurais Artificiais $\quad 34$ 
4.1 Análise do Simulador Kipu . . . . . . . . . . . . . . . . . . . . . . 34

4.2 Component Object Model - COM . . . . . . . . . . . . . . 36

4.2 .1 Interfaces $\mathrm{COM} \ldots \ldots \ldots \ldots \ldots \ldots \ldots \ldots$

4.2 .2 Herança . . . . . . . . . . . . . . . . . . 39

4.2 .3 Agregação . . . . . . . . . . . . . . . . . 40

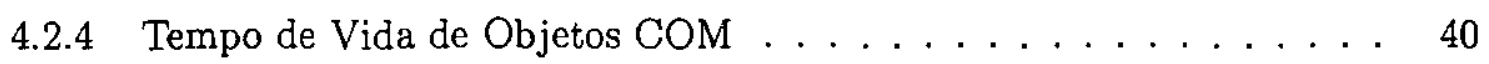

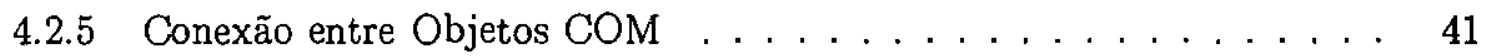

4.3 Considerações Finais $\ldots \ldots \ldots \ldots \ldots \ldots$

5 O Simulador Kipu como um Framework para Redes Neurais 44

5.1 Hierarquia de Classes . . . . . . . . . . . . . . . . . . 46

5.1.1 Os elementos de uma Rede Neural $\ldots \ldots \ldots \ldots \ldots$

5.1 .2 Algoritmos de Treinamento . . . . . . . . . . . . . 47

5.1 .3 Algoritmos Construtivos . . . . . . . . . . . . 47

5.1 .4 Tratamento de padrões . . . . . . . . . . . . . . 53

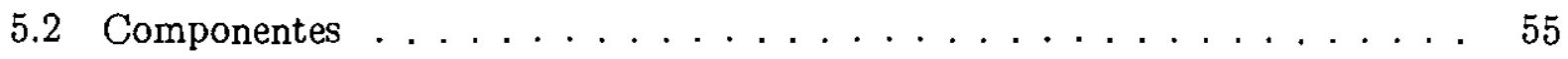

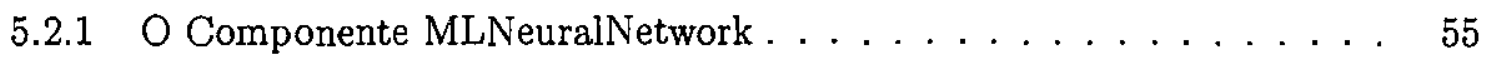

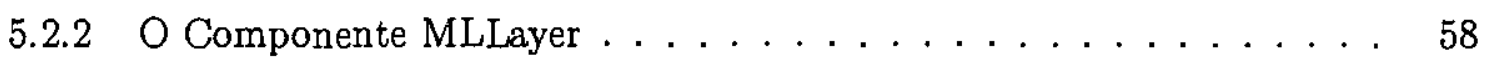

5.2 .3 O Componente Neuron . . . . . . . . . . . . . . . . 59

5.2.4 Componentes para Algoritmos de Treinamento . . . . . . . . . . 59

5.2.5 Componentes para Algoritmos Construtivos . . . . . . . . 62

5.2.6 Componentes para Conjunto de Padrões . . . . . . . . . . . 67

5.3 Modelo de Dados para Redes MLP e Visualizadores . . . . . . . . . . 68

5.4 O Repositório de Dados . . . . . . . . . . . . . . . . 70

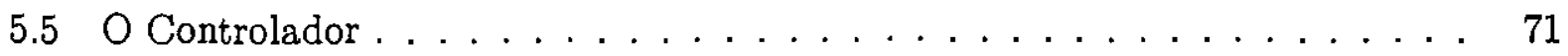

5.6 Conexão entre Componentes . . . . . . . . . . . . . . . . . 72

5.7 O Módulo Cliente . . . . . . . . . . . . . . . . . . . 73

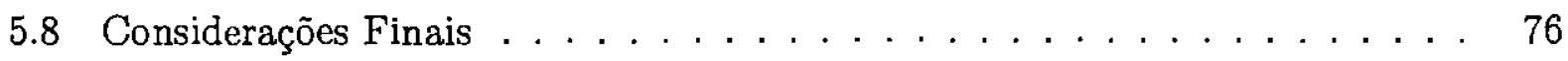

6 Experimentos $\quad$. $\quad 78$

6.1 Conjunto de Padrões Diabetes . . . . . . . . . . . . . . . . 79 
6.1.1 Resultados Obtidos pelo Tower ... . . . . . . . . . . . 80

6.1.2 Resultados Obtidos pelo Pyramid . . . . . . . . . . . . . . 81

6.1 .3 Análise dos Resultados . . . . . . . . . . . . . . . 82

6.2 Conjunto de Padrões Gene . . . . . . . . . . . . . . . . . . 83

6.2 .1 Resultados Obtidos pelo Tower ................ 84

6.2 .2 Resultados Obtidos pelo Pyramid . . . . . . . . . . . . 85

6.2 .3 Análise dos Resultados . . . . . . . . . . . . . . 86

7 Conclusão $\quad 87$

7.1 Contribuições . . . . . . . . . . . . . . . . . . 90

7.2 Dificuldades Encontradas . . . . . . . . . . . . . . . . . 91

7.3 Trabalhos Futuros . . . . . . . . . . . . . . . . 91 


\section{Lista de Figuras}

2.1 Representação linear de um neurônio em uma RNA e a combinação linear de

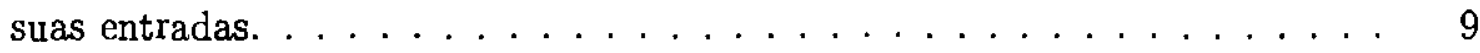

2.2 Gráficos das funções de ativação Linear, Threshold e Threshold Bipolar. . . . 9

2.3 Gráficos das funçôes de ativação Sigmoid e Sigmoid Logística. . . . . . . . . . 10

3.1 Seleção de uma nova unidade entre um conjunto de candidatos. . . . . . . 18

3.2 Os neurônios candidatos são organizados em uma camada. . . . . . . . . . 19

3.3 Estado inicial da rede Cascade Correlation. . . . . . . . . . . . . . . . 20

3.4 Estado da rede após inserção de um neurônio. . . . . . . . . . . . . . 20

3.5 Estado da rede após inserção de um segundo neurônio. . . . . . . . . . . . 20

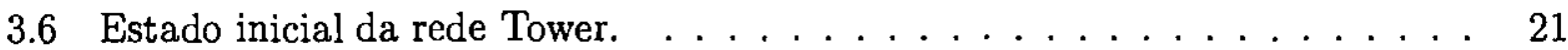

3.7 Inserção de uma nova camada: a camada de saída torna-se uma camada

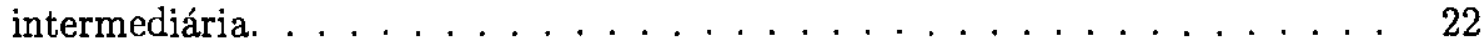

3.8 Inserção de uma segunda camada: novamente, a camada de saída torna-se uma camada intermediária. . . . . . . . . . . . 22

3.9 Rede Pyramid. A seta indica a conexão entre a camada Inter 1 e a camada

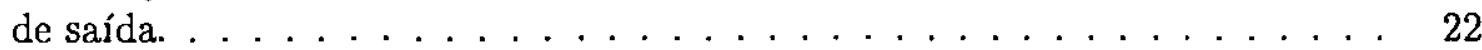

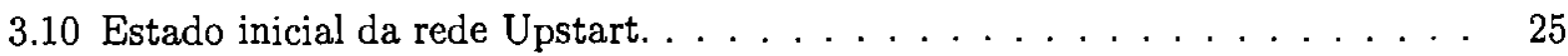

3.11 Inserção de um novo neurônio $X$ ou $Y$ em uma camada intermediária. . . . . 26

3.12 Inserção de um segundo neurônio $X$ ou $Y$ na mesma camada intermediária

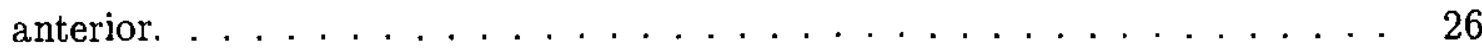

3.13 Estado inicial da rede Tiling. . . . . . . . . . . . . . . . . . . . 29

3.14 Inserção de neurônios auxiliares para cumprir o critério da Fidelidade. . . . . 29

3.15 Uma nova camada de saída é criada e o critério da Fidelidade é novamente verificado. . . . . . . . . . . . . . . . . . . . . 29

4.1 Antiga hierarquia de classes representando os algoritmos no simulador Kipu. 35 
4.2 Esquema de comunicação entre objeto e cliente utilizando connection points.

5.1 As interfaces IUnknown e IDispatch são pais das classes da nova hierarquia. 45

5.2 Hierarquia de classes representando os elementos de uma Rede Neural. . . . 48

5.3 Hierarquia de classes para as variações do Algoritmo back-propagation. . . . 49

5.4 Hierarquia de classes do algoritmo Tower e sua variação Pyramid. . . . . . . 51

5.5 Hierarquia de classes para os algoritmos Cascade Correlation e MTiling. . . . 52

5.6 Classes para tratar padrões (IPattern, IPersistPattern e IPatternIterator). 54

5.7 O componente MLNeuralNetwork. . . . . . . . . . . . . 56

5.8 O componente MLLayer. . . . . . . . . . . . . . . . . . 58

5.9 O componente Neuron. . . . . . . . . . . . . . . . . . . . . 59

5.10 . componente StdBackProp. . . . . . . . . . . . . 60

5.11 O componente BackPropMomentum. . . . . . . . . . . . . . . 61

5.12 O componente QuickProp. . . . . . . . . . . . . . . . . 61

5.13 O componente CascadeCorrelation. . . . . . . . . . . . 64

5.14 O componente Tower. . . . . . . . . . . . . . . . 65

5.15 O componente Pyramid. . . . . . . . . . . . . 65

5.16 O componente Upstart. . . . . . . . . . . . . . . . . 66

5.17 O componente PerceptronCascade. . . . . . . . . . . . . . 66

5.18 O componente MTiling. . . . . . . . . . . . . . . . 67

5.19 Os componentes SNNSPattern e Pattern. . . . . . . . . . . . 68

5.20 Estrutura de dados representando uma Rede Neural Multi-Camadas. . . . . 69

5.21 Relacionamento entre o Controller e os demais componentes. . . . . . . . . 72

5.22 Janelas do módulo cliente. . . . . . . . . . . . . . . . . . 74 


\section{Lista de Tabelas}

6.1 Estatística do conjunto de dados Diabetes. . . . . . . . . . . . 80

6.2 Resultados do Algoritmo Tower treinado com back-propagation. . . . . . 80

6.3 Resultados do Algoritmo Tower treinado com back-propagation momentum. 80

6.4 Resultados do Algoritmo Tower treinado com quick-propagation. . . . . . . . 81

6.5 Resultados do Algoritmo Pyramid treinado com back-propagation. . . . . . . 81

6.6 Resultados do Algoritmo Pyramid treinado com back-propagation momentum. 81

6.7 Resultados do Algoritmo Pyramid treinado com quick-propagation. . . . . 82

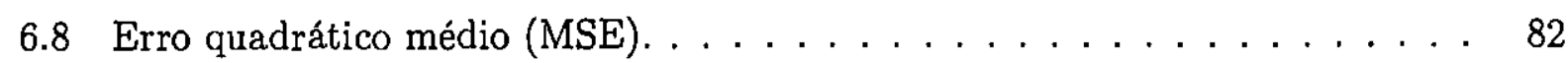

6.9 Resultados do Algoritmo back-propagation aplicado em uma Rede Neural 8-

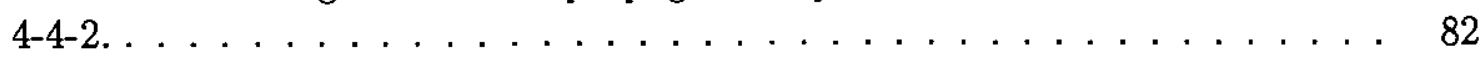

6.10 Mapeamento dos padrões de entrada. . . . . . . . . . . . . 84

6.11 Resultados do Algoritmo Tower treinado com back-propagation. . . . . . . 84

6.12 Resultados do Algoritmo Tower treinado com quick-propagation. . . . . . . . 84

6.13 Resultados do Algoritmo Pyramid treinado com back-propagation. . . . . . 85

6.14 Resultados do Algoritmo Pyramid treinado com quick-propagation. . . . . 85

6.15 Comparação entre o MSE de cada configuração. . . . . . . . . . . . 86

6.16 Resultados do Algoritmo back-propagation aplicado em uma Rede Neural $120-2-3 . \ldots \ldots \ldots \ldots \ldots \ldots \ldots$. . . . . . . . . . . . . . . . . 


\title{
Lista de Abreviações
}

\author{
ATL Active Template Library \\ CLSID Class Identifier \\ COM Component Object Model \\ DLL Dynamic Link Library \\ GUID Global Unique Identifier \\ IID Interface Identifier \\ MFC Microsoft Foundation Class \\ MLP Multilayer Perceptron \\ RNA Rede Neural Artificial \\ RNC Rede Neural Construtiva \\ RPC Remote Procedure Call \\ TLU Threshold Logic Unit
}




\section{Capítulo 1}

\section{Introdução}

Esta dissertação é o resultado de um trabalho cujo objetivo inicial é investigar a aplicação de Redes Neurais Construtivas, RNCs, em tarefas de Reconhecimento de Padrōes. Durante as pesquisas realizadas para este trabalho, diversas soluções propostas na literatura para o projeto de Redes Neurais mais eficientes foram revisadas.

Para suprir a necessidade de comprovar a eficiência de vários dos modelos propostos através de experimentação, o simulador para Redes Neurais Artificiais chamado Kipu, desenvolvido em um trabalho de Mestrado (Vargas, 1998), foi avaliado, contatando-se a necessidade do desenvolvimento de uma versão mais eficiente e flexível. A implementação desta nova versão do Simulador Kipu explora conceitos de orientação a objetos mais abstratos, permitindo uma flexibilidade no projeto de modelos e algoritmos de Redes Neurais ainda maior que a encontrada na versão anterior do Simulador. Estes conceitos são definidos pelo modelo de objetos componentes (Component Object Model - COM) (Microsoft, 1995).

Ao definir um conjunto de classes para o desenvolvimento de Redes Neurais, foi possivel estabelecer uma estrutura onde a adição de novos algoritmos e modelos de Redes Neurais torna-se totalmente independente do programa executável responsável pelo controle do treinamento e utilização de uma Rede Neural. Esta independência permite também que os mesmos objetos criados para o Simulador possam ser facilmente compartilhados com outras aplicações sem influência na sua implementação.

Os experimentos descritos neste trabalho representam as primeiras comparações dos Algo- 
ritmos Construtivos discutidos e implementados na nova versão do Simulador Kipu. Os conjuntos de dados reais utilizados estão disponíveis em um repositório público, e os resultados obtidos nestes experimentos foram analisados de acordo com as regras dispostas no benchmark Proben1(Prechelt, 1994).

As próximas seções descrevem as motivações e objetivos deste trabalho, bem como a sua organização.

\subsection{Considerações Iniciais}

Redes Neurais Artificiais (RNAs) vêm sendo amplamente utilizadas em tarefas de Reconhecimento de Padrões, envolvendo aplicaçōes como análise de crédito (Refenes, 1995) e reconhecimento automático de alvos (Haykin, 1999). O sucesso destas tarefas está diretamente relacionado ao desempenho da RNA utilizada, o qual é analisado a partir da sua capacidade de generalização e precisão (Mehra and Wah, 1992).

Um dos modelos mais estudados em problemas de Reconhecimento de Padrões é a rede Perceptron Multi-Camadas (Multilayer Perceptron ou MLP) (Rumelhart et al., 1986) (Haykin, 1999). Este modelo utiliza originalmente o algoritmo de treinamento back-propagation, que realiza gradiente descendente no espaço de pesos. Entretanto, para apresentar um bom desempenho, a rede MLP requer uma definição do número de neurônios e a disposição dos mesmos entre as camada antes do início do treinamento. Redes muito pequenas dificilmente resolvem problemas complexos, enquanto redes muito grandes perdem a capacidade de generalização, reduzindo o desempenho para novos dados (overfitting). A definição do tamanho da rede e a disposição dos neurônios, conhecida como escolha da topologia, não é orientada por regras ou critérios baseados no problema aplicado. Esta escolha torna-se então um problema empírico, resultando em perda de tempo e esforço na busca pela topologia mais adequada para o problema abordado (Kwok and Yeung, 1997).

Com o objetivo de suprir esta limitação, as Redes Neurais Construtivas (RNCs) oferecem uma abordagem atrativa para a construção incremental de topologias a partir de uma rede mínima. Uma rede mínima possui apenas camadas de entrada e saída, necessárias para a correta representação do conjunto de dados utilizado no treinamento da Rede Neural. Durante 
seu treinamento, uma RNC insere novos neurônios e conexōes de acordo com um critério definido por seu Algoritmo Construtivo, até que uma solução satisfatória seja encontrada ou o algoritmo seja interrompido. Desta maneira, uma topologia é criada de acordo com a necessidade do problema abordado, dispensando uma busca exaustiva pela topologia mais adequada. Entre as principais motivações do estudo de Redes Neurais Construtivas, pode-se citar (Parekh et al., 1997a):

- Flexibilidade na exploração do espaço de topologias: RNCs superam a limitação de busca por uma solução no espaço de pesos de uma topologia determinada a priori (antes do treinamento) através da extensão controlada da busca em todo o espaço de topologias da rede.

- Trocas entre medidas de desempenho: Algoritmos Construtivos diferentes permitem a troca de certas medidas de desempenho (como tempo de aprendizado) por outras (como tamanho da rede e precisão de generalização).

- Adição de conhecimento anterior: as RNCs permitem que conhecimento específico ao problema seja incorporado através da configuração inicial da rede ou pela modificação deste conhecimento utilizando novos exemplos de treinamento.

- Aprendizado contínuo: RNCs permitem que uma Rede Neural que já possui um domínio de conhecimento em sua topologia para resolver problemas simples possa ser utilizada como rede inicial no treinamento de uma nova topologia para tratar tarefas mais complexas dentro do mesmo domínio.

As Redes Neurais Construtivas consideradas neste trabalho são extensões do modelo MLP, em que a topologia é definida durante o processo de aprendizado da rede. Esta abordagem torna-se interessante quando o tempo gasto na definição da topologia é relevante.

Cada modelo de RNC possui seu próprio critério de inserção de novos neurônios e conexões. A diferença entre estes critérios permite a construção de redes diferentes para um mesmo problema. Portanto, não é possível determinar qual modelo é mais propício para um determinado problema sem um estudo comparativo do desempenho das RNCs. 


\subsection{Motivação e Objetivo}

A criação de algoritmos que implementem Redes Neurais Construtivas, chamados Algoritmos Construtivos, é recente nas pesquisas em Redes Neurais Artificiais. A implementação destes algoritmos normalmente é restrita às preferências do projetista, sendo muitas vezes dependente de plataformas e formato de dados. Uma correta comparação do desempenho de RNCs depende da homogeneidade do ambiente de execução, onde a estrutura de dados que representa cada RNC e as operações que envolvem esta estrutura sejam as mesmas para todos os modelos. Atualmente, uma série de simuladores de Redes Neurais (Vargas, 1998) fornecem este ambiente homogêneo para modelos convencionais. Entretanto, poucos implementam modelos construtivos e poucos Algoritmos Construtivos são disponibilizados nestes simuladores.

Da necessidade de trabalhar com as RNCs em um único ambiente, o Simulador Kipu (Vargas, 1998) foi inicialmente projetado. Este simulador oferece recursos gráficos para a edição de Redes Neurais e permite a inclusão de novos modelos e algoritmos de treinamento. Entretanto, no decorrer deste trabalho observou-se que o projeto original do Simulador Kipu não atenderia às necessidades impostas pela proposta de trabalho.

A reformulação do projeto do simulador superou as expectativas em respeito à complexidade. Porém, no seu decorrer surgiu a oportunidade da criação de um simulador para Redes Neurais Artificiais com um grande diferencial sobre os já encontrados em ambientes de pesquisa, principalmente no que se refere à flexibilidade de utilização, desenvolvimento de novos modelos e interação com diferentes tipos de aplicações.

Dos Algoritmos Construtivos citados no Capítulo 3, alguns já estavam implementados na primeira versão do Simulador Kipu. Estes foram revisados e adaptados ao novo projeto do simulador, comparando os resultados obtidos na nova implementação dos algoritmos aos resultados publicados por seus autores, visando eliminar possíveis erros de interpretação na nova implementação. Os experimentos apresentados neste trabalho utilizaram os Algoritmos Construtivos que foram revisados e utilizados com sucesso no treinamento de Redes Neurais com os conjuntos de padrōes selecionados.

Os demais Algoritmos Construtivos ainda necessitam de revisão mais detalhada, e os ex- 
perimentos realizados com estes algoritmos serão apresentados futuramente em relatórios técnicos publicados pelo Instituto de Ciências Matemáticas e de Computação.

Um novo objetivo e conseqüente resultado alcançado por este trabalho foi o nível de flexibilidade e abertura do novo projeto, que nāo só permitiu a implementação de uma nova versão do Simulador Kipu, mas também permite que outros aplicativos possam utilizar o mesmo conjunto de classes. Enquanto na primeira versão qualquer extensão ao projeto era dependente do modelo de dados implementado e deveria adaptar-se à estrutura já definida pelo módulo principal do programa, a nova versão permite que novas estruturas de dados sejam facilmente acopladas ao módulo principal, reutilizando partes (aqui chamadas de componentes) já implementadas ou criando novos componentes necessários para a correta execução do treinamento de Redes Neurais. Novos componentes são criados tomando como base classes abstratas, ou templates, adicionados através de bibliotecas (Dynamic Link Libraries - DLLs) incorporadas ao programa principal em tempo de execução. As vantagens resultantes desta nova abordagem sāo detalhadas nos Capítulos 4 e 5 .

Uma vez que a conclusão do novo projeto consumiu mais dedicação do que inicialmente previsto, apenas os primeiros experimentos planejados foram executados. Os resultados obtidos já ilustram uma tendência sobre o comportamento de alguns dos algoritmos avaliados. Estes experimentos utilizaram as regras de execução e os conjuntos de padrões disponíveis em Proben1 (Prechelt, 1994), que é um conjunto de benchmarks contendo diversos conjuntos de padrões relacionados a diferentes domínios de problemas reais envolvendo Reconhecimento de Padrões.

\subsection{Organização do Trabalho}

Este trabalho apresenta a seguinte organização:

- Capítulo 1: são apresentadas as idéias que motivaram o desenvolvimento do trabalho, seu objetivo e organização;

- Capítulo 2: são apresentados conceitos gerais sobre Redes Neurais Artificiais e Reconhecimento de Padrões; 
- Capítulo 3: são apresentados e discutidos os modelos de Redes Neurais Construtivas estudados, citando suas peculiaridades. Estes modelos são baseados no Perceptron Multi-camadas (Multi-Layer Perceptron ou MLP);

- Capítulo 4: são apresentados a análise do protótipo inicial do Simulador Kipu, o projeto da nova versāo e os conceitos do modelo de objetos componentes (COM) utilizado nesse projeto;

- Capítulo 6: é apresentado um resumo dos experimentos realizados e os resultados obtidos. Estes resultados são analisados e discutidos;

- Capítulo 7: é apresentada a conclusão deste trabalho e sugestões para trabalhos futuros;

- Referências Bibliográficas. ${ }^{1}$

\footnotetext{
${ }^{1}$ As referências bibliográficas deste texto foram geradas com o aplicativo BibText, portanto esta e todas as citaçōes estarão em inglês.
} 


\section{Capítulo 2}

\section{Redes Neurais Artificiais e}

\section{Reconhecimento de Padrões}

\subsection{Introdução}

Redes Neurais Artificiais (RNAs) são modelos computacionais inspirados no funcionamento do sistema nervoso humano, cujo funcionamento é totalmente diferente de um sistema computacional convencional. Enquanto um sistema convencional opera sobre algoritmos, regras e processamento exato, uma RNA explora diversas hipóteses que competem entre si simultaneamente. Para isto, uma RNA utiliza vários elementos computacionais conectados por ligações ponderadas por pesos (Lippmann, 1992). Este tratamento faz com que RNAs ofereçam uma solução mais atrativa para problemas de difícil tratamento em sistemas convencionais, como reconhecimento de imagens e fala, controle, e outras tarefas cognitivas. Entre os problemas eficientemente tratados por RNAs estão as tarefas de Reconhecimento de Padrões. Estas tarefas consistem em compreender e classificar um grupo de medidas ou características em uma entre várias classes. Um exemplo de um problema de Reconhecimento de Padrões é o reconhecimento de imagens, em que o conjunto de valores dos pixels de uma imagem pode ser classificado em uma classe que representa o objeto representado pela imagem.

Técnicas de programação convencionais usualmente não apresentam um bom desempenho 
na resolução de tarefas de Reconhecimento de Padrões, devido à sua dificuldade de generalização. Ou seja, apenas os exemplos mostrados ao classificador são corretamente classificados, enquanto exemplos inéditos pertencentes à mesma classe não são devidamente classificados. Para um melhor entendimento de como RNAs tratam tarefas de Reconhecimento de Padrões, as próximas seções apresentam os fundamentos teóricos e a notação utilizada no desenvolvimento deste trabalho.

\subsection{Redes Neurais Artificiais}

Existem várias formas de se definir uma Rede Neural Artificial. Do ponto de vista computacional, uma RNA compreende uma forma de representar funções utilizando elementos aritméticos simples e métodos para aprender como representar estas funções a partir da apresentação de exemplos. Do ponto de vista biológico, uma RNA é um modelo matemático que representa como são feitas as operações do sistema nervoso humano (Russel and Norvig, 1995). Uma definição mais formal de RNAs pode ser encontrada em (Haykin, 1999):

Uma Rede Neural é um processador massivamente paralelo e distribuído, composto de unidades de processamento simples, as quais possuem uma propensão natural para armazenar conhecimento adquirido por experimentaçâo e torná-lo disponível para utilização. Uma Rede Neural assemelha-se com o cérebro em dois aspectos:

1. O conhecimento é adquirido pela rede a partir do seu ambiente através de um processo de aprendizado.

2. Conexões de reforço entre neurônios, conhecidas como pesos sinápticos, são utilizadas para armazenar o conhecimento adquirido.

A unidade básica de processamento de uma RNA é chamada neurônio. A Figura 2.1 mostra um modelo simplificado de um neurônio, onde a seta à direita do neurônio representa seu valor de saída $y$ e o conjunto de setas que apontam para o lado esquerdo do neurônio representam as conexões com as saídas de outros neurônios ou entradas da rede. A Equação 
2.1 descreve a combinação linear, $u(t)$, sobre os valores de entrada, onde $t$ indica o instante em que o sinal da rede é propagado para esse neurônio.

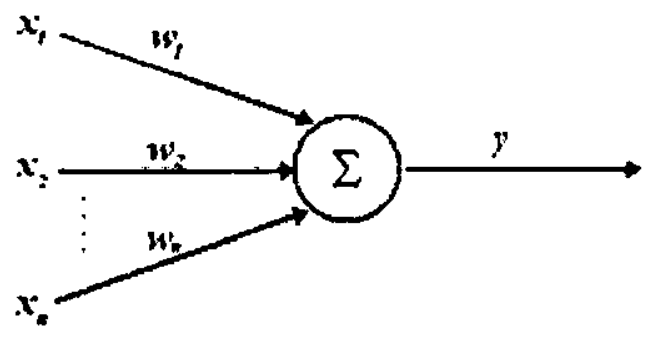

Figura 2.1: Representação linear de um neurônio em uma RNA e a combinação linear de suas entradas.

$$
u(t)=\sum_{j=0}^{n} x_{j}(t) . w_{j}
$$

O vetor de entrada $X=\left[x_{1}, x_{2}, \ldots, x n\right]^{(t)}$ pode ser a entrada da rede ou o conjunto de saídas dos neurônios que estão conectados à entrada do neurônio em questão. Cada valor de entrada $x_{j}$ é multiplicado por um fator de excitação (ou inibição) $w_{j}$, conhecido como peso da conexão. A saída $y(t)$ produzida por um neurônio é o resultado de uma função de ativação $a(t)$ aplicada sobre o valor $u(t)$. As funções de ativação mais usuais são apresentadas na Figura 2.2 e na Figura 2.3, com suas respectivas equações.

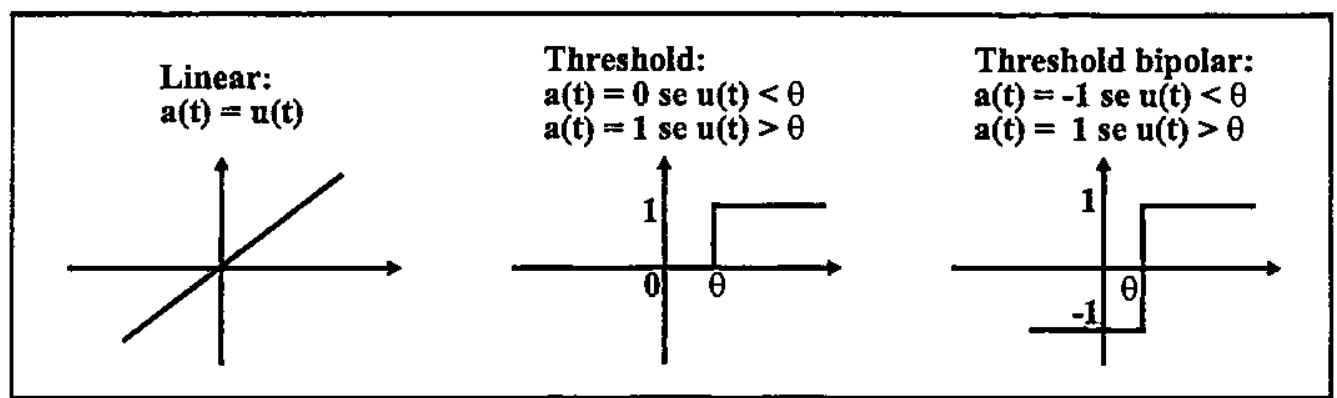

Figura 2.2: Gráficos das funções de ativação Linear, Threshold e Threshold Bipolar.

Vários modelos de RNAs têm sido propostos na literatura. Este trabalho concentra-se em redes Perceptron Multi-Camadas. Estas redes caracterizam-se por manter os neurônios agrupados em camadas distintas, classificadas como camada de entrada, intermediária (ou escondida) e de saída. Em uma arquitetura convencional da rede MLP, os neurônios de uma 


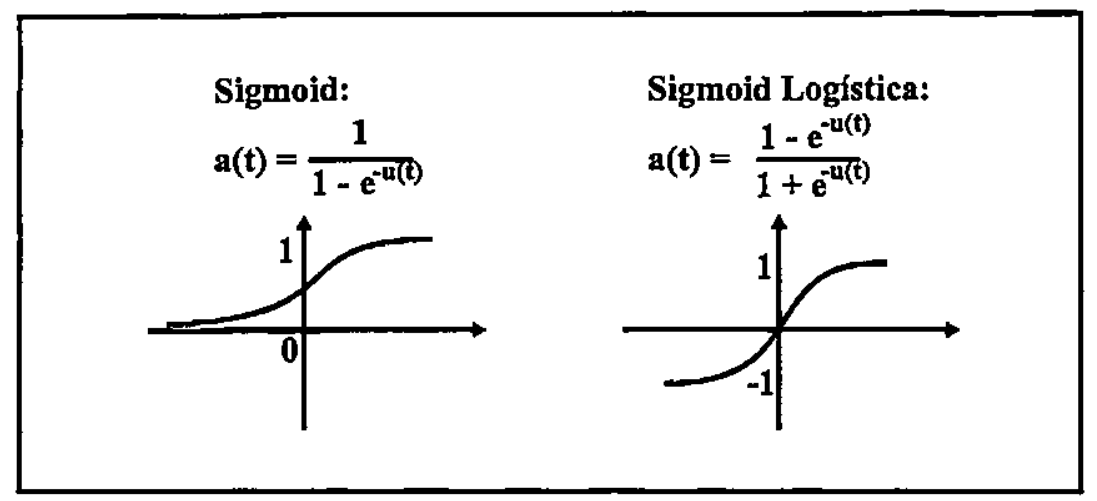

Figura 2.3: Gráficos das funções de ativação Sigmoid e Sigmoid Logística.

camada $l$ estão conectados a todos os neurônios da camada $l+1$. Caso a camada $l$ seja a camada de entrada, cada um de seus neurônios recebe um único valor de entrada $i_{j}$. O vetor $I=\left[i_{1}, i_{2}, \ldots, i_{n}\right]^{(t)}$ composto por estes valores de entrada é chamado de padrão de entrada. Em problemas de classificação, vinculado a cada padrão de entrada existe um padrão de saída que indica a qual classe pertence este padrão. O padrão de saída é composto pelo um vetor $O=\left[o_{1}, o_{2}, \ldots, o_{m}\right]^{(t)}$, tal que apenas o valor $o_{k}=1$ indica que o padrão de entrada correspondente pertence à classe $k$. Um conjunto de padrōes de entrada-saída é utilizado para treinar a rede a discernir cada classe representada pelos padrões de entrada. A correta classificação de um padrão é alcançada quando a rede o associa somente à classe à qual ele pertence.

Uma vez apresentado um padrão, a rede propaga o sinal gerado por este padrão seqüencialmente da camada de entrada, pelas camadas intermediárias e finalmente pela camada de saída. A camada de entrada de uma rede MLP não processa sua entrada, apenas propaga seu sinal para a próxima camada. Já as camadas intermediárias e a camada de saída executam a combinação linear de suas entradas e aplicam sobre esta combinação uma função de ativação.

Neurônios que utilizam funções Threshold ou Threshold Bipolar são chamados de Threshold Logic Units (TLU) ${ }^{1}$ e são utilizados em redes Perceptron de uma camada que, apesar do

\footnotetext{
${ }^{1}$ Embora sejam funcionalmente equivalentes, evidência empírica sugere que redes construídas com TLUs bipolares sāo menores que as construídas com TLUs binários, considerando-se o mesmo problema (Gallant, 1990).
} 
nome, possuem apenas camadas de entrada e saída (não possuem camadas intermediárias) ${ }^{2}$. Neurônios que utilizam funçōes Sigmoid ou Sigmoid Logística são utilizados em algoritmos como o back-propagation e em alguns Algoritmos Construtivos (Fahlman and Lebiere, 1991), como será comentado no Capítulo 3.

Para que uma RNA possa ser aplicada na solução de um problema, ela deve ser treinada para resolver este problema. Existem três tipos de treinamento: supervisionado, não supervisionado e por reforço (Haykin, 1999). Redes MLP utilizam treinamento supervisionado, o qual consiste na redução dos erros cometidos pela rede através da mudança (ou correção) iterativa dos pesos de suas conexões. Como exemplo, a equação da mudança dos pesos no algoritmo back-propagation é dada por:

$$
w_{j, i}(t+1)=w_{j, i}(t)+\eta x_{j} y_{i}\left(1-y_{i}\right) \delta_{i}
$$

onde $w_{j, i}$ é o peso da conexão que sai do neurônio $j$ e chega ao neurônio $i, \eta$ é a taxa de aprendizado, $x_{j}$ é o valor de entrada do neurônio $i$ proveniente do neurônio $j, y_{i}$ é a saída produzida pelo neurônio $i$, e $\delta_{i}$ é dado por:

$$
\delta_{i}= \begin{cases}d_{i}-o_{i}, & \text { se o neurônio } i \text { pertence à camada de saída } \\ \sum_{k} w_{j, i} \delta_{k}, & \text { c.c. }\end{cases}
$$

onde $d_{i}$ e $o_{i}$ são as saídas desejada e obtida do neurônio $i$, respectivamente, e $\delta_{k}$ refere-se aos valores de $\delta$ dos $k$ neurônios posteriores ao neurônio $i$.

A Equação 2.2 é obtida através da determinação do gradiente descendente da função de erro em relação aos pesos. A correção dos pesos em uma RNA tende a atingir uma região de mínimo da superfície de erro, que é uma representação gráfica da função do erro (Haykin, 1999) dada por:

$$
E^{(p)}=\frac{1}{2} \sum_{p} \sum_{i}\left(d_{i}^{(p)}-o_{i}^{(p)}\right)^{2}
$$

\footnotetext{
${ }^{2}$ Normalmente, por não processar o sinal, a camada de entrada de redes MLP não é considerada uma camada propriamente dita, porém no decorrer do trabalho a camada de entrada será constantemente citada, mantendo-se assim esta denominação.
} 
onde os neurônios indicados por $i$ pertencem à camada de saída e $p$ é o padrão apresentado para a rede.

A superfície de erro para problemas complexos apresenta regiões de mínimos locais e de mínimo global. O objetivo do treinamento é atingir o mínimo global. Entretanto, é possível que o treinamento fique preso a uma região de mínimo local, não alcançando um desempenho satisfatório.

Um dos fatos que agravam a possibilidade da configuração dos pesos se estabelecer em uma região de mínimo local é a inalteração do espaço de pesos. Em redes de topologia fixa, o espaço de pesos e por conseqüência a superfície de erro, ficam estáticos durante o treinamento. Esta limitação é diretamente abordada pelas Redes Neurais Construtivas, que ao inserir novos neurônios e conexōes, podem modificar o espaço de pesos e a superfície de erro, possivelmente evitando que a configuração dos pesos permaneça em uma região de mínimo local (Parekh et al., 1996).

\subsection{Reconhecimento de Padrões}

Uma das principais tarefas de Reconhecimento de Padrões é a classificação. Ou seja, dados certos valores de entrada, pode-se analisar esta entrada de maneira a fornecer uma classificação ou categorização destes dados (Beale and Jackson, 1990). Vários problemas reais podem ser mapeados em um sistema para Reconhecimento de Padrões. Entre os mais utilizados pode-se citar: reconhecimento automático de alvos em radar (Vargas et al., 1998), análise de crédito (de Sousa and de Carvalho, 1999a), reconhecimento de assinaturas (Ribeiro and Vasconcelos, 1998), comando de robôs via gestos e comandos verbais (Waldherr et al., 1998), entre outros.

Outra tarefa que envolve Reconhecimento de Padrões é a de regressão. Enquanto a classificação trata problemas qualitativos, a regressão trata problemas quantitativos. Ou seja, dado um conjunto de valores de entrada, pode-se estimar o valor de um número de variáveis dependentes (Smith, 1996). O uso de regressão em Reconhecimento de Padrões é freqüentemente encontrado em aplicações reais do mercado financeiro, como predição de falência de bancos, análise de risco em hipotecas, entre outros (Trippi and Turban, 1993). 
Um sistema para Reconhecimento de Padrōes consiste de três estágios: no primeiro estágio, medidas são obtidas e preprocessadas para normalização e redução de ruído. No segundo estágio, é realizada uma extração e seleção de características das medidas, e uma representação mais abstrata é construída. No último estágio esta representação mais abstrata é analisada para se obter a classificação. Durante os três estágios, o sistema deve possuir um alto grau de tolerância a falhas e erros, sendo capaz de interagir com dados do mundo real e não apenas registros estáticos armazenados (Oja and Kohonen, 1992).

Embora a tarefa de reconhecer padrões seja trivial para o cérebro humano, é de extrema complexidade para um computador. Problemas de Reconhecimento de Padrões podem ser tratados na computação tradicional através de algoritmos que criam conjuntos de modelos para comparação. Por exemplo, caso fosse desejado reconhecer engrenagens em uma linha de produção para separá-las, bastaria entrar com conjuntos de dados com todas as dimensōes possíveis para as engrenagens previstas nesta linha. Entretanto, se uma engrenagem defeituosa com medidas inesperadas surgir, este classificador não conseguirá classificá-la.

Redes Neurais Artificiais são vantajosas para a tarefa de reconhecer padrões, pois além de serem eficientes na identificação de padrões que participaram da fase de treinamento, as redes são capazes de generalizar, isto é, as redes podem reconhecer padrões semelhantes e classificá-los corretamente mesmo quando estes não fazem parte do conjunto de treinamento. A generalizaçāo ocorre através da deteç̧ão de características relevantes do padrāo de entrada. Portanto, padrões não apresentados anteriormente são atribuídos a classes cujos padrões apresentam características semelhantes, permitindo assim, uma tolerância a falhas (Braga et al., 2000).

Para que a tarefa de Reconhecimento de Padrões seja bem sucedida, é necessário efetuar uma correta extração de características dos dados que se deseja classificar. Além do treinamento e implementação das Redes Neurais, a extração de características dos dados e a formulação de padrões representativos das classes é de grande importância.

Os experimentos realizados neste trabalho utilizaram conjuntos de padrões contidos em Proben1, comentado no Capítulo 1, dispensando a preocupação com a coleta e processamento de dados de problemas reais. 


\subsection{Considerações Finais}

A aplicação de Redes Neurais Artificiais em tarefas de Reconhecimento de Padrões é uma prática comum em várias pesquisas da área de Inteligência Artificial. As RNAs muitas vezes apresentam um desempenho superior, nestas tarefas, quando comparadas a sistemas de computação convencional. Um dos motivos desta melhora é o fato da Rede Neural ser capaz de generalizar seu comportamento para padrões desconhecidos e classificá-Ios de acordo com sua semelhança aos padrões utilizados durante o treinamento.

Um dos modelos de RNAs mais aplicados em problemas de Reconhecimento de Padrão é a rede MLP. Este modelo aprende a classificar os padrões apresentados através da modificação dos pesos das conexões entre seus neurônios, procurando minimizar o erro da rede através de um gradiente descendente sobre a função do erro em relação aos pesos. Para que esta modificação resulte em uma maior precisão na classificação, uma topologia ótima da rede deve ser determinada antes do início do treinamento dos pesos. Caso esta topologia não seja corretamente escolhida, a Rede Neural possivelmente apresentará baixa precisão de classificação dos padrões (no caso de ser muito pequena) ou perderá a capacidade de generalização (no caso de ser muito grande). Em ambos os casos, uma degradação do desempenho será observada.

Na tentativa de suprir esta limitação, as Redes Neurais Construtivas comentadas no Capítulo 3, constróem gradativamente a topologia da rede, evitando a perda de tempo e esforço na busca de uma topologia otimizada. 


\section{Capítulo 3}

\section{Redes Neurais Construtivas}

\subsection{Introdução}

A aplicação de uma Rede Neural Artificial (em particular uma rede MLP) na resolução de um problema exige que a mesma seja treinada dentro do domínio deste problema através da apresentação de padrões que caracterizam o comportamento desejado. No caso de Redes Neurais convencionais, a sua topologia deve ser definida antes do início do processo de aprendizagem. Entretanto, a determinação da topologia de uma Rede Neural Artificial frente a um determinado problema não é uma tarefa trivial, resultando na maioria das vezes em uma busca exaustiva que pode ser incluída em uma entre quatro abordagens (de Sousa and de Carvalho, 1999b):

- Empírica: consiste na realização de uma busca cega no espaço de topologias, ou seja, diversas topologias são testadas e comparadas até que se encontre uma Rede Neural cujo desempenho seja satisfatório. Embora seja a mais utilizada, a busca empírica normalmente resulta em um elevado custo de tempo e esforço. Algumas heurísticas são utilizadas na tentativa de acelerar o tempo de busca por uma Rede Neural apropriada.

- Genética: esta abordagem gera um conjunto de variações de Redes Neurais e combina as características das que apresentam melhores desempenhos, gerando assim, um novo conjunto de Redes Neurais. Esta técnica utiliza Algoritmos Genéticos (Holland, 1975) para realizar uma busca global por Redes Neurais eficientes. Como um grande número 
de diferentes Redes Neurais têm de ser treinadas, esta abordagem requer grande poder computacional e demanda um elevado tempo de processamento.

- Poda (ou Pruning): nesta abordagem, uma Rede Neural com um gránde número de neurônios é treinada até que a precisão não possa mais ser melhorada. Um algoritmo de pruning é utilizado durante ou após o treinamento para remover os neurônios redundantes ou irrelevantes das camadas intermediárias da rede, com o objetivo de melhorar seu grau de generalização (Karnin, 1990). No fim do processo, uma topologia mais compacta é obtida.

- Construtiva: a abordagem construtiva gradualmente insere novos neurônios e conexões em uma Rede Neural inicialmente sem neurônios intermediários, procurando melhorar seu desempenho frente ao problema em questão.

As abordagens Construtiva e Pruning são particularmente interessantes para a determinação automática da topologia da Rede Neural devido ao ganho de tempo em relação às demais abordagens. Contudo, de acordo com (Kwok and Yeung, 1997), a abordagem Construtiva apresenta algumas vantagens sobre Pruning:

1. RNCs permitem a definição de uma rede inicial para o treinamento, embutindo na rede conhecimento inicial sobre o problema;

2. RNCs buscam solucionar o problema em questão explorando primeiro pequenas topologias, gerando, portanto, redes mais eficientes e possivelmente reduzindo o tempo necessário para o treinamento da rede;

3. Ao contrário dos algoritmos de Pruning, que avaliam a modificação do erro da rede durante a remoção de neurônios e conexões, as RNCs avaliam a necessidade da inserção de novos elementos para melhorar a precisão de classificação, evitando que durante a modificação da topologia a Rede Neural apresente degradação desta precisão.

O processo de aprendizagem de uma Rede Neural Cunstrutiva é controlado por um Algoritmo Construtivo. Este algoritmo avalia a necessidade da Rede Neural adicionar mais neurônios, e os insere de acordo com seu próprio critério. Portanto, a topologia da rede é 
determinada durante o processo de treinamento. A próxima seção descreve seis Algoritmos Construtivos estudados para este trabalho.

\subsection{Algoritmos Construtivos}

Os Algoritmos Construtivos descritos nesta seção diferenciam-se pelo critério adotado para avaliar quando e como um novo neurônio deve ser inserido na rede. Este critério varia da avaliação do erro de treinamento da rede até a presença de uma determinada característica em uma camada da rede.

Os algoritmos descritos nesta seção inserem neurônios e conexões em redes baseadas no modelo MLP, utilizando um segundo algoritmo de treinamento para atualizar os pesos da Rede Neural. Normalmente este segundo algoritmo é uma derivação da regra delta (Lippmann, 1987) ou do algoritmo back-propagation, citados no Capítulo 2.

\subsubsection{Cascade Correlation}

O algoritmo Cascade Correlation (Fahlman and Lebiere, 1991) utiliza uma técnica construtiva de aprendizado supervisionado para treinar RNAs. Este algoritmo começa com uma rede mínima (apenas camadas de entrada e saída) e, durante o treinamento, insere novos neurônios intermediários, um por vez, criando uma estrutura de múltiplas camadas. $\mathrm{O}$ algoritmo Cascade Correlation combina duas propriedades: a arquitetura em cascata e a seleção de novos neurônios a partir de um conjunto de candidatos.

No processo de treinamento, cada novo neurônio inserido na rede é conectado à camada de entrada, saída e a todos os neurônios intermediários previamente inseridos na rede, formando assim, uma arquitetura em cascata. O novo neurônio começa então a participar permanentemente das operaçōes da rede, sendo utilizado para detectar novas características do conjunto de padrões.

Todos os neurônios da rede Cascade Correlation possuem função de ativação sigmoid ou sigmoid logística ${ }^{1}$. Os pesos relacionados às conexões da camada de saída podem ser treina-

\footnotetext{
${ }^{1}$ Outras funções de ativaçāo podem ser aplicadas gerando variações deste modelo. Contudo, o processo
} 
dos por uma série de algoritmos de aprendizado; os demais pesos, relacionados às unidades intermediárias, são treinados durante a fase de seleção de candidatos (como será mostrado a seguir) e permanecem inalterados após a inserção destas unidades.

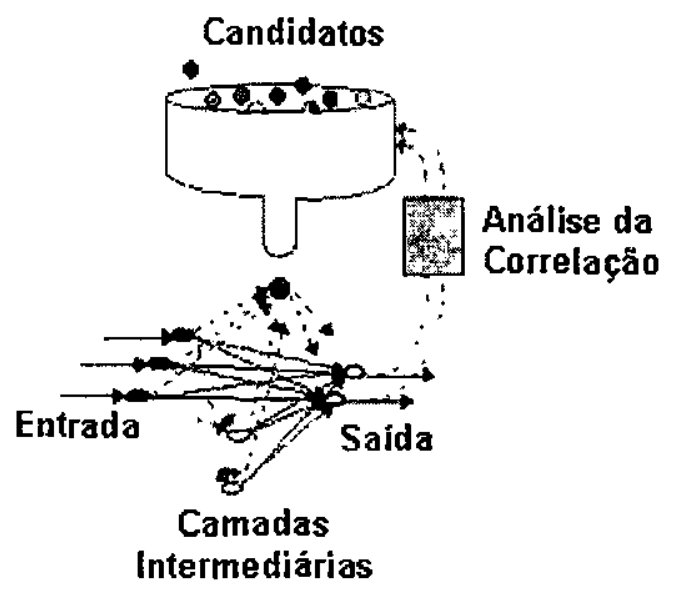

Figura 3.1: Seleção de uma nova unidade entre um conjunto de candidatos.

A unidade a ser incluída na rede é selecionada de um conjunto de candidatos, como mostra a Figura 3.1. Os candidatos podem ser organizados em uma camada, de maneira que esta, chamada camada de candidatos, é conectada à camada de entrada e aos neurônios intermediários previamente inseridos, mas não é conectada à saída, pois não deve influir diretamente no resultado da rede. O critério de seleção do candidato é determinado pela correlação entre seu valor de ativação e o erro da camada de saída da rede. Quanto maior a correlação, maior a influência que este candidato exercerá ño resultado da rede caso seja selecionado. $O$ valor da correlação entre o neurônio candidato $c$ e o neurônio o da camada de saída é dado por:

$$
C O R R E L_{o}=\sum_{p}\left(a_{c}^{(p)}-\overline{a_{c}}\right)\left(E R R O R_{o}^{(p)}-\overline{E R R O R_{o}}\right)
$$

onde $p$ é o padrão apresentado para a rede, $a_{c}$ é o valor da ativação do candidato, $E R R O R_{o}$ é o erro do neurônio de saída $o$, e os termos com barra referem-se às médias sobre todos os padrões (Squires and Shavlik, 1991).

Os pesos das conexões relacionadas aos candidatos devem ser treinados de maneira a maximizar essa correlação. O termo a ser maximizado é:

de comparação planejado neste trabalho não avalia estas variações, mantendo a similaridade dos modelos apresentados. 


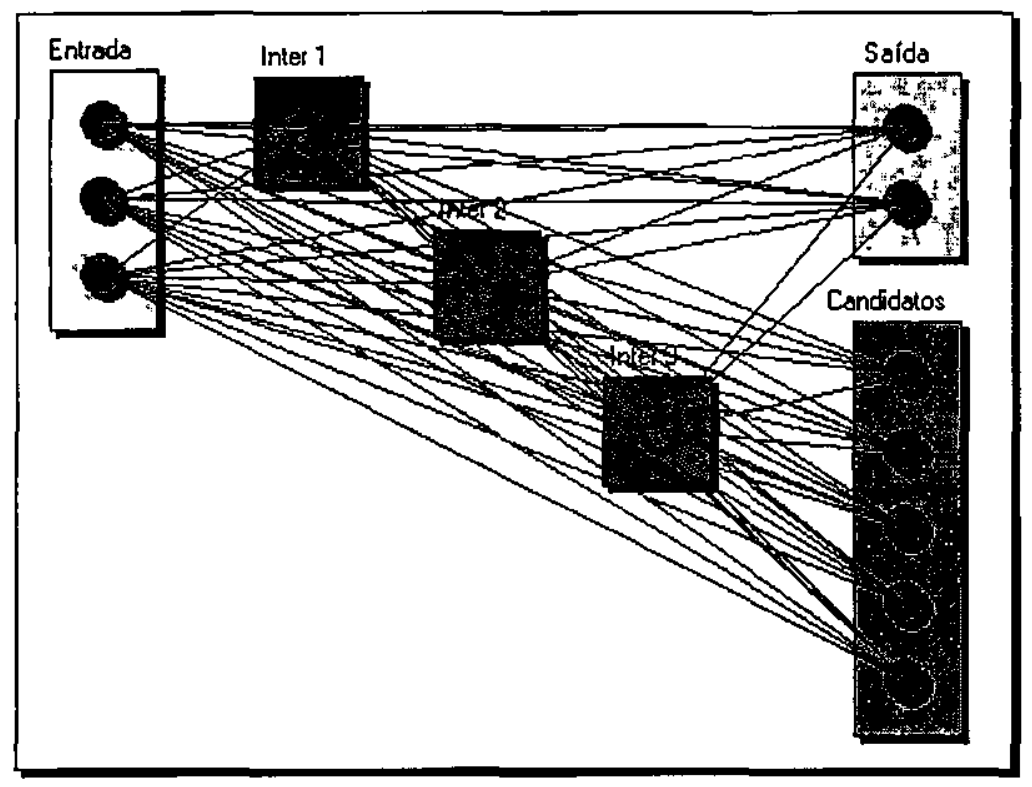

Figura 3.2: Os neurônios candidatos são organizados em uma camada.

$$
\overline{C O R R E L}=\sum_{o}\left|C O R R E L_{o}\right|
$$

A fim de maximizar $\overline{C O R R E L}$, a variação do peso associado à conexão entre um candidato $c$ e um neurônio $i$ é dada por:

$$
\Delta W_{c, i}=\sum_{o} \sigma_{o} \sum_{p}\left(E R R O R_{o}^{(p)}-\overline{E R R O R_{o}}\right) a_{i}^{(p)} a_{c}^{(p)}
$$

onde $\sigma_{o}$ é o sinal de CORREL $L_{o}$. Assim, o candidato que apresentar o maior valor de $\overline{C O R R E L}$ será incluído na rede como uma nova camada intermediária, sendo conectado a todas as camadas da rede, como ilustra a Figura 3.2.

A inserção de neurônios nestas redes pode ser observada mais claramente nas Figuras 3.3, 3.4 e 3.5 a seguir. A Figura 3.3 mostra o estado inicial da rede (topologia mínima). A Figura 3.4 mostra a inserção de uma nova unidade intermediária, e a Figura 3.5 mostra a inserção de uma segunda unidade intermediária.

Entre as vantagens das redes Cascade Correlation, está a simplificação do treinamento, pois tanto o treinamento dos pesos associados à camada de saída, quanto daqueles associados aos candidatos, envolvem o ajuste das conexões de apenas uma camada. 


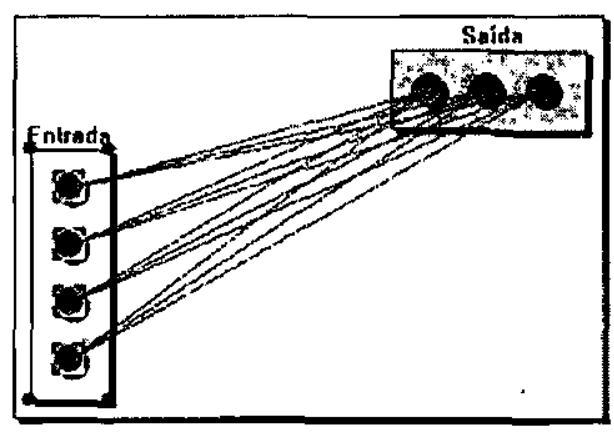

Figura 3.3: Estado inicial da rede Cascade Correlation.

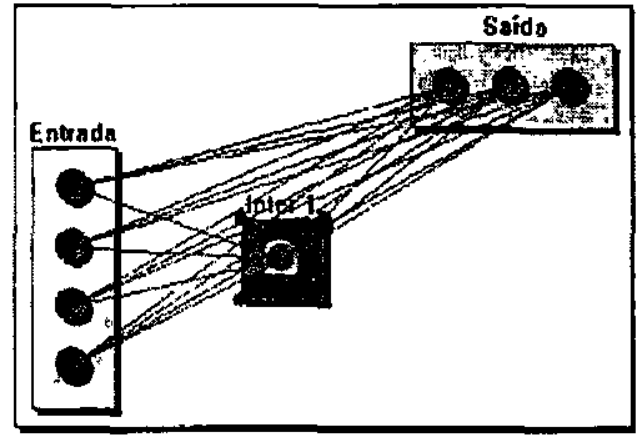

Figura 3.4: Estado da rede após inserção de um neurônio.

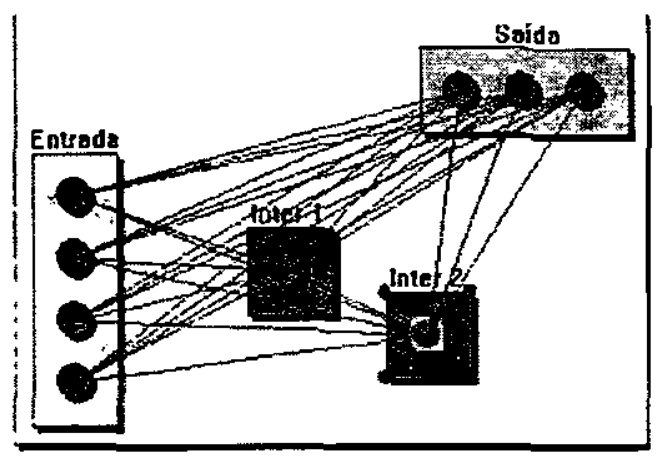

Figura 3.5: Estado da rede após inserção de um segundo neurônio.

O Algoritmo Construtivo Cascade Correlation segue os seguintes passos:

1. Começar com uma rede inicial cuja camada de entrada está conectada à camada de saída;

2. Treinar os pesos relacionados à camada de saída até a precisão desejada ser atingida ou não haver diminuição do erro da rede;

3. Se a precisão desejada não foi atingida, faça:

3.1. Criar uma camada de candidatos e conectá-la à camada de entrada; 
3.2. Treinar os pesos relacionados à camada de candidatos até que um valor máximo de correlaçäo seja determinado;

3.3. Selecionar o neurônio candidato que apresente o maior valor de correlação;

3.4. Inserir o neurônio escolhido como uma unidade intermediária da rede e conectá-lo à camada de entrada, a qualquer neurônio previamente inserido e à camada de saída;

3.5. Repetir o processo a partir do ítem 2.

\subsubsection{Tower e Pyramid}

Ao contrário do algoritmo Cascade Correlation, que insere uma unidade por vez durante o treinamento, os algoritmos Tower (Parekh et al., 1997a) e Pyramid (Parekh et al., 1997a) (Parekh et al., 1998) inserem, a cada ajuste na topologia, uma camada com um número fixo de neurônios. A nova camada possui o mesmo número de neurônios que a camada de saída. No algoritmo Tower, a nova camada tem seus neurônios conectados à camada de entrada e à camada de saída. A camada de saída torna-se, então, a última camada intermediária e a camada inserida se torna a nova camada de saída. Este procedimento é repetido até que a precisão de classificação desejada seja atingida, ou o número máximo de camadas permitido seja alcançado. Limitar o número de camadas inseridas pode prevenir perda de generalização e desempenho da Rede Neural. As Figuras 3.6, 3.7 e 3.8 a seguir ilustram o processo de construção da rede. A Figura 3.6 mostra o estado inicial de uma Rede Neural Tower (topologia mínima). A Figura 3.7 mostra a inserção de uma nova camada e a Figura 3.8 mostra a inserção de uma segunda camada.

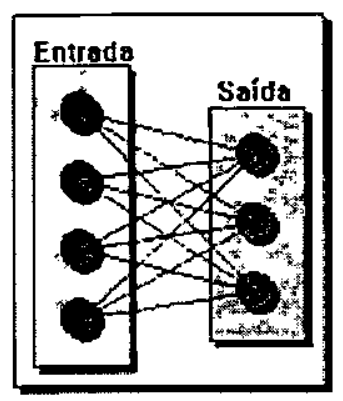

Figura 3.6: Estado inicial da rede Tower.

O algoritmo Pyramid é de uma extensão do algoritmo Tower, diferenciando-se apenas na 


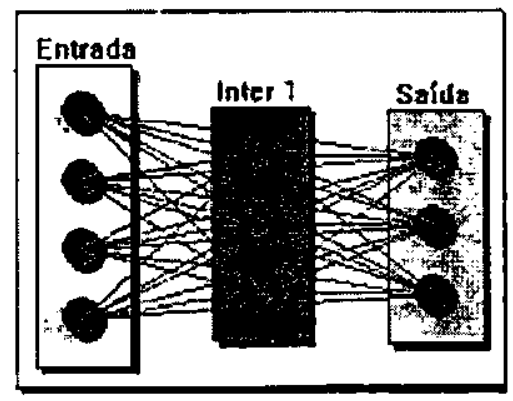

Figura 3.7: Inserção de uma nova camada: a camada de saída torna-se uma camada intermediária.

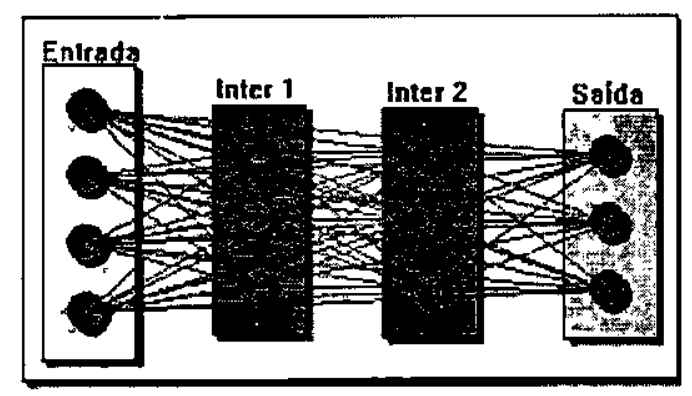

Figura 3.8: Inserção de uma segunda camada: novamente, a camada de saída torna-se uma camada intermediária.

maneira como são inseridas as conexões da nova camada. A camada inserida, além de conectada à camada de entrada e à camada de saída, é também conectada a todas as camadas intermediárias previamente inseridas na rede, tornando os neurônios totalmente conectados entre si. A Figura 3.9 apresenta uma rede já treinada, com duas camadas intermediárias. Note que a camada Inter 1 está conectada à nova camada de saída, o que não acontece no algoritmo Tower.

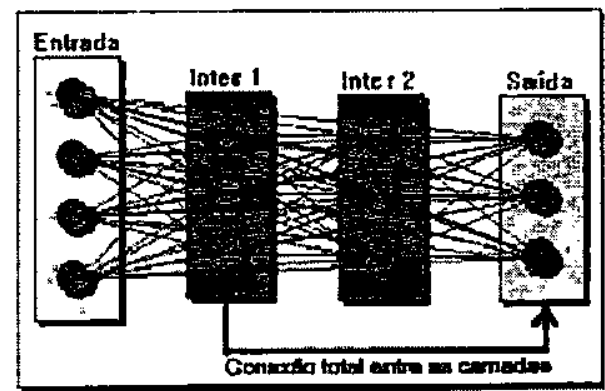

Figura 3.9: Rede Pyramid. A seta indica a conexão entre a camada Inter 1 e a camada de saída. 
Os Algoritmos Construtivos Tower e Pyramid seguem os seguintes passos:

1. Começar com uma rede inicial cuja camada de entrada está conectada à camada de saída;

2. Treinar os pesos relacionados à camada de saída até a precisão desejada ser atingida ou não haver diminuição do erro da rede;

3. Se a precisão desejada não foi atingida, faça:

3.1. Criar uma nova camada com o mesmo número de neurônios da camada de saída;

3.2. Se o algoritmo em questão for Tower, conectar a nova camada às camadas de entrada e de saída;

3.3. Senão, conectar a nova camada às camadas de entrada, de saída e às camadas previamente inseridas;

3.4. A camada de saída torna-se a última camada intermediária da rede;

3.5. A nova camada inserida torna-se a camada de saída da rede;

3.6. Repetir o processo a partir do ítem 2 .

Os algoritmos Tower e Pyramid constróem uma seqüência de camadas compostas por unidades perceptron, também conhecidas como Threshold Logic Units (TLUs), citadas no Capítulo 2. Como TLUs geram saídas binárias ou bipolares, a real precisão da resposta produzida pela rede (diferença entre a saída produzida e a desejada) é escondida, prejudicando o algoritmo que trabalha com correção de erro.

A estratégia proposta em (Parekh et al., 1998) para reduzir esta dificuldade consiste na projeção dos padrōes em uma superfície parabólica através da inclusão de um atributo de entrada para cada padrão $\left(X^{(p)}=\left[x_{1}^{(p)}, \ldots, x_{n}^{(p)}\right]\right)$, onde o novo atributo é a soma dos quadrados dos demais atributos $\left(x_{n+1}^{(p)}=\sum_{j=1}^{n}\left(x_{j}^{(p)}\right)^{2}\right)$. Com esta projeção, é possível treinar uma TLU para diferenciar qualquer padrão de todos os outros, de maneira que a saída da TLU será 1 para o padrão diferenciado e 0 (ou -1 no caso de uma rede bipolar) para todos os outros.

Entretanto, outro problema com a geração de saídas binárias ou bipolares é a impossibilidade da utilização da Rede Neural em problemas de regressão. Estes problemas necessitam de valores reais para a avaliação quantitativa da saída da Rede Neural. 
A estratégia proposta neste trabalho é a substituição das TLUs por neurônios com funções de ativação sigmoid ou sigmoid logística. Assim, problemas de classificação teriam a saída dos neurônios da camada de saída avaliada por uma regra que trabalhe com uma faixa de valores reais, como é o caso da regra 402040 (Zell, 1995). Em problemas de regressão, o próprio valor da saída dos neurônios da camada de saída seria considerado. Esta proposta foi utilizada com sucesso em experimentos contidos em (de Sousa and de Carvalho, 1999b) e (de Sousa and de Carvalho, 1999a).

\subsubsection{Upstart}

O Algoritmo Construtivo Upstart (Frean, 1989) também treina uma rede com saída binária ou bipolar. Seu objetivo é melhorar o desempenho da rede através da inserção de pares de neurônios para cada neurônio de saída que classifique incorretamente um padrão. Um neurônio de saída pode apresentar dois tipos de erro:

- Incorretamente ativado (wrongly on): para um dado padrão $p$, a saída desejada de um neurônio de saída $o$ é $D_{o}^{(p)}=0$ (ou -1 no caso bipolar) e a saída produzida é $O_{o}^{(p)}=1$.

- Incorretamente desativado (wrongly off): para um dado padrão $p$, a saída desejada de um neurônio de saída $o$ é $D_{o}^{(p)}=1$ e a saída produzida é $O_{o}^{(p)}=0$ (ou -1 no caso bipolar).

Sempre que um dos erros acima ocorrer, dois neurônios $X$ e $Y$ são inseridos e conectados à camada de entrada e ao neurônio de saída que apresentou o erro. Os pesos do neurônio $X$ são então treinados para eliminar os padrões que causam os casos wrongly on, e os pesos do neurônio $Y$ são treinados para eliminar os padrões que causam os casos wrongly off do neurônio de saída em questão. Após o treinamento, estes pesos são congelados e permanecem inalterados até o fim do treinamento.

Por eliminação de um padrão entende-se que, para um padrão $p$ do conjunto de treinamento que caracterize um caso wrongly on, os pesos do neurônio $X$ inserido são treinados para que a saída deste neurônio, dado o padrão $p$, seja $y_{X}^{(p)}=0$, e ao peso relacionado à conexão entre este neurônio e o neurônio de saída o é atribuído um valor negativo grande o suficiente para 
cobrir a soma dos pesos positivos incidentes em 0 . Analogamente, para casos wrongly off, os pesos do neurônio $Y$ inserido são treinados para que a saída deste neurônio, dado o padrão $p$, seja $y_{Y}^{(p)}=0$, e o peso relacionado à conexão entre os neurônio $Y$ e $o$ recebe um valor positivo que supere a soma dos pesos negativos incidentes em $o$. A atribuição de um valor negativo ou positivo a um peso pode ser feita explicitamente ou através de treinamento pela regra perceptron (como citado no Capítulo 2).

Caso a inclusão destes neurônios não seja suficiente para a correção de todos os erros dos neurônios de saída, o processo é repetido para os neurônios $X$ e $Y$, gerando assim, uma Rede Neural em forma de árvore para cada um dos neurônios da camada de saída.

No que diz respeito à organização multi-camadas do modelo MLP em problemas envolvendo mais de duas classes, a topologia resultante não é convencional, pois nem todos os neurônios presentes no nível $l$ estão conectados aos neurônios do nível $l-1$. Uma nova abordagem deste algoritmo, proposta em (Frean, 1989) e (Parekh et al., 1997a), fornece uma alternativa para a inserção de novos neurônios em uma única camada intermediária. Esta nova abordagem insere um neurônio $X$ ou $Y$ por vez e o conecta a todos os neurônios da camada de saída. Assim, este novo neurônio reduz parte dos erros de todos os neurônios de saída, em vez de tratar um neurônio por vez.

O Algoritmo Construtivo Upstart, assim como os algoritmos Tower e Pyramid, foi originalmente desenvolvido para tratar redes com saídas binárias ou bipolares. Portanto, as estratégias citadas na Seção 3.2 .2 também são necessárias para tratar conjuntos de padrões com valores de entrada e \ou saída reais.

As Figuras 3.10, 3.11 e 3.12 ilustram a inserção de novos neurônios de acordo com esta nova abordagem.

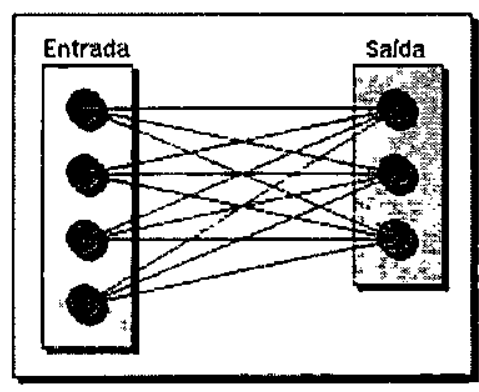

Figura 3.10: Estado inicial da rede Upstart. 


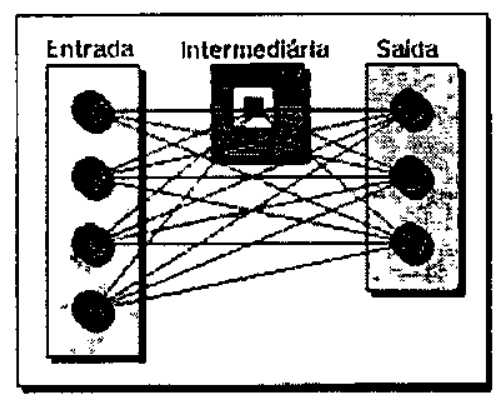

Figura 3.11: Inserção de um novo neurônio $X$ ou $Y$ em uma camada intermediária.

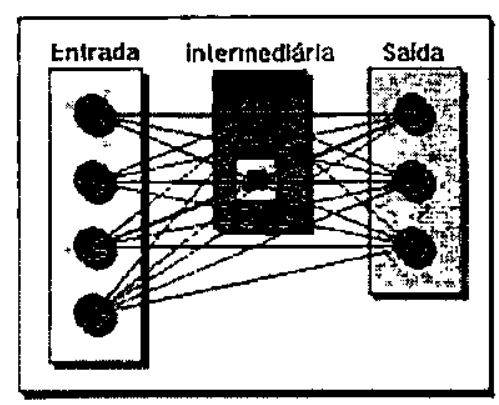

Figura 3.12: Inserção de um segundo neurônio $X$ ou $Y$ na mesma camada intermediária anterior.

A segunda abordagem citada segue os seguintes passos:

1. Começar com uma rede inicial cuja camada de entrada está conectada à camada de saída;

2. Treinar os pesos relacionados à camada de saída até a precisão desejada ser atingida ou não haver diminuição do erro da rede;

3. Se a precisão desejada não foi atingida, faça:

3.1. Selecionar o neurônio de saída que apresente o maior número de erros;

3.2. Se o neurônio selecionado cometer mais erros wrongly on, faça;

3.2.1. Criar um neurônio $X$, conectá-lo à camada de entrada e treinar seus pesos para eliminar o(s) padrão(ões) que causa(m) o caso wrongly on, corrigindo alguns dos erros do neurônio de saída selecionado (após o treinamento, os pesos são congelados);

3.3. Se o neurônio selecionado cometer mais erros wrongly off, faça;

3.3.1. Criar um neurônio $Y$, conectá-lo à camada de entrada e treinar seus pesos para eliminar $\circ(\mathrm{s})$ padrão(ões) que causa $(\mathrm{m})$ o caso wrongly off. corrigindo alguns dos erros do neurônio de saída selecionado (após o treinamento, os pesos são congelados); 
4. Conectar o novo neurônio à camada de saída e treinar os pesos de cada neurônio de saída para reduzir os casos wrongly on e wrongly off.

5. Voltar ao passo 2.

\subsubsection{Perceptron Cascade}

O Algoritmo Construtivo Perceptron Cascade (Parekh et al., 1997a) foi baseado no mesmo princípio do algoritmo Upstart descrito na Seção 3.2.3, embora construa a topologia da rede de uma forma similar à utilizada pelo algoritmo Cascade Correlation descrito na Seção 3.2.1. O algoritmo Perceptron Cascade treina uma rede composta por TLUs, inserindo neurônios $X$ e $Y$ para corrigir erros wrongly on e wrongly off, respectivamente, quando necessário. Os neurônios inseridos são treinados da mesma forma que no algoritmo Upstart, e conectados aos outros neurônios da rede criando uma topologia semelhante à do algoritmo Cascade Correlation.

Este algoritmo segue os seguintes passos:

1. Começar com uma rede inicial cuja camada de entrada está conectada à camada de saída;

2. Treinar os pesos relacionados à camada de saída até a precisão desejada ser atingida ou não haver diminuição do erro da rede;

3. Se a precisão desejada não foi atingida, faça:

3.1. Selecionar o neurônio de saída que apresente o maior número de erros;

3.2. Se o neurônio selecionado cometer mais erros wrongly on, faça;

3.2.1. Criar um neurônio $X$, conectá-lo à camada de entrada e a todos os neurônios previamente inseridos, e treinar seus pesos para eliminar $o(s)$ padrão(ões) que causa $(m) \circ$ caso wrongly on, corrigindo alguns dos erros do neurônio de saída selecionado (após o treinamento, os pesos são congelados);

3.3. Se o neurônio selecionado cometer mais erros wrongly off, faça;

3.3.1. Criar um neurônio $Y$ conectá-lo à camada de entrada e a todos os neurônios previamente inseridos, e treinar seus pesos para eliminar o(s) padrão(ões) que causa(m) o caso wrongly off. corrigindo alguns dos erros do neurônio de saída selecionado (após o treinamento, os pesos são congelados); 
4. Conectar o novo neurônio à camada de saída e treinar os pesos de cada neurônio de saída para reduzir os casos wrongly on e wrongly offi

5. Voltar ao passo 2 .

A correta classificação de uma Rede Neural treinada com este algoritmo, utilizando padrões com valores de entrada reais, depende da projeção dos padrões em uma superfície parabólica, como descrito na Seção 3.2.2. Neste trabalho, a substituição das TLUs por neurônios com função de ativação sigmoid ou sigmoid hiperbólica, como citada na Seção 3.2.2, foi aplicada.

\subsubsection{Tiling}

O Algoritmo Construtivo Tiling (ou M-Tiling para referenciar múltiplas saídas) (Parekh et al., 1996) difere dos outros algoritmos citados por seu método de avaliação da necessidade de inclusão de novos neurônios na rede. Este algoritmo usa o critério da Fidelidade (Faithfulness). Este critério advoga que dois padrões de treinamento pertencentes a classes diferentes não devem produzir saídas idênticas em uma dada camada.

Caso o critério da Fidelidade não seja cumprido por uma camada da rede, o algoritmo Tiling insere nesta camada neurônios ditos auxiliares, treina seus pesos e repete a inserção até que o critério seja cumprido. Uma vez verificado o critério de Fidelidade para uma camada, seus pesos são então congelados e uma nova camada é criada com o número de neurônios original da camada que sofreu as inserçōes. A nova camada é conectada à camada anterior e assume a sua função, tendo seus pesos treinados e sua fidelidade avaliada. Caso esta nova camada se mostre infiel, o processo é repetido até que todas as camadas mostrem-se fiéis.

O algoritmo Tiling normalmente é iniciado com uma rede mínima e a camada avaliada pelo critério da Fidelidade é a camada de saída. Se necessário, novos neurônios auxiliares são inseridos e uma nova camada é criada com o número de neurônios originais da camada de saída. A nova camada assume então a função da camada de saída e a antiga camada de saída torna-se uma camada intermediária.

O processo de inserção de neurônios da rede Tiling é ilustrado pelas Figuras 3.13, 3.14 e 3.15 . 


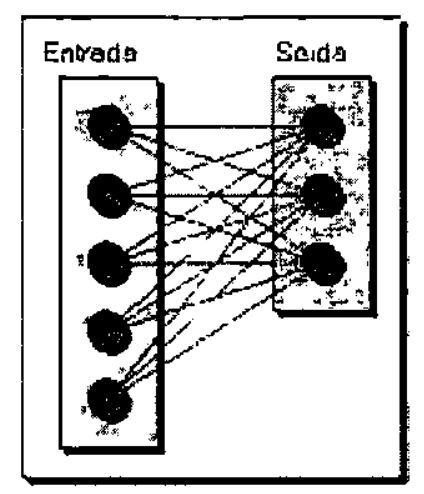

Figura 3.13: Estado inicial da rede Tiling.

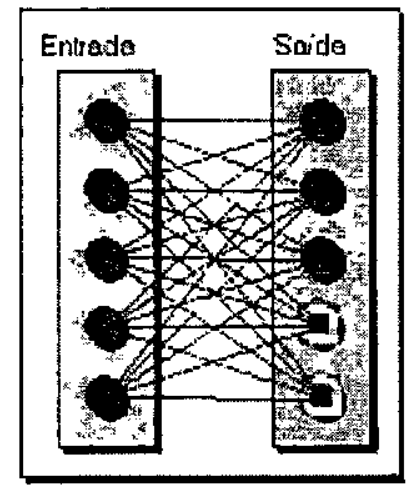

Figura 3.14: Inserção de neurônios auxiliares para cumprir o critério da Fidelidade.

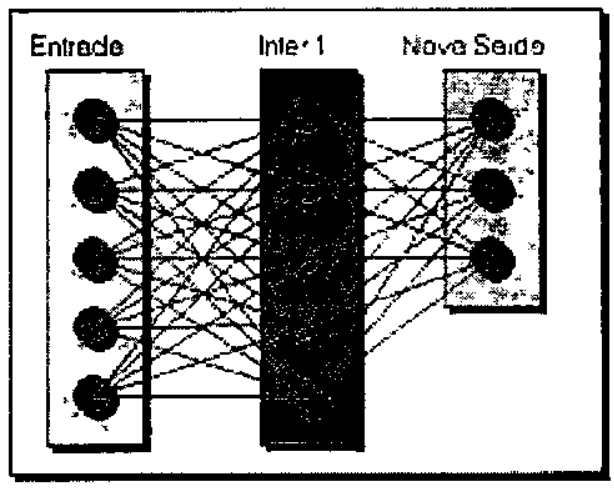

Figura 3.15: Uma nova camada de saída é criada e o critério da Fidelidade é novamente verificado.

O algoritmo Tiling segue os seguintes passos:

1. Começar com uma rede inicial cuja camada de entrada está conectada à camada de saída;

2. Treinar os pesos relacionados à camada de saída até a precisão desejada ser atingida ou não haver diminuição do erro da rede; 
3. Se a precisão desejada não foi atingida e não foi atingido o número máximo de camadas inseridas, faça:

3.1. Verificar se a camada de saída com $M$ neurônios é fiel;

3.2. Se a camada de saída não cumpre o critério da Fidelidade, faça:

3.2.1. Determinar o número $K$ de padrões que não atendem ao critério da Fidelidade;

3.2.2. Inserir $K$ neurônios auxiliares e treinar seus pesos;

3.2.3. Voltar ao passo 3.2;

3.3. Criar uma nova camada de saída com $M$ neurônios;

3.4. Conectar a nova camada de saída à antiga camada de saída;

3.5. A antiga camada de saída torna-se uma camada intermediária;

3.6. Voltar ao passo 2 .

O número de neurônios auxiliares incluídos na camada sob avaliação depende do número de padrões que não atendem ao critério da Fidelidade, pois para cada padrão que falhe no teste de Fidelidade um novo neurônio é inserido. Portanto, quanto maior o número de padrões de um conjunto, maior o número de testes sobre o critério de Fidelidade, e conseqüentemente, aumenta a probabilidade de inserção de um número elevado de neurônios. Vale observar que alguns destes neurônios acabam se tornando redundantes.

Para evitar a existência de neurônios redundantes na rede Tiling, é recomendado que um processo de poda (ou Pruning) seja conduzido logo após a determinação da fidelidade da camada (Parekh et al., 1997b). Este processo busca e elimina neurônios redundantes dentro da camada avaliada.

O procedimento de verificação de um neurônio redundante é simples: dada uma camada fiel, os neurônios auxiliares sāo, um a um, retirados da camada e a fidelidade é novamente testada. Se a camada continuar fiel após a exclusão de um neurônio, este é permanentemente eliminado da camada. Caso contrário, o neurônio é recolocado na camada. O processo de Pruning inflige um custo adicional no algoritmo, porém uma rede mais compacta e eficiente é obtida.

Apesar de treinar uma rede composta por TLUs, o algoritmo Tiling não requer a projeção dos padrões em uma superfície parabólica, como descrito na Seção 3.2.2 (Parekh et al., 1998). 
Contudo, a estratégia que substitui TLUs por neurônios com função de ativação sigmoid para o tratamento de dados reais, também descrita na Seção 3.2.2, foi aplicada para melhorar o desempenho do algoritmo.

\subsection{Taxonomia para Redes Neurais Construtivas}

As RNCs podem ser classificadas segundo o critério de inserção de novas unidades. Os seis Algoritmos Construtivos apresentados podem ser classificados da seguinte maneira:

1. Redes que avaliam a precisão de classificação:

- Tower;

- Pyramid.

2. Redes que avaliam a presença de classificaçāo incorreta:

- Upstart;

- Perceptron Cascade.

3. Redes que avaliam a correlação entre a ativação de um neurônio e a função de erro dos neurônios de saída:

- Cascade Correlation.

4. Redes que avaliam o critério de fidelidade de uma camada:

- Tiling.

Outra forma de organizar estes algoritmos é em relação ao número de neurônios inseridos:

1. Redes que inserem um neurônio a cada passo:

- Upstart;

- Perceptron Cascade;

- Cascade Correlation. 
2. Redes que inserem uma camada de neurônios a cada passo:

- Tower;

- Pyramid;

- Tiling.

Entretanto, as redes Tower, Pyramid e Tiling podem inserir apenas um neurônio a cada passo. No caso das redes Tower e Pyramid, apenas um neurônio será inserido a cada passo se a rede possuir apenas um neurônio na camada de saída. Uma rede Tiling irá inserir um neurônio se apenas um padrão falhar no teste de Fidelidade.

Existem outros Algoritmos Construtivos que não se enquadram no modelo MLP e não foram incluídos neste trabalho, como é o caso da rede RBF-DDA (Radial Basis Function with Dynamic Decay Adjustment) que é uma extensão da rede RBF (Radial Basis Function) (Berthold and Diamond, 1995), ou das redes que utilizam treinamento não-supervisionado, como as redes treinadas pelos algoritmos Kohonen Construtivo (Halgamuge, 1997), SOFT (Carvalho et al., 1997) e SONN (Tenorio and Lee, 1989).

\subsection{Considerações Finais}

Este capítulo citou quatro abordagens usadas na determinação da topologia de uma Rede Neural, enfatizando a abordagem construtiva. Esta abordagem utiliza Algoritmos Construtivos que, a partir de uma rede mínima (apenas camadas de entrada e saída), inserem novos neurônios e conexões de acordo com a necessidade da Rede Neural Construtiva em questão, buscando a melhora do seu desempenho.

Seis Algoritmos Construtivos, aplicados em extensōes do modelo MLP, foram revisados. Estes algoritmos possuem seus próprios critérios de avaliação da necessidade de inserção de novos neurônios. Além disso, eles variam na maneira como novos neurônios devem ser treinados e conectados à Rede Neural Construtiva.

Os algoritmos apresentados baseiam-se na idéia de decompor a determinação da topologia em duas tarefas: a adição gradativa de neurônios e conexões alternada com a modificação 
interativa dos pesos para cada grupo de neurônios inserido. Isto permite a utilização de um segundo algoritmo de aprendizado dedicado ao treinamento dos pesos. Este segundo algoritmo é geralmente mais simples e mais rápido, uma vez que é aplicado a uma camada da rede por vez, sem propagação do erro para outras camadas internas, reduzindo assim a complexidade relacionada à modificaçāo de pesos em redes multi-camadas. O algoritmo aplicado normalmente é uma variação da regra delta ou do algoritmo back-propagation, citados no Capítulo 2. 


\section{Capítulo 4}

\section{Kipu - Um Simulador para Redes Neurais Artificiais}

O Simulador Kipu (Vargas, 1998) foi inicialmente projetado para a simulação de Redes Neurais Artificiais, mais especificamente para o treinamento de modelos Perceptron MultiCamadas (MLP) com alguns dos Algoritmos Construtivos citados no Capítulo 3. Buscando o melhor desempenho do simulador nos experimentos planejados neste trabalho, uma revisão minuciosa do projeto inicial foi realizada, sendo detectada a necessidade de várias mudanças que resultaram em uma nova abordagem e a implementação de uma nova versão.

A Seção 4.1 descreve os problemas encontrados durante a análise do Simulador Kipu e a Seçāo 4.2 comenta o modelo de objetos componentes, ou Component Object Model (COM).

\subsection{Análise do Simulador Kipu}

A análise do Simulador Kipu teve como objetivo avaliar as classes que representam Redes Neurais e Algoritmos relacionados, a interdependência entre estas classes e a interface gráfica com o usuário, e a expansibilidade do simulador. Desta análise surgiu a necessidade de alterações no projeto que resultaram no desenvolvimento de uma nova versão.

A primeira alteração diz respeito à hierarquia de algoritmos implementada, onde as classes correspondentes aos Algoritmos Construtivos eram implementadas como classes filhas do 
algoritmo back-propagation, como ilustra a Figura 4.1.

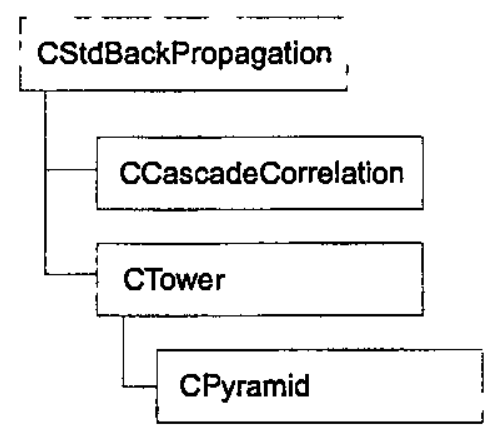

Figura 4.1: Antiga hierarquia de classes representando os algoritmos no simulador Kipu.

Deste modo, os algoritmos construtivos Cascade Correlation, Tower e Pyramid se restringiam ao uso do algoritmo back-propagation para treinar os pesos dos novos neurônios inseridos. Entretanto, variações do algoritmo back-propagation, como back-propagation momentum, quick-propagation e RPROP, podem apresentar melhores alternativas para o treinamento destes pesos, uma vez que geralmente convergem mais rápido, como indicado em (Shiffmann et al., 1994) e (Fahlman, 1988).

Como a proposta de trabalho consiste em analisar as Redes Neurais Construtivas em busca de um melhor desempenho, a inclusão destas variações do algoritmo back-propagation é de grande importância para a completa avaliação dos experimentos. Porém, a implementação deste tipo de funcionalidade não é trivial, principalmente considerando que outras variações deste algoritmo podem vir a ser posteriormente incluídas no simulador.

Uma característica do simulador que também apresentou a necessidade de mudança foi a dependência das classes que representam a própria Rede Neural com as classes responsáveis pela interface gráfica do simulador. Esta dependência dificulta a manipulaçāo eficiente da Rede Neural e o controle de concorrência entre as threads criadas pelo programa, além de caracterizar falta de modularidade.

Outros detalhes de implementação que também despertaram o interesse de reformulação foram: a possibilidade de treinar mais de uma Rede Neural simultaneamente em threads diferentes para maximizar o desempenho de computadores multiprocessados, embutir aos próprios modelos de Redes Neurais o controle sobre quais algoritmos podem ser utilizados para treiná-los, e centralizar o controle sobre a entrada de parâmetros de treinamento na implementação do próprio algoritmos de treinamento, independendo da interface gráfica com 
o usuário.

Uma vez decidida a execução destas alterações, buscou-se uma linha de planejamento que não só satisfizesse as condições citadas, mas também permitisse a futura aplicação do simulador em conjunto com outras aplicações e ferramentas. Esta abordagem é tratada diretamente pelo modelo COM (Abernethy, 1999), comentado na Seção 4.2.

\subsection{Component Object Model - COM}

O modelo de objetos compoñentes ou Component Object Model, geralmente referenciado pela sigla COM, é um modelo de programação distribuído baseado em objetos, projetado para promover interoperabilidade de software (Microsoft, 1995). Este modelo define e implementa mecanismos que permitem que componentes de software, como aplicações, objetos de dados, controles e serviços, interajam uniformemente como objetos.

Um objeto de software engloba um corpo de dados, juntamente com uma ou mais funções para acesso e utilização destes dados. Estes componentes de software podem ser totalmente independentes, sendo desenvolvidos em projetos diferentes e em épocas diferentes. Um componente COM permite acesso aos dados de um objeto através do uso exclusivo de um gu mais conjuntos de funções chamados de interfaces. O nome de uma interface é convenciorialmente precedido de um "I", como em IUnknown.

Um objeto é a instanciação de alguma classe, geralmente com o propósito de fornecer um serviço a um módulo de software fora do escopo deste objeto. Este módulo trata-se de um ou mais clientes que desejam utilizar o serviço oferecido. A única diferença entre um objeto $\mathrm{C}++$ convencional e um objeto COM é a maneira como um cliente acessa este objeto.

Um objeto servidor disponibiliza um componente COM através da implementação de uma ou mais interfaces. Um cliente de um componente COM consegue acesso ao objeto ao obter um ponteiro a uma de suas interfaces. Com este ponteiro, o cliente pode seguramente utilizar o objeto sem precisar entender sua implementação e com a certeza de que o objeto irá se comportar da mesma forma sempre que acessado. Visto desta maneira, uma interface COM é um contrato que define o comportamento de um objeto frente ao seu cliente. $O$ objeto irá honrar este contrato mesmo que o cliente esteja em um processo ou máquina diferente, 
rodando em um sistema operacional diferente, escrito em outra linguagem de programação por um outro programador, ou representando uma versão mais nova ou mais antiga do que a utilizada anteriormente pelo cliente.

Ao definir interfaces como contratos entre objetos e seus clientes, o modelo COM resolve efetivamente o problema de controle de versões. Ao criar uma nova versão de um objeto, basta adicionar novas interfaces sem alterar as já existentes. Estas novas interfaces são definidas de maneira que clientes têm permissão para buscar tanto a nova versão da interface como a versão anterior. Com esta restrição, adicionar novas interfaces ou novas versões de interfaces antigas não interfere na maneira com que clientes utilizam um objeto.

COM é baseado em chamadas de procedimento remoto ou RPC (Remote Procedure Call), ou seja, permite que objetos em processos ou máquinas diferentes comuniquem-se como se estivessem em um único processo. O que permite esta comunicação através de interfaces é o processo envolvendo a implementação destas interfaces em um objeto. A implementação de uma interface por um objeto significa que o objeto utiliza o código que implementa cada método especificado na interface e fornece ponteiros que apontam para o código binário das funções publicadas ${ }^{1}$ na interface. O próprio modelo torna estas funções acessiveis a qualquer cliente que solicitá-las por um ponteiro à interface, estando dentro ou fora do processo que implementa as funções.

\subsubsection{Interfaces COM}

COM faz uma distinção clara entre a definição de uma interface e a sua implementação. Uma interface define o uso de um grupo de funções semanticamente relacionadas, mas não fornece nenhuma informação sobre sua implementação. Estes protótipos de funções são equivalentes a classes base puramente virtuais em $\mathrm{C}++$. A definição de uma interface especifica suas funções membros (ou métodos) e, para cada função, especifica seu tipo de retorno, o número e tipo de seus parâmetros e o comportamento esperado da função.

A implementação de uma interface é dada pelo código que o programador fornece para executar as ações especificadas na definição desta interface. Implementações de muitas das

\footnotetext{
${ }^{1}$ Uma função publicada na interface é um método implementado no objeto COM que pode ser acessado por um cliente.
} 
interfaces que um programador poderia utilizar em uma aplicação orientada a objetos estão incluídas em bibliotecas COM, por exemplo, a implementação da interface IPropertyPage. Entretanto, os programadores são livres para ignorá-las e escrever suas próprias implementações. Uma implementação de uma interface deve ser associada a um objeto quando uma instância deste objeto é criada, fornecendo assim, a funcionalidade dos serviços oferecidos pelo objeto .

Por exemplo, uma interface chamada IStack pode definir dois métodos: Push e Pop, especificando que chamadas sucessivas do método Pop retornam, em ordem inversa, os valores previamente passados ao método Push. No entanto, esta definição de interface não especifica como estas funções devem estar implementadas em código. Ao implementar a interface, o programador pode implementar a stack (pilha) como um array e implementar os métodos Push e Pop de uma forma que eles trabalhem sobre este array. Outro programador pode preferir utilizar uma lista encadeada e implementar estes métodos para que trabalhem com a lista. Independente da implementação particular dos métodos Push e Pop, a representação em memória do ponteiro à interface IStack e seu uso por um cliente são totalmente determinados pela definição da interface.

Objetos simples podem suportar apenas uma única interface. Objetos mais complexos normalmente suportam várias interfaces. Clientes somente acessam um objeto COM através de um ponteiro a uma de suas interfaces, a qual, por sua vez, permite ao cliente chamar qualquer método que esteja definido nesta interface. Estes métodos determinam como um cliente pode utilizar os dados do objeto.

Um objeto, quando suporta uma interface, deve fornecer direta ou indiretamente a implementação para todos os métodos definidos na interface. Porém, nem todos os métodos em uma implementação precisam ter uma funcionalidade. Caso o objeto não apresente um propósito para um dos métodos da interface, sua implementação pode ser apenas um comando de retorno.

A instância de uma implementação de uma interface em um objeto é, na verdade, um ponteiro para um array de ponteiros para métodos. Quando um método de uma interface é chamado, este array é acessado e o endereço da função desejada é recuperado. De posse deste endereço, a interface pode executar o método implementado no objeto em questão. $\mathrm{O}$ 
array de ponteiros pode ser considerado como uma tabela de funçōes com referências para a implementação do objeto para todos os métodos especificados na interface. Objetos com múltiplas interfaces podem fornecer ponteiros a mais de uma tabela de funções. Qualquer código que possua um ponteiro através do qual possa acessar este array pode chamar os métodos da interface em questão.

Para ser utilizada, uma interface é obtida em tempo de execução através de um identificador global e único (Globally Unique Identifier ou GUID) chamado de IID (Interface Identifier). O IID permite a um cliente perguntar a um objeto se este suporta a semântica de uma interface específica sem resultar em overhead desnecessário e sem causar confusão em sistemas que possuem múltiplas versões da mesma interface com o mesmo nome.

\subsubsection{Herança}

COM permite dois tipos de herança: herança de interface e herança de implementação. Herança de interface não significa reutilização de código. Como não existe associação direta entre implementação e interfaces, a herança de interface não acarreta em herança de código. Significa apenas que o contrato associado com uma interface é herdado como uma classe base puramente virtual e modificado ou pela adição de novos métodos ou incrementando a permissão de uso dos métodos herdados. Não existe herança seletiva em COM, ou seja, se uma interface é herdada de outra, ela inclui todos os métodos que a interface base define.

Todas as interfaces COM são, em algum nível, herdadas da interface IUnknown, que contém três métodos essenciais: QueryInterface, AddRef e Release. Todos os objetos COM devem implementar a interface IUnknown, pois esta fornece os meios para caminhar livremente entre diferentes interfaces suportadas em um mesmo objeto através do método QueryInterface, e gerenciar o tempo de vida do objeto com os métodos AddRef e Release.

A herança de implementação não é completamente implementada em COM, ou seja, classes COM que herdam a implementação de outra classe COM não possuem acesso aos dados de implementação da classe base. Contudo, esta limitação é superada pelo uso do conceito de agregação, que além de assegurar a funcionalidade de herança de implementação, oferece outros recursos mais poderosos, que serão discutido na Seção 4.2.3. 


\subsubsection{Agregação}

Um conceito muito útil em COM que foi amplamente utilizado na nova versão do Simulador Kipu é a agregação. Agregação é basicamente um mecanismo de reutilização de código, no qual um objeto externo expõe interfaces de um objeto interno como se estas estivessem implementadas no próprio objeto externo. Isto é útil quando o objeto externo for delegar todas as chamadas a uma de suas interfaces à mesma interface do objeto interno.

A maior vantagem na utilização de objetos agregados é a possibilidade de escolher qual o tipo de objeto que será agregado em tempo de execução. Isto é possível devido ao fato do objeto externo receber um ponteiro para a interface IUnknown do objeto interno no momento da criação do objeto agregado. Como todo objeto COM implementa a interface IUnknown, qualquer tipo de objeto COM pode ser agregado em tempo de execução, bastando que o identificador da classe (CLSID) do objeto interno seja especificado no momento da agregação.

Caso o objeto externo precise acessar métodos específicos do objeto interno, chamadas ao método QueryInterface permitem ao objeto externo navegar pelas outras interfaces suportadas pelo objeto interno.

\subsubsection{Tempo de Vida de Objetos COM}

Em sistemas orientados a objetos tradicionais, o ciclo de vida de objetos (o momento em que são criados e destruídos) é manipulado implicitamente pela linguagem de programação (controle de escopo e variáveis globais) ou explicitamente pelo programador (alocação dinâmica).

Em um sistema COM, nem a linguagem de programação nem o programador têm certeza de quando um objeto não está mais sendo utilizado por um cliente. Enquanto que para um cliente com os privilégios de segurança adequados é relativamente fácil criar objetos através de uma simples requisiçāo, determinar quando é seguro destruir um objeto não é tão claro. Mesmo que o cliente que criou um objeto termine sua execução, este não pode simplesmente removê-lo, pois outro cliente (ou clientes) pode estar acessando este objeto.

Para determinar quando é seguro destruí-lo, o próprio objeto mantém um contador de referência (reference count), normalmente um número de 32 bits, que é incrementado quando 
um cliente informa ao objeto que começou a referenciá-lo através da chamada ao método AddRef e decrementado quando um clinete informa que terminou de utilizá-lo através da chamada ao método Release. Quando o contador chega a zero, o próprio objeto se autodestrói.

Da mesma forma que é obrigação da aplicação liberar a memória alocada quando a mesma não é mais necessária, é responsabilidade do cliente que está utilizando um objeto liberar suas referências quando termina sua execução.

\subsubsection{Conexão entre Objetos COM}

A principal razão em se criar objetos COM é a facilidade em utilizá-los em conjunto, controlando a interação entre eles através das já discutidas interfaces. Porém, até este momento só foram discutidas interfaces de entrada, que permitem acesso ao objeto. COM também oferece interfaces de saída para troca de informações externas, criando assim, uma comunicação bidirecional com o seu cliente. Interfaces de entrada, conhecidas como incoming interfaces, são implementadas em um objeto e recebem chamadas de clientes externos ao objeto. Por outro lado, interfaces de saída, ou outgoing interfaces, são implementadas no cliente e recebem chamadas do objeto. Neste caso, o objeto define uma interface que gostaria de utilizar. A implementação desta interface está contida no cliente, constituindo o que é chamado de $\operatorname{sink}$.

Um objeto define suas incoming interfaces e fornece implementações a estas interfaces. Incoming interfaces estão disponíveis para clientes através do método QueryInterface da interface IUnknown do objeto. Um cliente chama os métodos de uma incoming interface e o objeto, por sua vez, executa a ação solicitada pelo cliente.

Uma outgoing interface também é definida pelo objeto, mas é o cliente que fornece a sua implementação em um objeto sink criado por ele. O objeto, então, chama métodos da outgoing interface no objeto sink para notificar o cliente de mudanças em seu estado interno, disparar eventos no cliente, ou pedir alguma informação contida no cliente. Na verdade, o objeto pode utilizar sua outgoing interface para qualquer objetivo projetado pelo programador.

Um bom exemplo de uma outgoing interface é a interface IButtonSink definida pelo clique de 
um controle botão (button control) para notificar seus clientes de seus eventos. Por exemplo, o objeto botão chama IButtonSink: :0nClick no objeto sink do cliente quando o usuário clica um botão na tela. O controle botão define a outgoing interface para comunicação. Para que o cliente deste botão manipule o evento, ele deve implementar esta outgoing interface em um objeto sink e conectá-lo ao controle botão. Só então, quando o evento é disparado pelo botão, o objeto sink é chamado, e o cliente executa a ação planejada para este botão.

Baseado neste princípio, a comunicação entre o sink do cliente e o objeto COM utiliza um mecanismo mais complexo chamado de Connection Point. Este mecanismo inclui os seguintes elementos:

- Objeto COM: implementa a interface IConnectionPointContainer, cria pelo menos um connection point object e define uma outgoing interface para o cliente;

- Cliente: busca pela interface IConnectionPointContainer do objeto para determinar se o objeto é "conectável"e cria o objeto sink para implementar a outgoing interface definida pelo objeto COM;

- Objeto Sink: implementa a outgoing interface, sendo utilizado para estabelecer uma conexão com o objeto COM;

- Connection Point Object: implementa a interface IConnectionPoint e gerencia a conexão com o $\operatorname{sink}$ do cliente.

O diagrama ilustrado na Figura 4.2 representa as relações entre estes elementos, esquematizando a utilização de connection points como meio de comunicação bidirecional entre objeto e cliente. Vários objetos criados na nova versão do Simulador Kipu utilizam este mecanismo de comunicação e todos apresentam esta mesma estrutura.

Quando se trabalha com objetos conectados, é importante lembrar que cada objeto connection point e sink, representa um objeto separado com implementações próprias da interface IUnknown. Cada um desses objetos possui, portanto, seu próprio contador de referência e seu próprio tempo de vida. Um cliente que utiliza estes objetos é responsável pelo controle destes contadores de referência. 


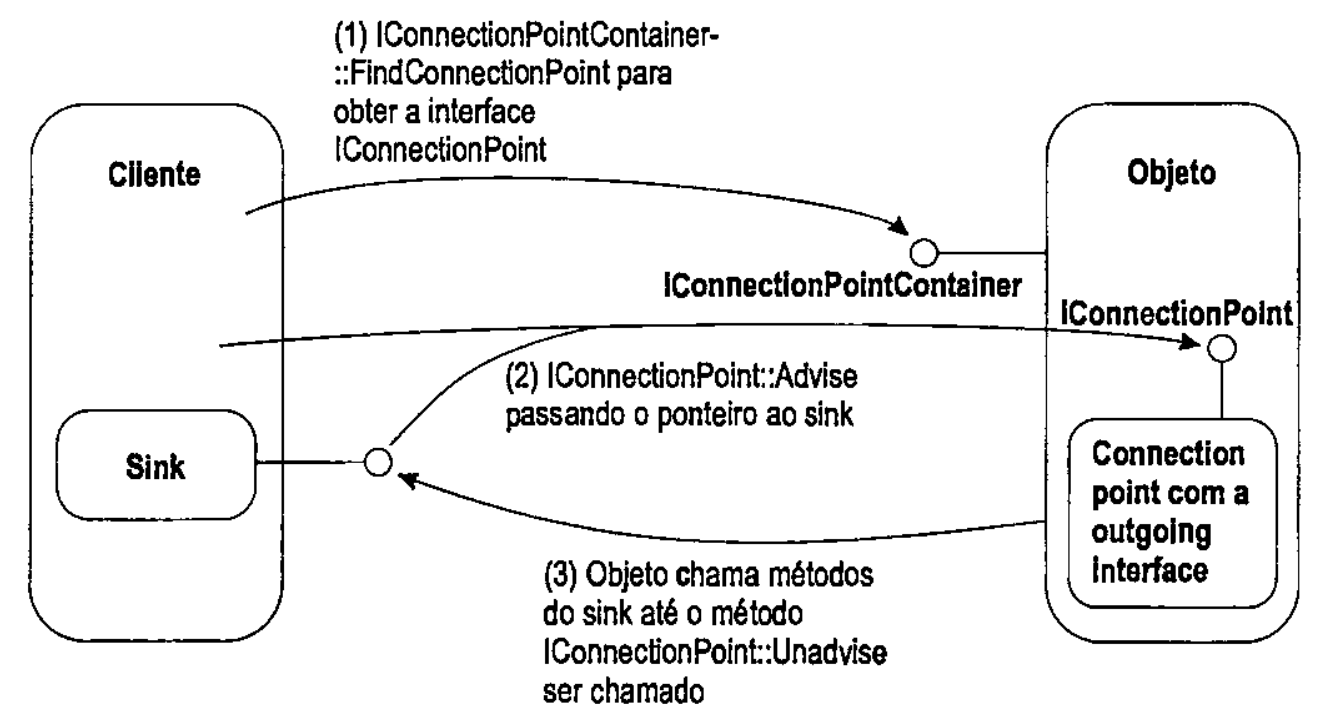

Figura 4.2: Esquema de comunicação entre objeto e cliente utilizando connection points.

Um objeto que utiliza este mecanismo de comunicação pode suportar mais de um cliente e pode suportar múltiplos sinks em um mesmo cliente. Similarmente, um sink pode estar conectado a mais de um objeto simultaneamente.

\subsection{Considerações Finais}

Este capítulo apresentou a análise da antiga versão do Simulador Kipu, comentando a motivação para a reestruturação do projeto utilizando o Component Object Model (COM). Este modelo foi revisado na Seção 4.2, destacando os conceitos abordados neste trabalho.

Do resultado da análise do Simulador Kipu frente à definição do COM, concluiu-se que pequenas alteraçōes no simulador não seriam suficientes para o correto andamento do trabalho proposto, sendo necessária a implementação de uma nova versão, mais correta e modularizada. Os detalhes da implementação da nova versão estão comentados no Capítulo 5 . 


\section{Capítulo 5}

\section{O Simulador Kipu como um}

\section{Framework para Redes Neurais}

A inclusão de componentes COM no simulador começou logo no início da especificação do projeto, onde o conjunto de classes ATL (Active Template Library) foi inicialmente estudado e aplicado. Notou-se neste momento a necessidade de separar o simulador em dois módulos: cliente e servidor.

O módulo cliente é o programa executável que interage com o usuário. Este programa é responsável pela apresentação dos modelos de Redes Neurais e algoritmos de treinamento disponíveis, início do processo de treinamento, ilustração das Redes Neurais resultantes do treinamento e execução de testes com estas redes.

O módulo servidor é uma DLL (Dynamic Link Library) chamada de Kernel ${ }^{1}$, ou núcleo do Kipu, onde toda a funcionalidade do simulador é implementada através de componentes COM. Desta forma, o módulo cliente tem conhecimento das interfaces COM presentes nesta DLL. Deve ser observado, no entanto, que todos os detalhes de implementação serão transparentes. Qualquer extensão do simulador, como novos modelos de Redes Neurais ou Algoritmos, pode ser implementada em novas DLLs, onde os novos componentes apresentarão suas interfaces para o simulador mantendo a transparência de implementação.

${ }^{1} \mathrm{O}$ nome Kernel é muito usado em softwares e sistemas operacionais, de maneira que foi decidido que o nome real da DLL seria KipuKernel. DLL. 
Assim, modificações e melhoramentos entre os módulos cliente e servidor são independentes, com a única restrição de que as futuras modificações no Kernel devem incluir novas interfaces COM sem alterar as existentes. Este texto referenciará o módulo cliente como Simulador e o módulo servidor como Kernel.

O primeiro passo na construção do Kernel foi a definição de uma nova hierarquia de classes para representar não somente os Algoritmos Construtivos como classes independentes do algoritmo back-propagation, mas também as Redes Neurais, conjuntos de padrões e dados persistentes como componentes independentes, e ainda assim permitir que variações e novos componentes possam ser facilmente integrados a esta hierarquia.

Todas as classes que representam estes elementos foram implementadas como componentes COM, portanto a classe pai no nível mais alto da hierarquia é a interface IUnknown e muitas classes são filhas da interface IDispatch. Estas classes são interfaces COM, cuja função é permitir a comunicação cliente-servidor de maneira uniforme.

A hierarquia de classes, apresentada na Seçāo 5.1, apresenta uma estrutura semelhante ao exemplo ilustrado na Figura 5.1. Neste exemplo, a interface IClasse contém o conjunto de métodos que o Simulador poderá utilizar, enquanto a classe CClasse contém a implementação destes métodos. Classes que contêm a implementação de uma interface, como a classe CClasse, são chamadas neste trabalho de classes núcleo.

\begin{tabular}{l} 
IDispatch \\
\hline IClasse: \\
\hline CClasse- \\
\hline
\end{tabular}

Figura 5.1: As interfaces IUnknown e IDispatch são pais das classes da nova hierarquia.

Outro aspecto considerado na elaboração da nova hierarquia foi a presença de vários elementos comuns a classes diferentes, como por exemplo, as variações do algoritmo backpropagation. Este aspecto foi tratado com o uso de templates.

As classes template implementam métodos e variáveis membros comuns às suas classes filhas, sem excluir a possibilidade da classe filha reimplementar algum método caso seja necessário. As classes template possuem a implementação de uma interface de acordo com a classe núcleo 
em questão. Estas classes convencionalmente começam com a letra "I"e possuem sufixo "Impl", seguido do parâmetro do template entre" $<>$ ", como em IDispatchImpl<IClasse >. As próximas seções deste capítulo descrevem o funcionamento, interação e utilização dos diversos componentes criados para o Simulador Kipu, ressaltando os pontos mais relevantes sem, no entanto, apresentar detalhes de implementação. As Seções 5.1, 5.2, 5.3, 5.4 e 5.5 apresentam o módulo servidor. As Seções 5.6 e 5.7 explicam o funcionamento do módulo cliente e sua interação com o módulo servidor.

\subsection{Hierarquia de Classes}

As próximas seções descrevem cada parte da hierarquia de classes de acordo com os elementos representados. As Seções 5.1.1, 5.1.2, 5.1.3 e 5.1.4 descrevem os elementos de uma Rede Neural, os algoritmos de treinamento, os Algoritmos Construtivos e o tratamento de padrões, respectivamente.

\subsubsection{Os elementos de uma Rede Neural}

Os modelos de Redes Neurais abordados neste trabalho são derivados do modelo MLP. Contudo, a possibilidade de utilização de outro modelo no simulador Kipu não deve ser descartada. Portanto, a classe template INeuralNetworkImpl contém métodos comuns a qualquer modelo de Rede Neural, como por exemplo, métodos de adição de elementos necessários para a montagem inicial da rede. Já a classe template IMLNeuralNetworkImpl e a classe núcleo CMLNeuralNetwork contêm a implementação mais especializada para redes MLP, tendo seus métodos publicados através da interface IMLNeural Network. Já a interface INeuralNetwork publica uma lista de métodos comuns a qualquer tipo de Rede Neural, como controle de concorrência e recuperação do nome da Rede Neural.

Uma rede multi-camadas pode ser composta de diferentes tipos de camadas. A classe template ILayerImpl possui a implementação comum a qualquer tipo de camada, enquanto a classe núcleo CMLLayer contém a implementação específica para camadas utilizadas em redes MLP. 
Novarnente, o mesmo raciocínio se aplica aos neurônios. Corn as classes template INeuron Impl, IMLNeuronImpl, que podem ser utilizadas na definição de urn tipo qualquer de neurônio, e a classe núcleo CNeuron, ternos a funcionalidade de neurônios típicos de redes MLP. A Figura 5.2 representa a hierarquia de classes para os elementos de urna Rede Neural.

\subsubsection{Algoritmos de Treinamento}

Os algoritmos de treinamento implementados foram as variações do algoritmo back-propagation comentadas na Seção 4.1. A Figura 5.3 ilustra a hierarquia de classes representando estes algoritrnos.

As classes CStdBackProp, CQuickProp, CRPROP e CBackPropMomentum representam os algoritmos back-propagation, quick-propagation (Fahlman, 1988), RPROP (Riedmiller, 1994) e back-propagation momentum (Shiffmann et al., 1994), respectivamente. Todas são filhas da classe template IBackPropImpl que implementa os métodos do algoritmo back-propagation e implementa a interface IStdBackProp. A diferença entre estas classes, com exceção da CStdBackProp, é a reimplementação dos métodos de cálculo do erro e ajuste dos pesos durante o treinamento. Esta reimplementação diz respeito às regras de treinamento específicas de cada algoritmo. A classe CStdBackProp não reimplementa os métodos da classe template por se tratarem dos métodos do algoritmo back-propagation padrão.

Além da classe template para as variações do back-propagation, uma classe template IAlgorithmImpl tarnbém está presente na hierarquia. Esta classe template contém os métodos cornuns a todos os algoritmos de treinamento, como, por exemplo, métodos para testar se os conjuntos de padrōes selecionados podern ser utilizados para treinar a Rede Neural em questão. Algoritmos de treinamento para outros modelos de Redes Neurais podern ser implementados corno classes filhas deste template.

\subsubsection{Algoritmos Construtivos}

Analogamente aos algoritmos de treinamento previamente mencionados, os Algoritmos Construtivos foram implementados de maneira a permitir que variações de um dado algoritmo sejam implementadas apenas modificando alguns métodos nas classes núcleo. As Figuras 


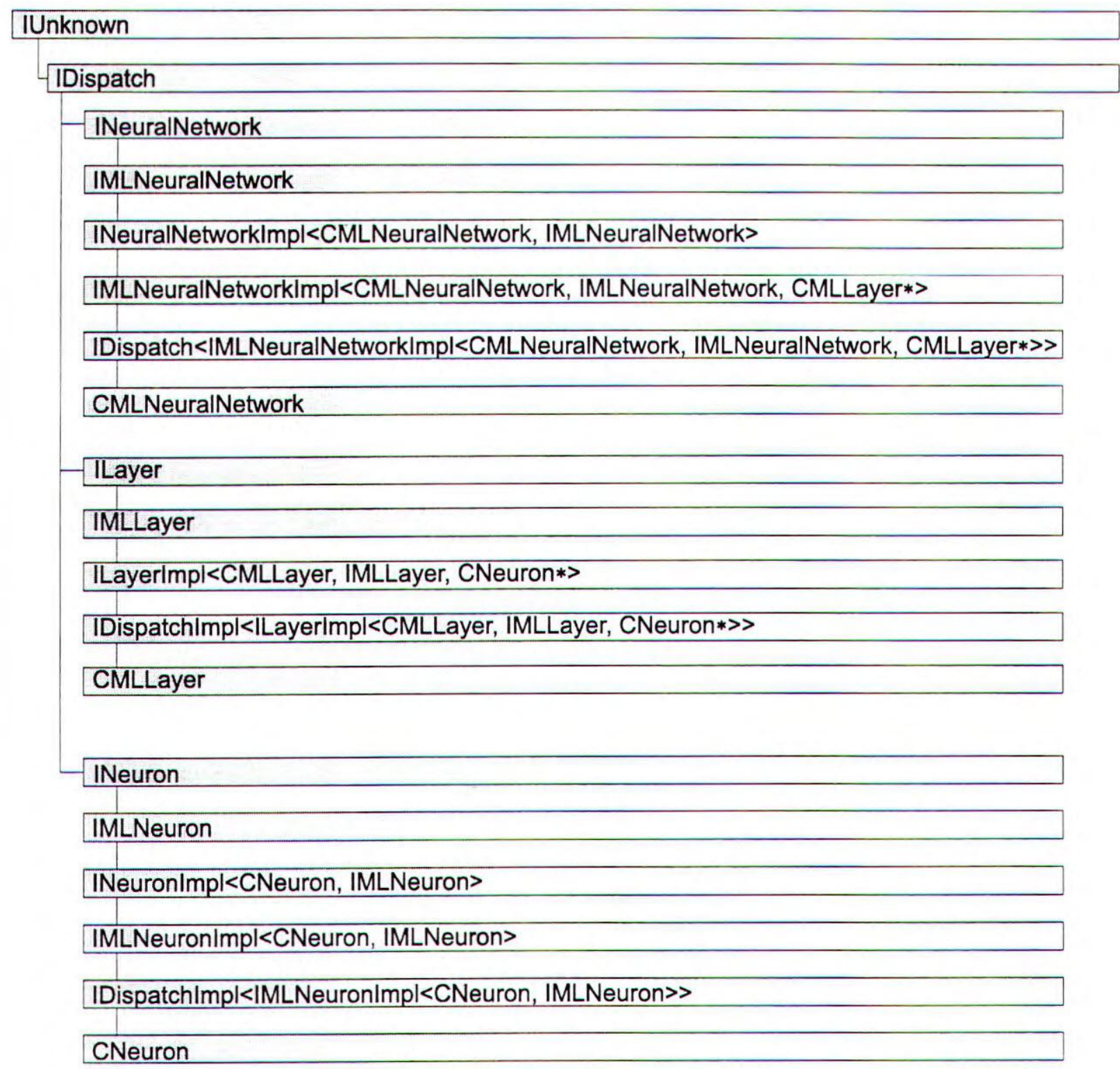

Figura 5.2: Hierarquia de classes representando os elementos de uma Rede Neural. 


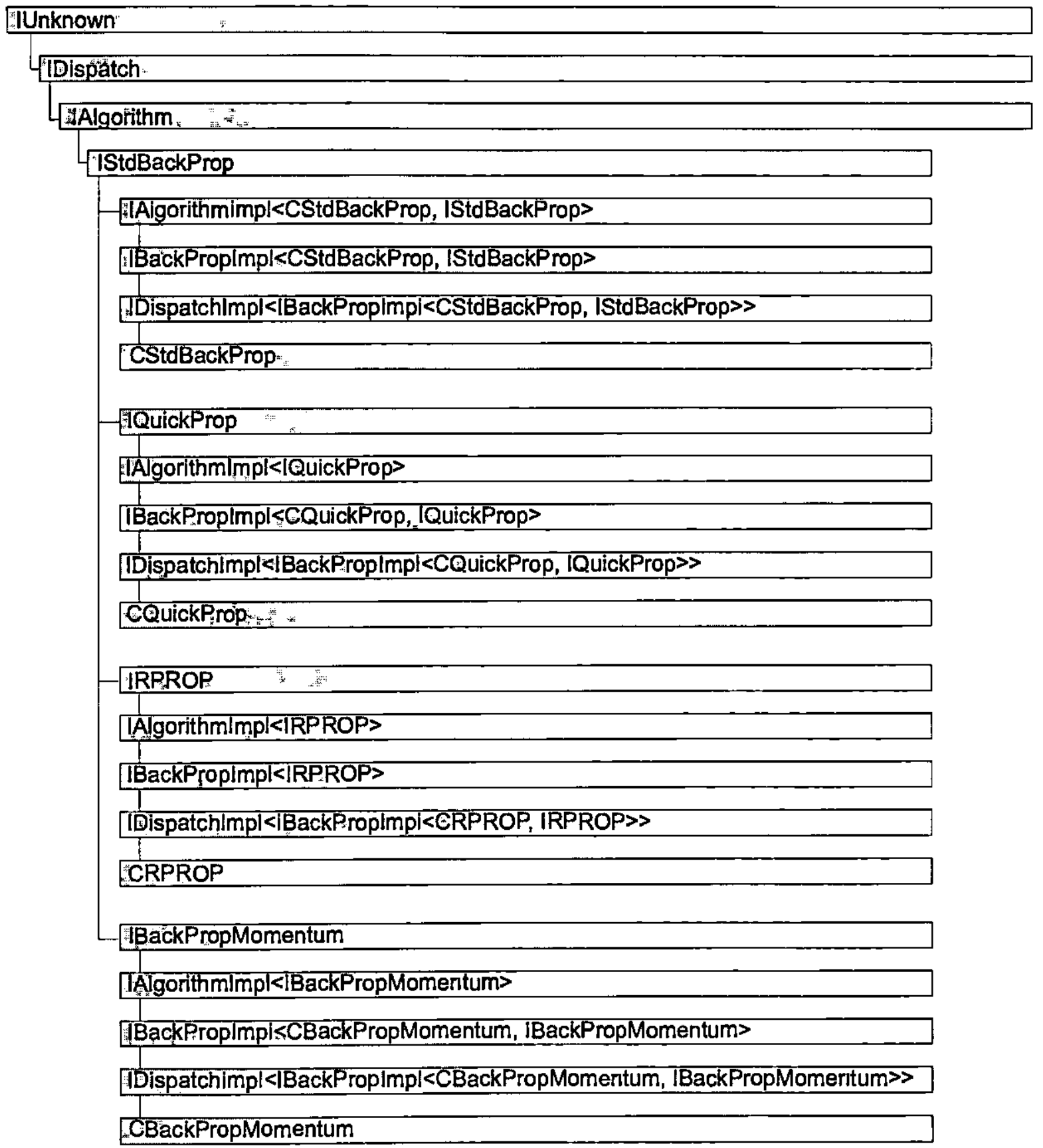

Figura 5.3: Hierarquia de classes para as variações do Algoritmo back-propagation. 
5.4 e 5.5 ilustram a hierarquia de classes do algoritmo Tower e sua variação Pyramid, do Upstart e sua variação Perceptron Cascade, e dos algoritmos Cascade Correlation (Fahlman and Lebiere, 1991) e MTiling (Parekh et al., 1997a).

A classe template ITower Impl possui as implementações dos métodos comuns aos dois algoritmos Tower e Pyramid. A classe CPyramid reimplementa o método responsável pela conexão da nova camada que caracteriza a diferença entre estes algoritmos.

Tomando como exemplo a classe CPyramid e acompanhando a hierarquia apresentada, esta classe possui métodos que a caracterizam como um componente COM (IDispathImpI), métodos que a caracterizam como uma variação do algoritmo Tower (ITowerImpI), métodos que a caracterizam como um algoritmo construtivo (IConstructiveAlgorithmImpI) e, finalmente, métodos que a caracterizam como um algoritmo para Redes Neurais (IAlgorithmImpl). Como o simulador é o cliente, ele apenas conhece os métodos listados pela interface IPyramid, não se preocupando com como estes métodos são implementados. Portanto, todo o caminho percorrido pela hierarquia torna-se transparente.

Como no caso anterior, os métodos comuns aos algoritmos Upstart e Perceptron Cascade foram implementados na classe template IUpstartImpI.

Embora não tenham sido implementadas variações dos algoritmos Cascade Correlation e MTiling, suas possíveis variações utilizarão as classes template ICascadeCorrelationImpI e ITilingImpl, respectivamente.

Todos os algoritmos apresentados são filhos da classe template IConstructiveAlgorithmImpl. Esta classe implementa métodos comuns a todos os algoritmos construtivos, além de possuir um ponteiro do tipo IAlgorithm para um algoritmo de treinamento. Este ponteiro representa uma agregação, ou seja, um Algoritmo Construtivo é também um algoritmo de treinamento de acordo com o algoritmo agregado. Utilizando o conceito de agregação do COM, o Algoritmo Construtivo pode modificar os pesos de determinadas conexões, normalmente vinculadas a uma camada específica, através de chamadas ao algoritmo agregado, independente de qual seja.

Potencialmente, qualquer algoritmo que implemente a interface IAlgorithm pode ser agregado a um Algoritmo Construtivo (incluindo os próprios Algoritmos Construtivos). Para 


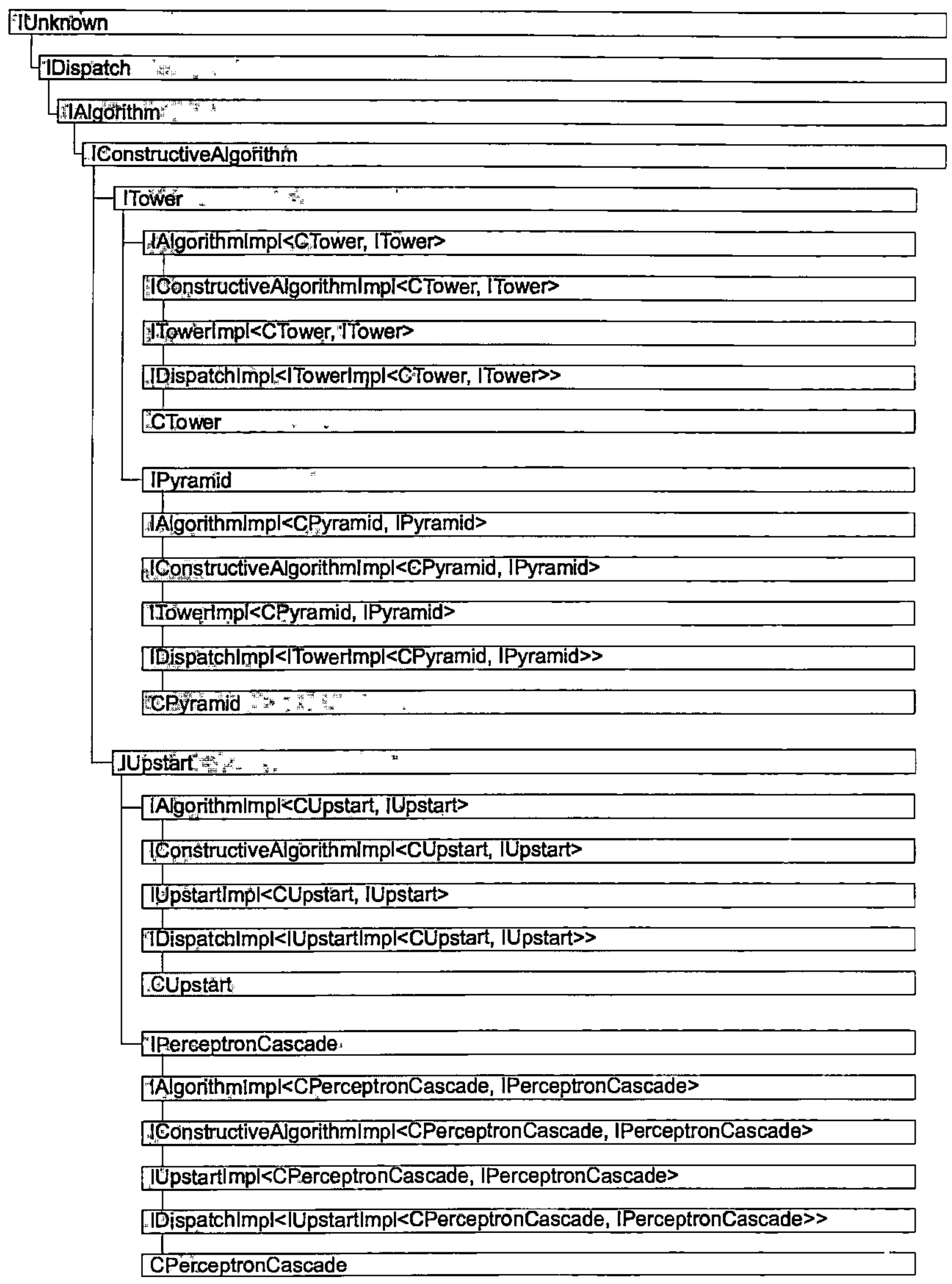

Figura 5.4: Hierarquia de classes do algoritmo Tower e sua variação Pyramid. 


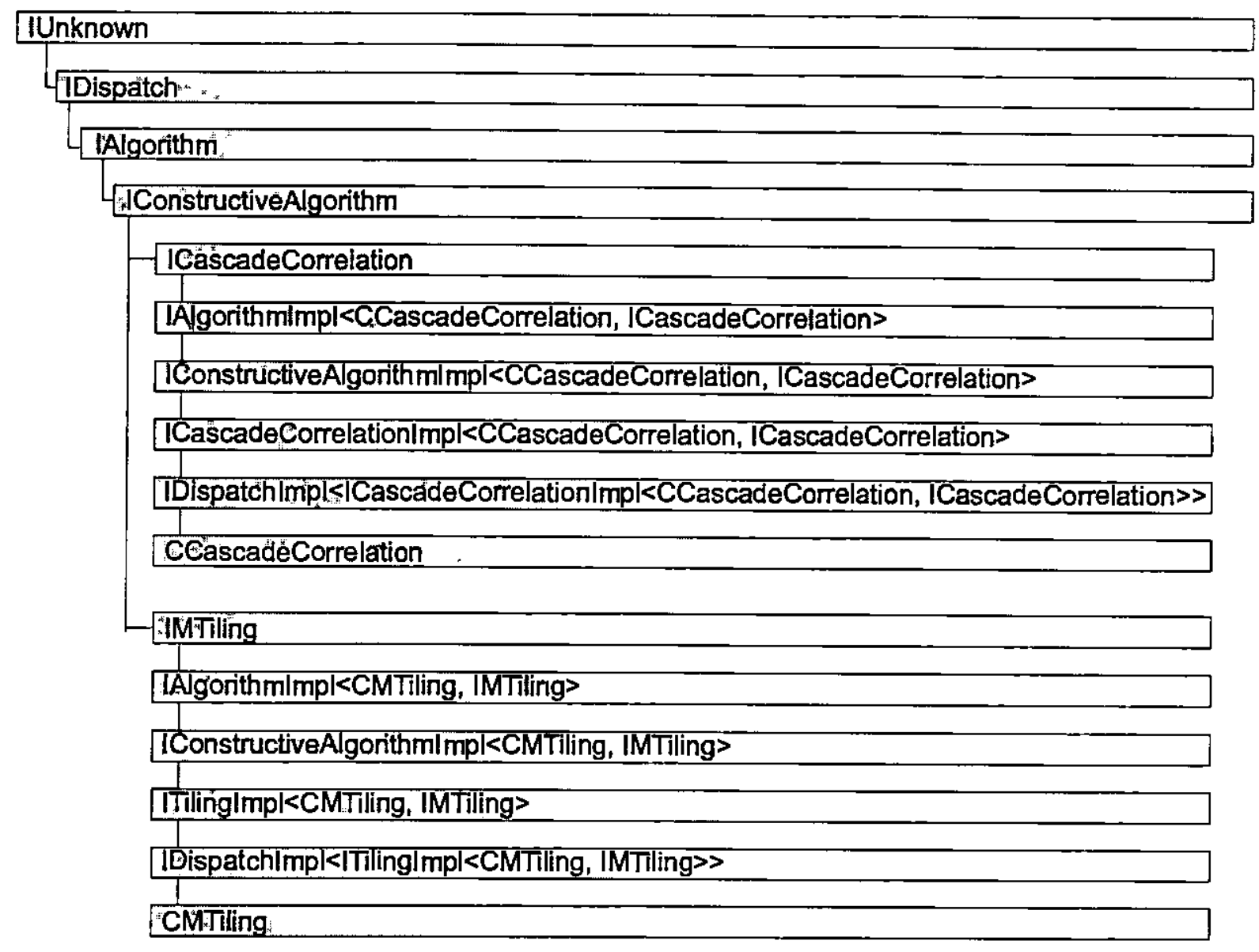

Figura 5.5: Hierarquia de classes para os algoritmos Cascade Correlation e MTiling.

restringir a agregação somente a algoritmos compatíveis, o Algoritmo Construtivo determina qual tipo de algoritmo pode ser agregado através de um mapa de interfaces. No caso dos Algoritmos Construtivos implementados neste trabalho, todos possuem uma única entrada neste mapa para a interface IStdBackProp, permitindo que qualquer variação do algoritmo back-propagation que implemente esta interface possa ser agregado, sem criar dependência de classe entre o Algoritmo Construtivo e o algoritmo de treinamento desejado.

A agregação é determinada pelo usuário durante a execução do programa, podendo ser alterada sempre que uma Rede Neural não estiver sendo treinada. Caso novos algoritmos de treinamentos sejam implementados, o Simulador é notificado e automaticamente disponibiliza esta nova opção ao usuário. Este processo de notificação será detalhado na Seção 5.4 . 


\subsubsection{Tratamento de padrões}

Para tratar conjuntos de padrões, o Kernel utiliza três conjuntos de classes: classes para tratar conjuntos de padrōes persistentes, classes para armazenar um conjunto de padrões e classes para navegar em um conjunto de padrões. A Figura 5.6 ilustra estes três conjuntos de classes.

Um conjunto de padrões é representado no Kernel através de matrizes. Para conjuntos de padrões utilizados em treinamento supervisionado, normalmente são utilizadas duas matrizes: uma para representar padrões de entrada e outra para representar os respectivos padrões de saída desejada. Esta representação é implementada pela classe CPattern.

Os conjuntos de padrões são lidos e gravados em disco pelo simulador em dois formatos. A classe CSNNSPattern implementa a manipulação de arquivos no formato SNNS (Zell, 1995), e a classe CExcelPattern implementa a manipulação de arquivos no formato Excel. Estas classes vinculam a informação persistente em disco com a representação de matrizes da classe CPattern através de agregação.

Diferente dos Algoritmos Construtivos, o objeto agregado às classes CSNNSPattern e CExcelPattern é sempre do tipo CPattern, e é criado no momento em que um arquivo de padrões é lido do disco. Este objeto é então armazenado em memória e acessado pelo Simulador através da interface IPattern, já apresentando independência de formato de arquivo.

Novos formatos de arquivos para armazenamento de padrões podem ser implementados de maneira análoga, bastando que a classe responsável pela leitura deste novo tipo de arquivo implemente a interface IPersistPattern e possua um objeto agregado do tipo CPattern.

A apresentação de padrões a uma Rede Neural em treinamento é feita por classes especiais chamadas Iteradores de Padrōes (ou Pattern Iterators). A função de um Iterador é atualizar o buffer de entrada de uma Rede Neural e, no caso de treinamento supervisionado, o seu buffer com a saída desejada. Este processo, que utiliza o conjunto de padrões armazenado nas matrizes da classe CPattern, consiste da seleção e cópia de dois vetores nos buffers da Rede Neural: da matriz de padrões de entrada e do seu respectivo vetor na matriz de valores de saida. 


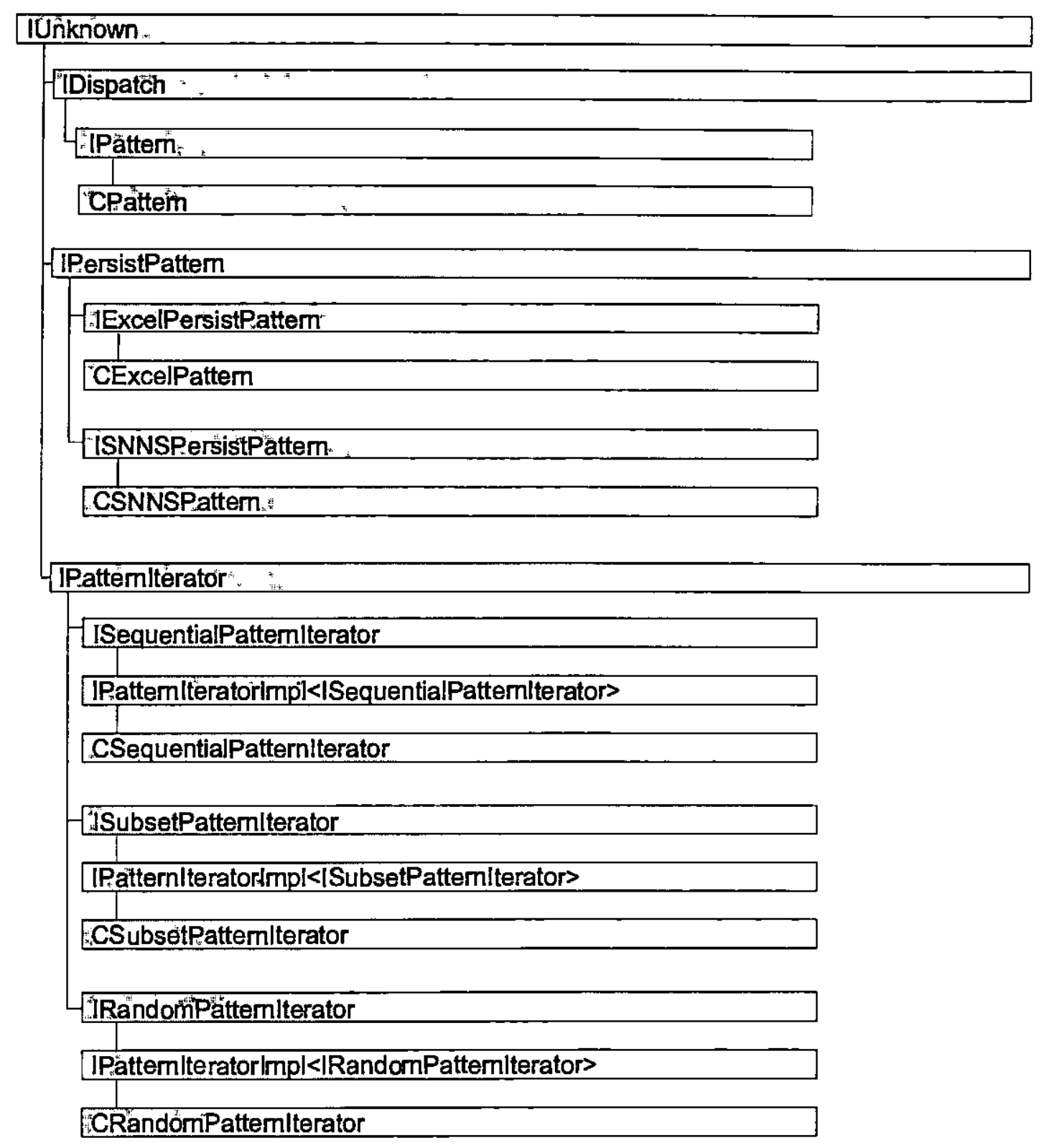

Figura 5.6: Classes para tratar padrōes (IPattern, IPersistPattern e IPatternIterator). 
As classes CSequentialPatternIterator e CRandomPatternIterator são responsáveis pela ordem de apresentação seqüencial e randômica de um certo padrão para a Rede Neural em treinamento. A classe CSubsetPatternIterator é especialmente usada em treinamento de Redes Neurais voltadas à predição, onde após uma certa seqüência de dados do padrão, o próximo dado é a saída desejada.

Os algoritmos de treinamento possuem um mapa de interfaces especificando quais Iteradores podem ser utilizados. No caso do algoritmo back-propagation e suas variações, todos os três são suportados e estão presentes no mapa, porém outros algoritmos que não suportarem algum destes Iteradores podem evitar o seu uso, eliminando sua entrada no mapa.

\subsection{Componentes}

Como mencionado anteriormente, o Kernel constitui-se de uma série de classes implementadas como componentes COM. A hierarquia de classes discutida na Seção 5.1 define o comportamento desses componentes através das suas classes base. Esta seção dedica-se a detalhar os componentes mais importantes do Simulador Kipu, explicando a funcionalidade das suas interfaces e esclarecendo as suas relações com outros componentes.

\subsubsection{O Componente MLNeuralNetwork}

A classe CMLNeuralNetwork implementa o componente responsável pela manipulação de Redes Neurais Multi-Camadas. A Figura 5.7 contém a representação esquemática deste componente.

Abaixo do nome da classe está o seu identificador, ou CLSID (Class Identifier). O CLSID está registrado no sistema operacional, permitindo ao COM criar um objeto deste tipo em qualquer aplicação cliente.

Os círculos ligados à classe representam as interfaces implementadas por este componente. Do lado direito estão as interfaces mais importantes que publicam os métodos relacionados à Rede Neural representada neste componente. As setas indicam a relaçāo hierárquica destas interfaces, onde a interface IMLNeuralNetwork é derivada da INeuralNetwork, e assim 

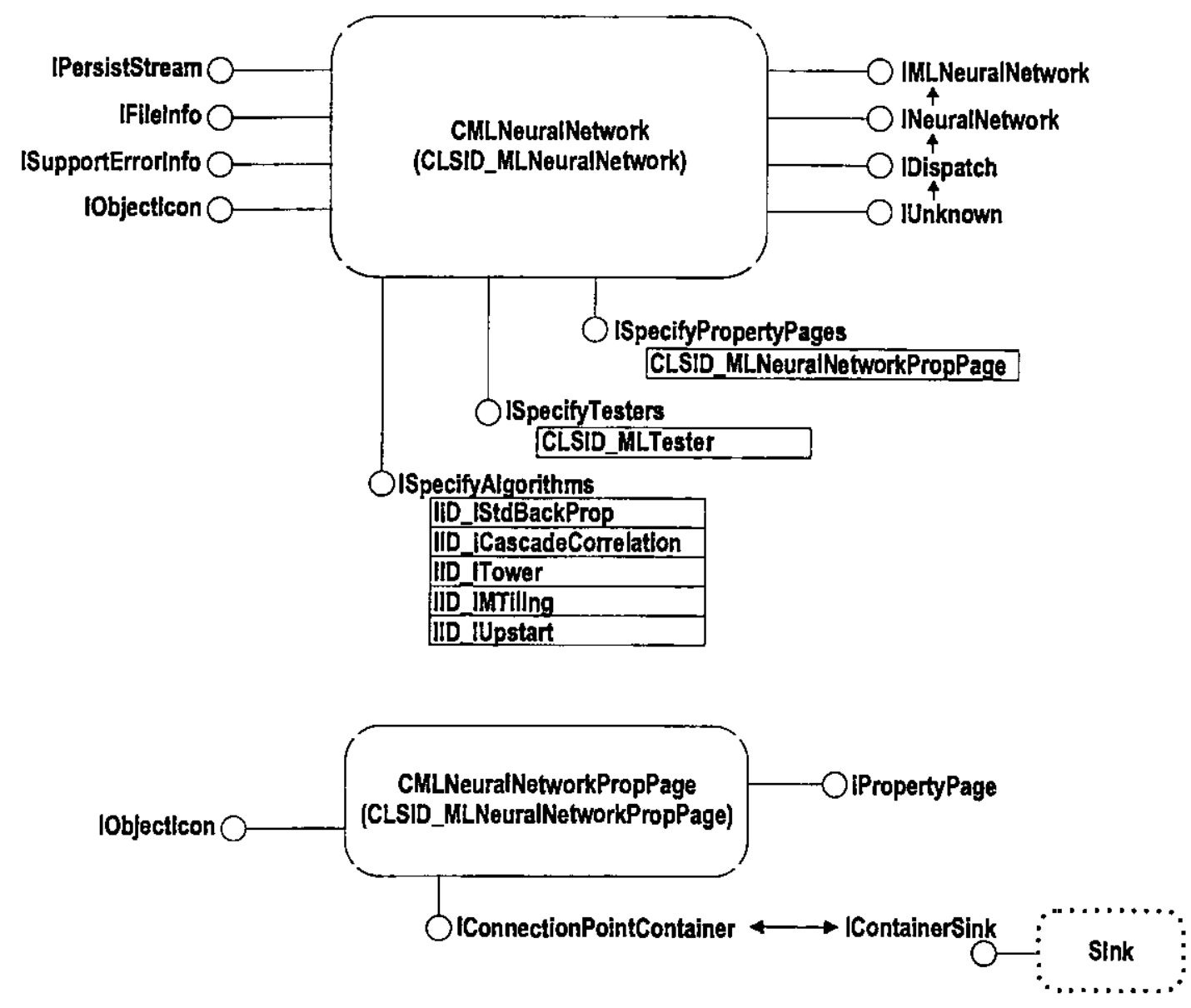

Figura 5.7: O componente MLNeuralNetwork.

sucessivamente até IUnknown.

As interfaces do lado esquerdo são as que publicam métodos para ações mais específicas do componente e podem ser utilizadas em outros componentes de forma idêntica. Suas funções são:

- IPersistStream: publica métodos para tornar o componente persistente, ou seja, gravar e ler seu estado do disco.

- IFileInfo: fornece informações sobre o arquivo em disco que contém seu estado persistente.

- ISupportErrorInfo: publica métodos de auxílio ao controle de erros.

- IObjectIcon: contém métodos para obter o ícone associado a este componente. 
As interfaces na parte de baixo da classe foram criadas para especificar quais outros componentes podem se relacionar com este. Abaixo de cada uma destas interfaces há uma lista de identificadores que estão listados dentro de um mapa no próprio componente. As interfaces são:

- ISpecifyPropertyPage: fornece uma lista de identificadores de classe das páginas de propriedade (property pages) utilizadas por este componente como forma de entrada de dados do usuário.

- ISpecifyTesters: fornece uma lista de identificadores das classes que contêm os mecanismos para testar o desempenho de uma Rede Neural e apresentar o resultado deste teste. Estas classes também são property pages, porém, como sua funcionalidade não afeta diretamente a Rede Neural, não estão incluídas na lista fornecida pela interface ISpecifyPropertyPage.

- ISpecifyAlgorithms: fornece uma lista de identificadores de interfaces (IIDs) de algoritmos de treinamento que podem ser utilizados para treinar esta Rede Neural. Esta interface é utilizada para filtrar as opções de algoritmos e evitar que o usuário tente treinar a Rede Neural com um algoritmo não suportado pela mesma.

A classe CMLNeuralNetworkPropPage, também ilustrada na Figura 5.7, é responsável pela implementação dos controles contidos na property page da Rede Neural. Todas as property pages do Kernel também são implementadas como componentes para permitir a sua utilização pela aplicação cliente, evitando que a aplicação esteja diretamente vinculada ao código do componente (no caso a Rede Neural).

Somente três interfaces são implementadas: IPropertyPage com os métodos comuns a qualquer property page, IObjectIcon, que, como no caso anterior, permite recuperar o ícone deste componente, e IConnectionPointContainer, que é utilizada para estabelecer a comunicação com a interface IContainerSink, que é implementada pelo sink do cliente, aqui representado pela caixa pontilhada. Este mecanismo de comunicação foi discutido na Seção 4.2 .5 . 


\subsubsection{O Componente MLLayer}

A classe CMLLayer implementa o componente que representa uma camada de uma Rede MLP. Seu esquema está ilustrado na Figura 5.8.

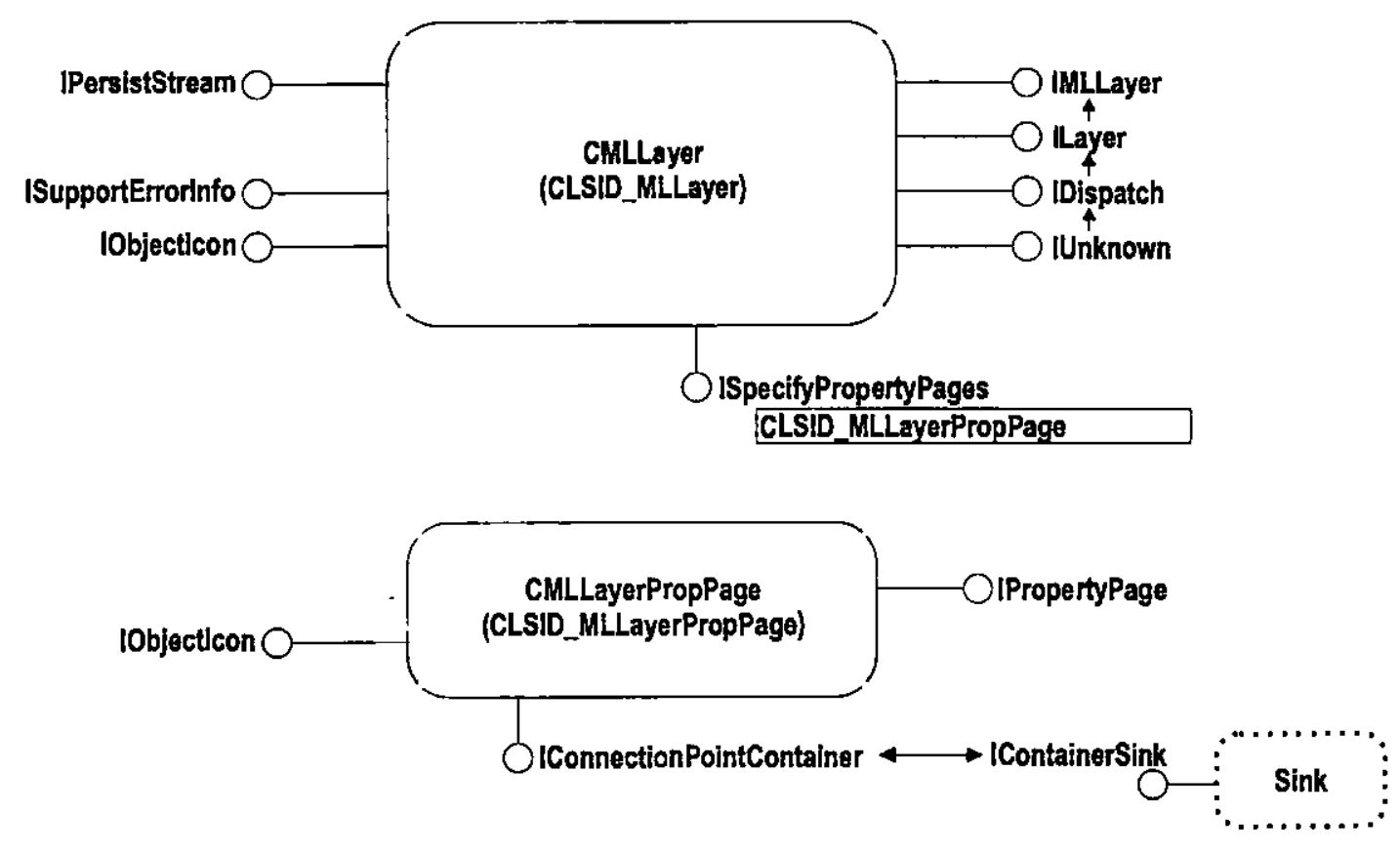

Figura 5.8: O componente MLLayer.

Como no componente MLNeuralNetwork, à direta estão as interfaces vitais deste componente. As interfaces IMLLayer e ILayer publicam os métodos de manipulação de camadas, como métodos para criar neurônios ou mudar o tipo da camada. As setas indicam, novamente, a relação hierárquica entre estas interfaces.

A funcionalidade das demais interfaces é a mesma do componente MLNeuralNetwork, onde a diferença está na implementação dos métodos publicados por estas interfaces que é adequada a este componente.

Apesar de uma camada não ser salva em um arquivo separado, ela contém informações sobre o estado da Rede Neural. Em operações de escrita e leitura, a Rede Neural além de acessar sua informação persistente, realiza chamadas aos métodos da interface IPersistStream de cada camada para que as informações persistentes de suas camadas e de seus neurônios também sejam acessadas.

A classe que implementa a property page do componente MLLayer está esquematizada na 
Figura 5.8. Esta classe possui o mesmo formato da classe CMLNeural NetworkPropPage, diferenciando-se apenas pelos controles e métodos implementados.

\subsubsection{O Componente Neuron}

Seguindo o modelo utilizado para os componentes anteriores, o esquema deste componente está ilustrado pela Figura 5.9. Novamente, as interfaces mais importantes estão à direita e sua property page está esquematizada a seguir.

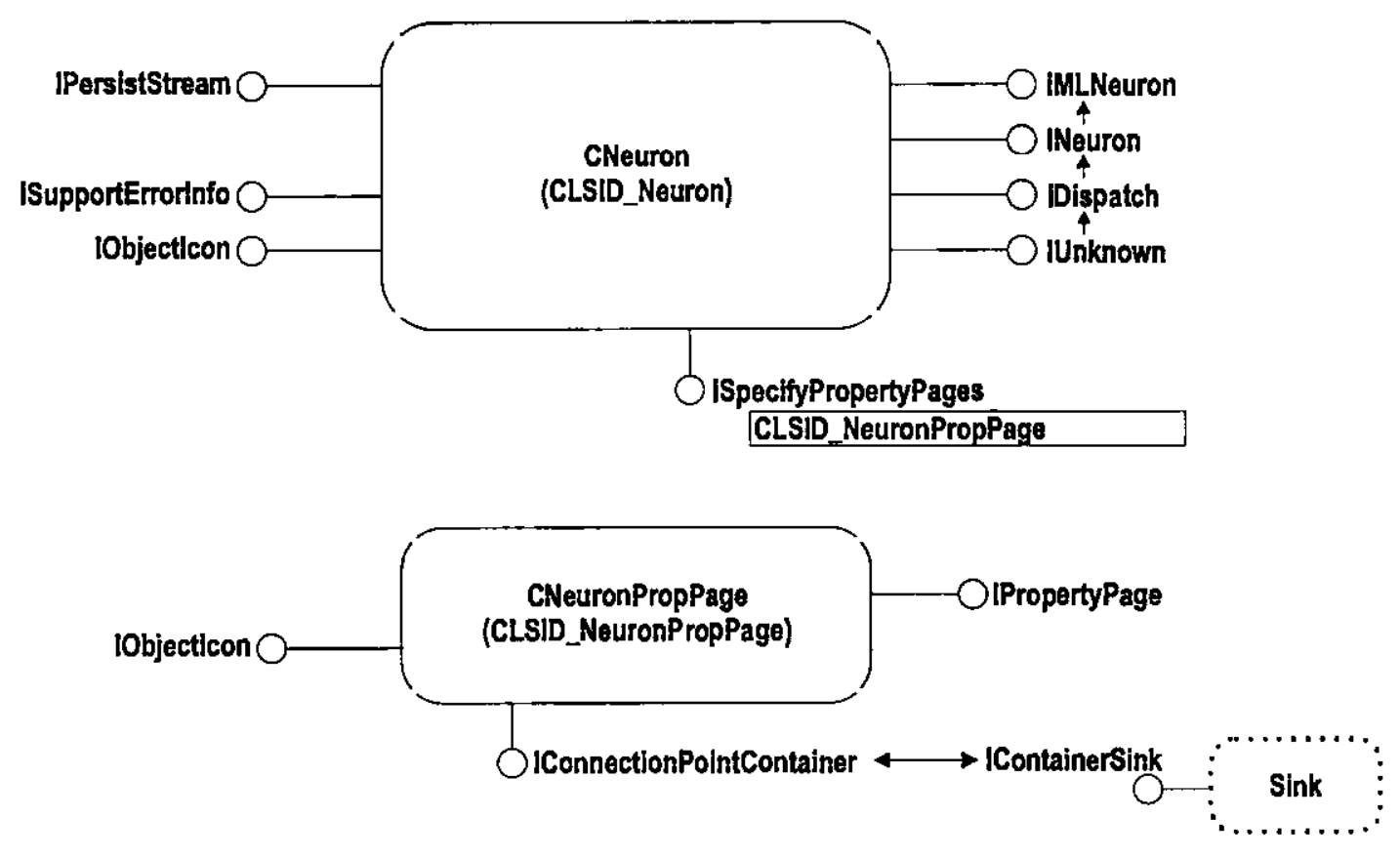

Figura 5.9: O componente Neuron.

\subsubsection{Componentes para Algoritmos de Treinamento}

Os algoritmos de treinamento implementados nesta versão do simulador são variações do algoritmo back-propagation. Os componentes responsáveis pelo seu funcionamento possuem as mesmas características. A Figura 5.10 ilustra o esquema do componente StdBackProp, que representa o próprio algoritmo back-propagation. Em seguida, as Figuras 5.11 e 5.12 ilustram os algoritmos back-propagation momentum e quick-propagation, respectivamente.

Os algoritmos precisam de um canal de comunicação com o cliente para enviar dados, como o andamento do treinamento ou o erro atual da Rede Neural. Para isso, todos implementam 

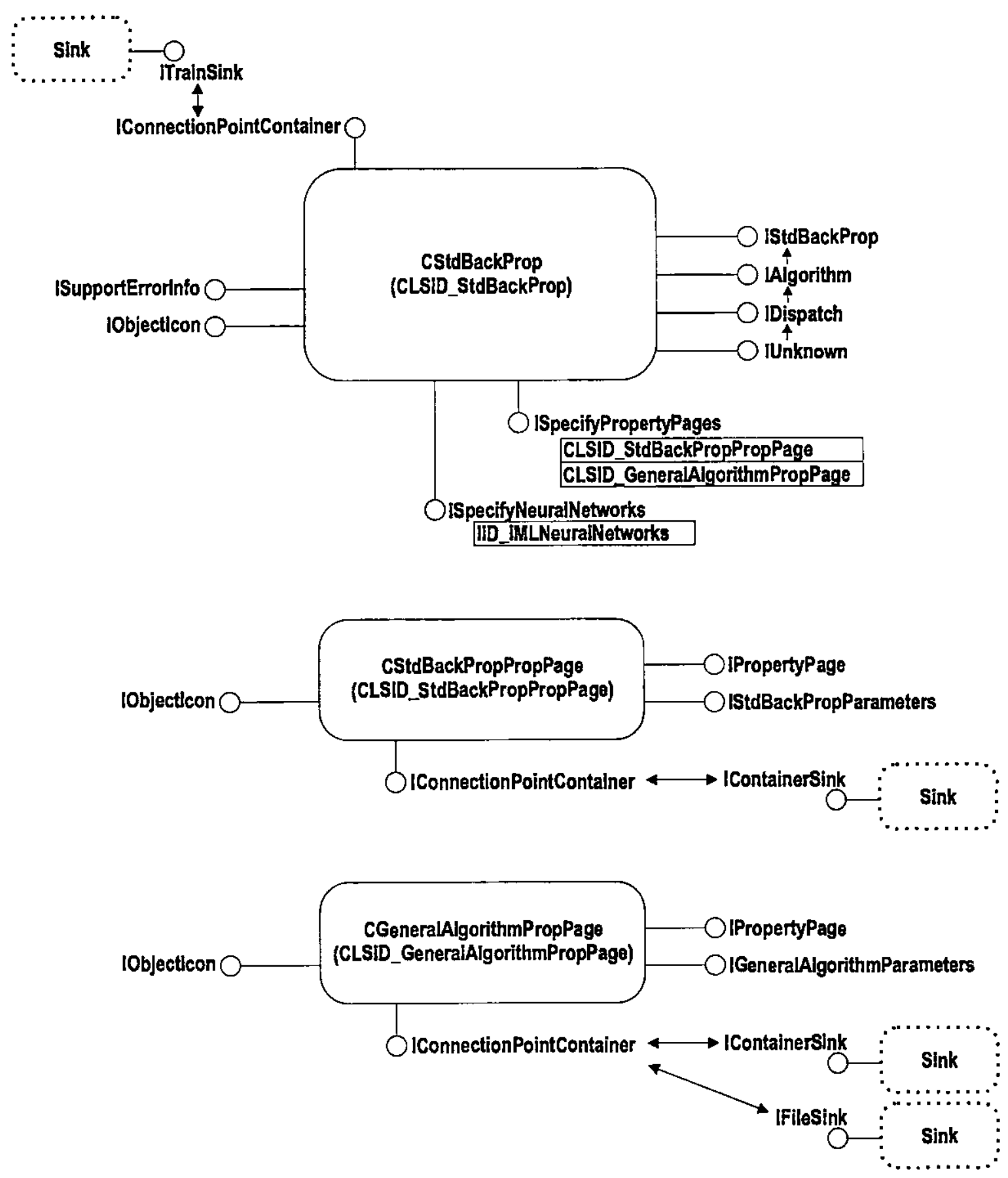

Figura 5.10: O componente StdBackProp. 


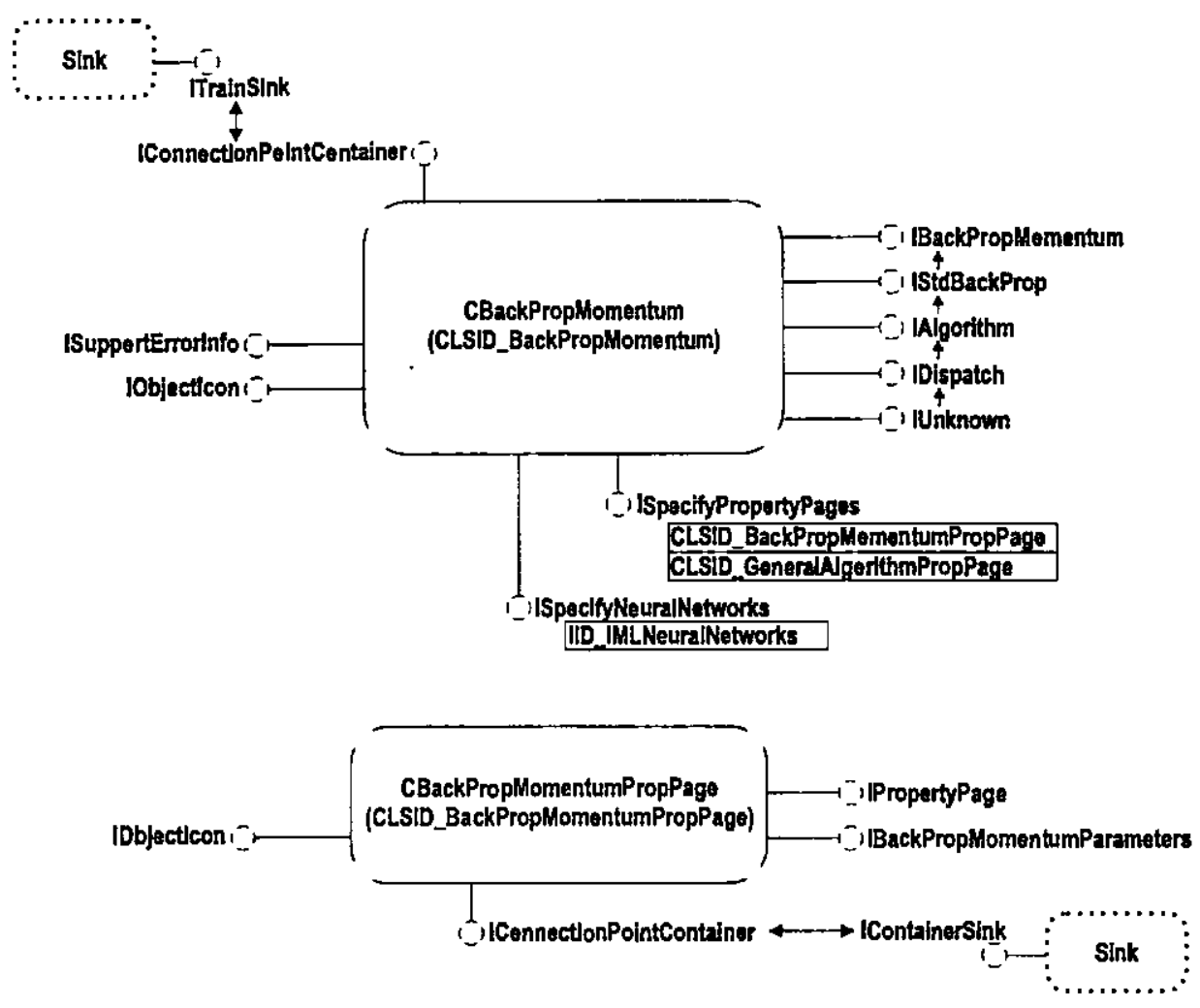

Figura 5.11: O componente BackPropMomentum.

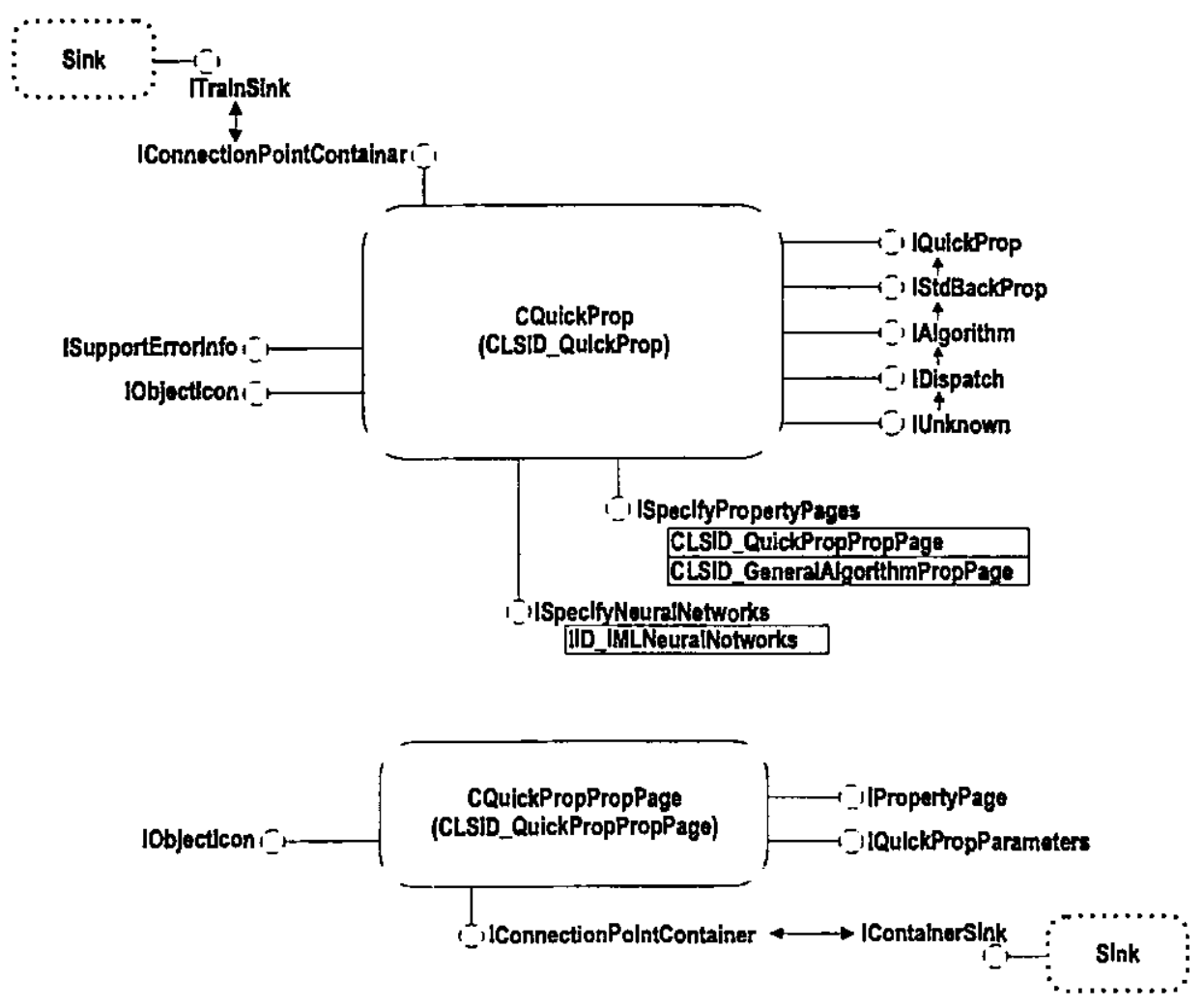

Figura 5.12: O componente QuickProp. 
a interface IConnectionPointContainer, que estabelece a comunicação com a interface ITrainSink implementada no sink do cliente. As Figuras 5.10, 5.11, e 5.12 representam o sink do cliente com a caixa pontilhada.

A interface ISpecifyNeuralNetworks é a contraparte da interface ISpecifyAlgorithms encontrada no componente MLNeuralNetwork. Os algoritmos de treinamento a implementam para especificar o tipo de Rede Neural que podem treinar, no caso, justamente redes do tipo MLNeuralNetwork.

Diferente dos componentes anteriores, os algoritmos de treinamento especificam duas property pages. A primeira é responsável pela entrada dos parâmetros de treinamento específicos para cada algoritmo. A segunda é comum a todos estes algoritmos e é utilizada para determinar os conjuntos de padrões a serem utilizados durante o treinamento. Os parâmetros destas property pages são passados aos algoritmos pelas interfaces IStdBackPropParameters, IBackPropMomentumParameters e IQuickPropParameters, específicas a cada algoritmo, e pela interface IGeneralAlgorithmParameters específica ao componente implementado pela classe CGeneralAlgorithmPropPage, ilustrado na Figura 5.10. Estas interfaces são facil mente obtidas pelo programa através do Controller, comentado na Seção 5.5 .

A interface IConnectionPointContainer do componente GeneralAlgorithmPropPage estabelece comunicação com um outro sink através da interface IFileSink. Esta segunda comunicação é utilizada quando o usuário carrega um novo arquivo de padrões a partir desta property page.

\subsubsection{Componentes para Algoritmos Construtivos}

Os componentes criados para os Algoritmos Construtivos não seguem o mesmo formato dos componentes para algoritmos de treinamento convencionais. A diferença fundamental está na presença da agregação, explicada na Seção 4.2.3.

A Figura 5.13 ilustra o esquema do componente CascadeCorrelation. No caso do algoritmo Cascade Correlation, existem dois componentes agregados: o algoritmo de treinamento utilizado para corrigir os pesos das conexōes da camada de saída minimizando o erro da Rede Neural, e uma variação do algoritmo quick-propagation dedicada a treinar os pesos 
das conexões da camada de candidatos para maximizar a correlação entre os neurônios candidatos e a saída da rede. O componente CascorQuickProp é responsável por este último treinamento e também está esquematizado na Figura 5.13.

A classe CCascorQuickProp, apesar de também representar uma variação do algoritmo backpropagation, não corresponde a um algoritmo de treinamento, por ser definida exclusivamente para o treinamento de neurônios candidatos. Portanto, muitas das interfaces comuns às variações do back-propagation não são implementadas e seus parâmetros são obtidos na própria property page do componente CascadeCorrelation.

A agregação do algoritmo de treinamento, presente em todos os Algoritmos Construtivos, está representada como um ponteiro à interface IAlgorithm. Isto se deve ao fato desta agregação ocorrer em tempo de execução, permitindo inicialmente que qualquer componente que implemente a interface IAIgorithm seja agregado. Para controlar e filtrar algoritmos que não devem ser agregados, a interface ISpecifyAlgorithms é implementada e sua utilização é muito similar à do componente MLNeuralNetwork.

Outra diferença entre os componentes para Algoritmos Construtivos e algoritmos de treinamento convencionais é o canal de comunicação com o cliente. No caso dos Algoritmos Construtivos, sua interface IConnectionPointContainer estabelece comunicação com a interface IConstructiveSink, pois a interface ITrainSink será utilizada pelo seu algoritmo de treinamento agregado. A interface IConstructiveSink é dedicada para informar o cliente do andamento de cálculos efetuados pelo Algoritmo Construtivo.

As Figuras 5.14 e 5.15 ilustram os esquemas dos componentes para os algoritmos Tower e Pyramid, respectivamente. Como o Algoritmo Pyramid é uma variação do Tower, esse também implementa a interface ITower.

As Figuras 5.16 e 5.17 ilustram os esquemas dos componentes para os algoritmos Upstart e Perceptron Cascade, respectivamente. Finalmente, a Figura 5.18 ilustra o esquema dos componentes para o algoritmo MTiling. 


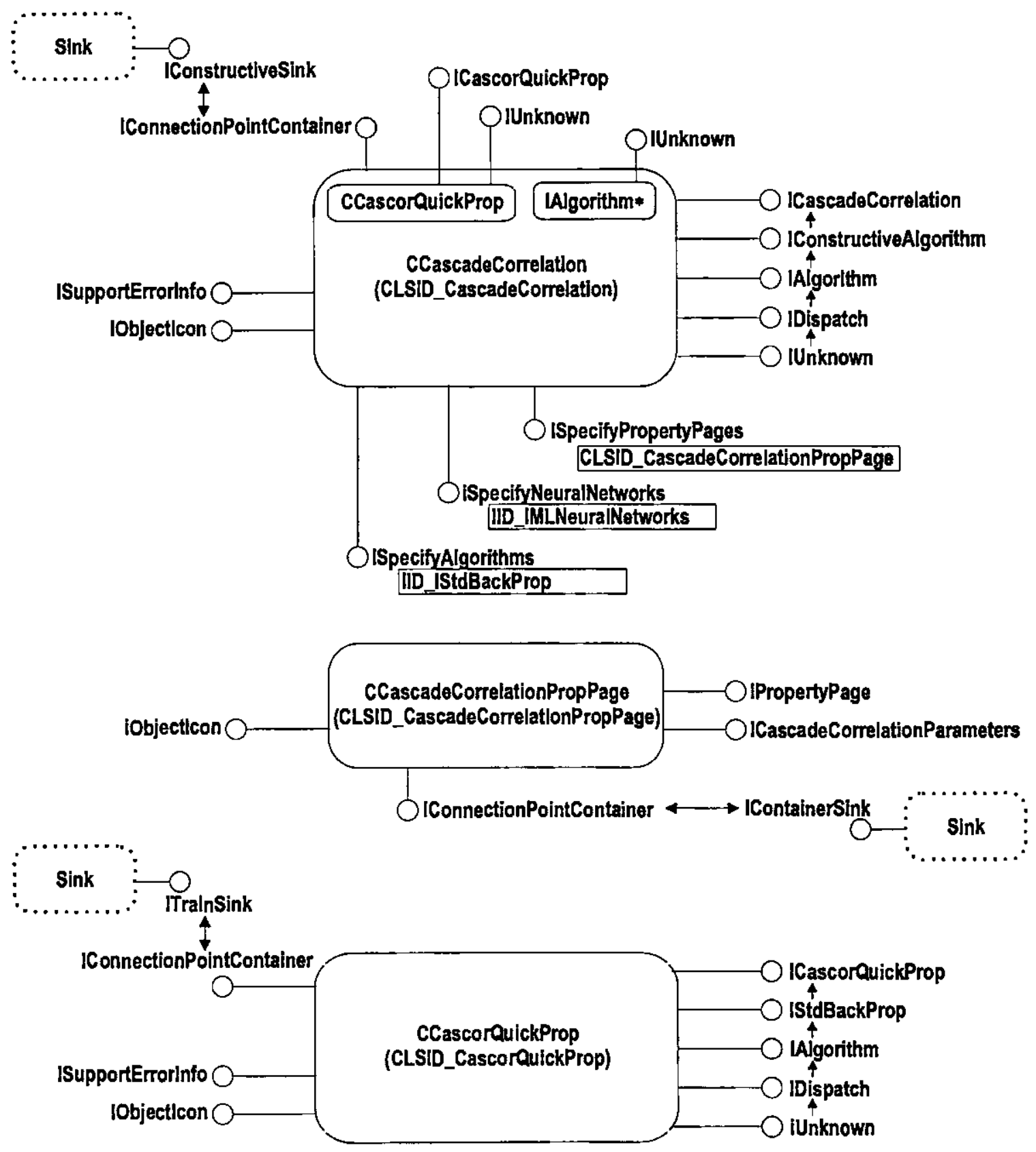

Figura 5.13: O componente CascadeCorrelation. 


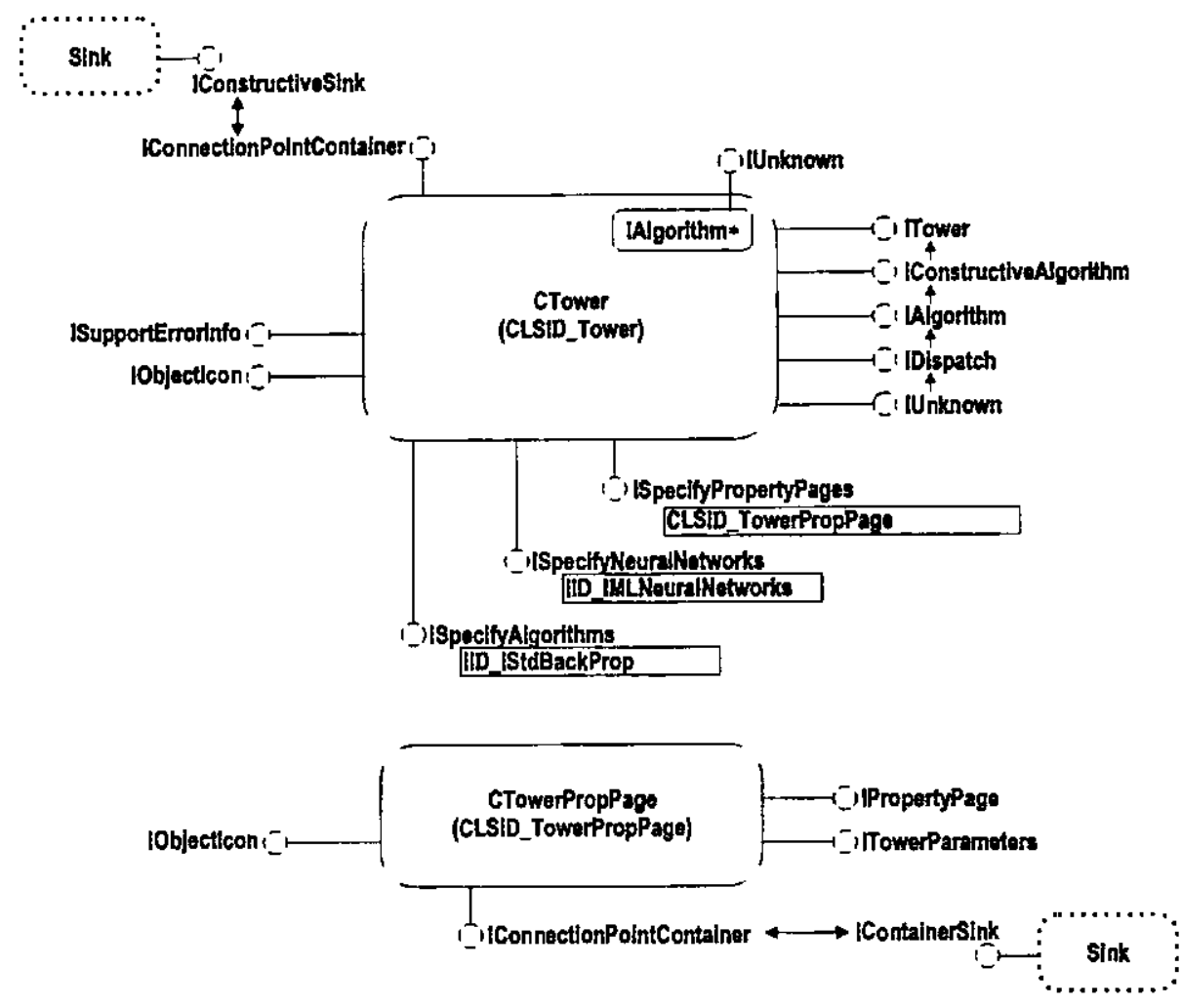

Figura 5.14: O componente Tower.

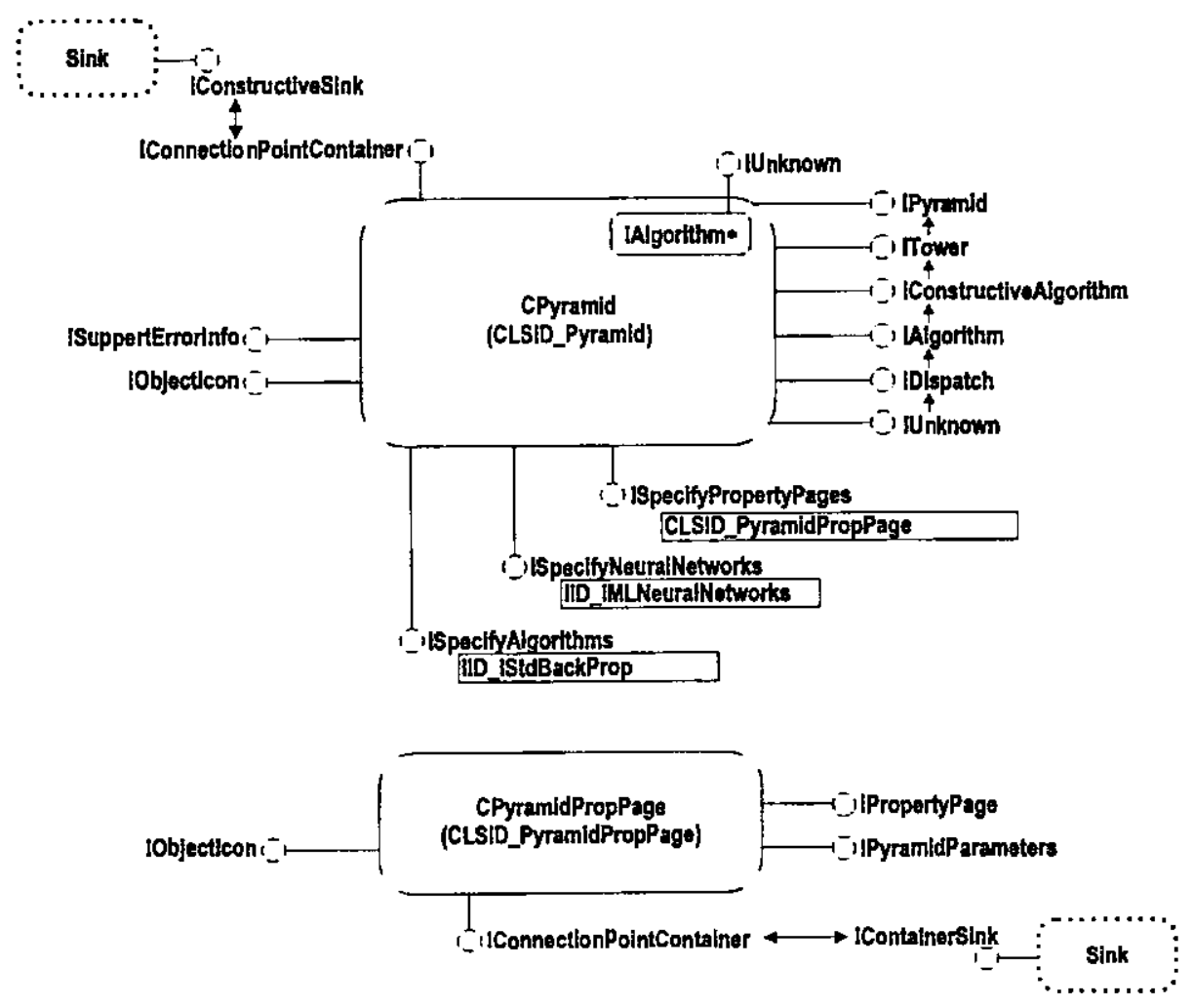

Figura 5.15: O componente Pyramid. 


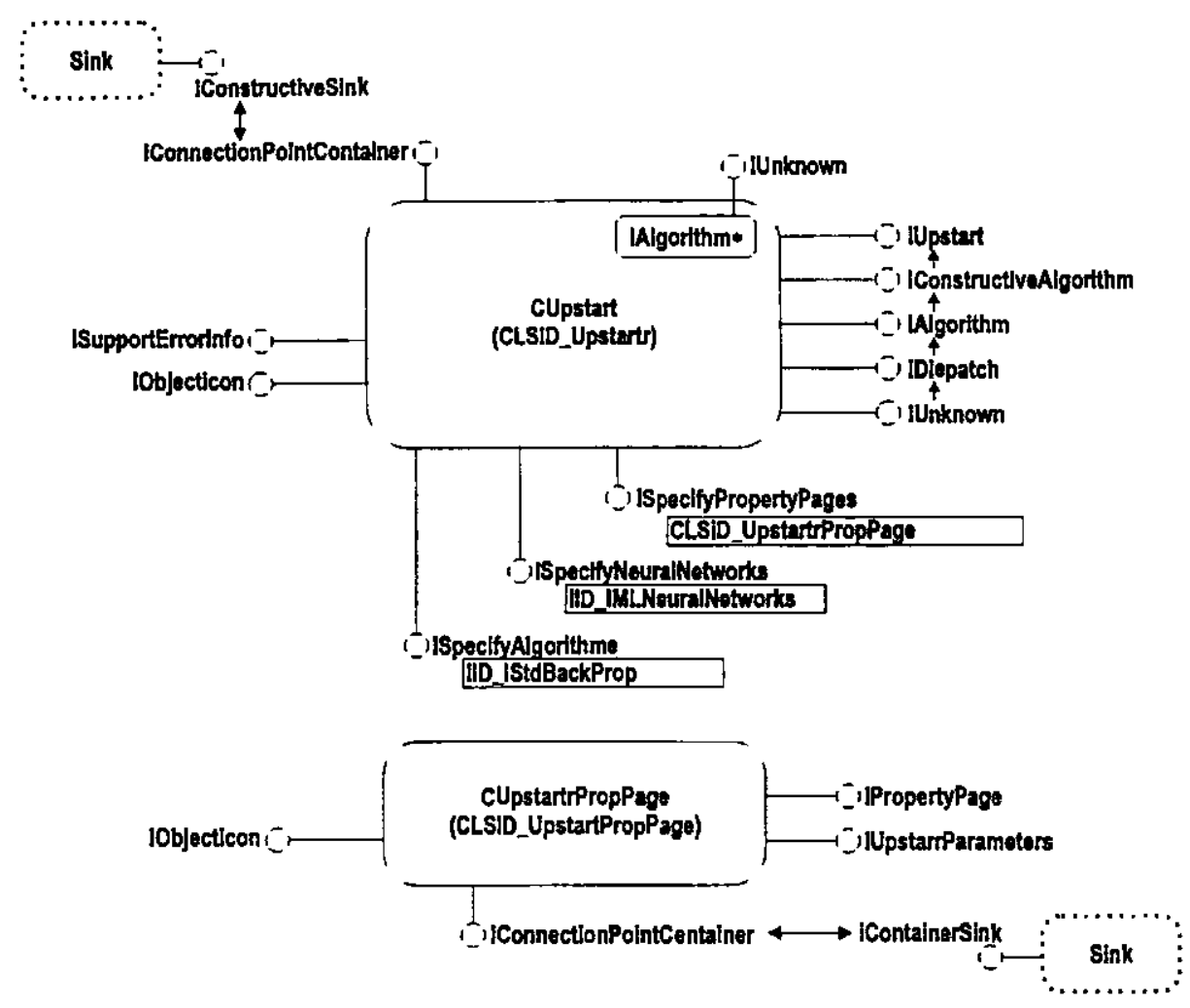

Figura 5.16: O componente Upstart.

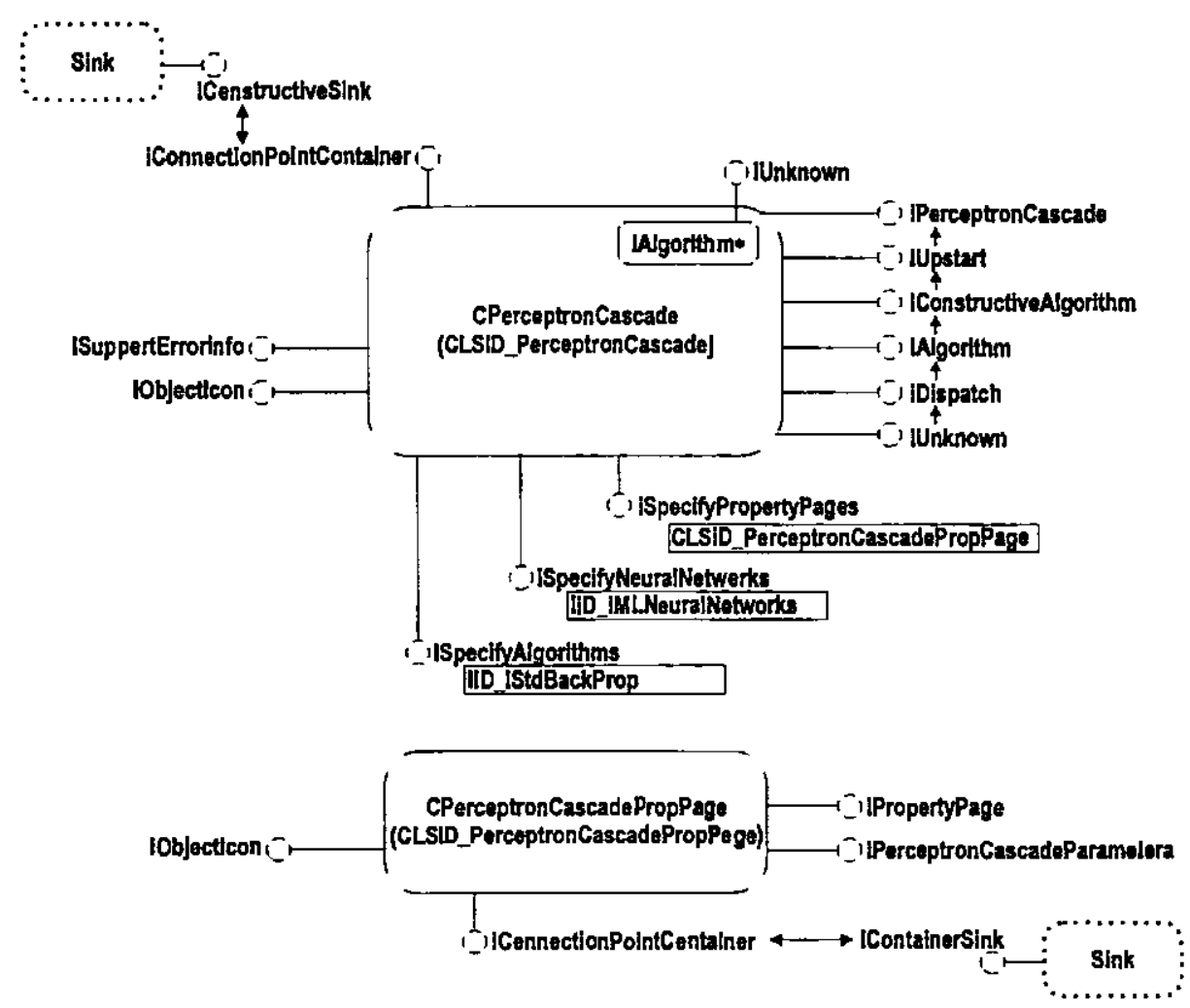

Figura 5.17: O componente PerceptronCascade. 


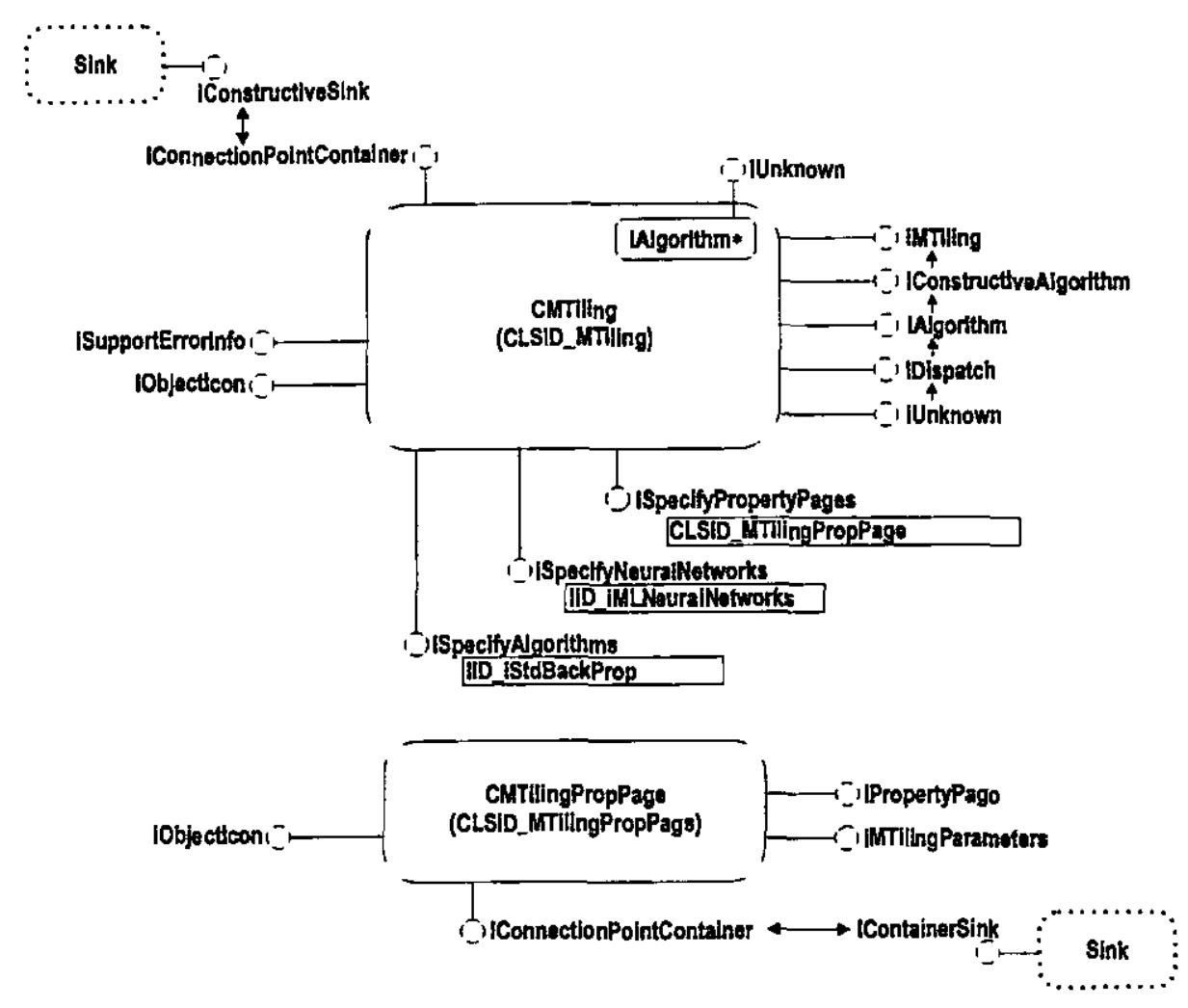

Figura 5.18: O componente MTiling.

\subsubsection{Componentes para Conjunto de Padrões}

Conjuntos de padrões são lidos em arquivos em disco. O formato de arquivo utilizado neste trabalho foi o formato SNNS (Zell, 1995). O componente SNNSPattern é responsável pela leitura e escrita de conjuntos de padrões em arquivos neste formato. A interface ISNNSPersistPattern, derivada de IPersistPattern, publica os métodos adequados para estas operações. Os padrões em si são armazenados no componente agregado implementado pela classe CPattern, que utiliza a interface IFileInfo para manter uma correspondência entre o conjunto de padrões e o seu arquivo. A Figura 5.19 ilustra os esquemas destes componentes.

A interface IConnectionPointContainer estabelece uma comunicação com a interface IFileSink para informar o cliente do andamento da operação de leitura e escrita do conjunto de padrões. 

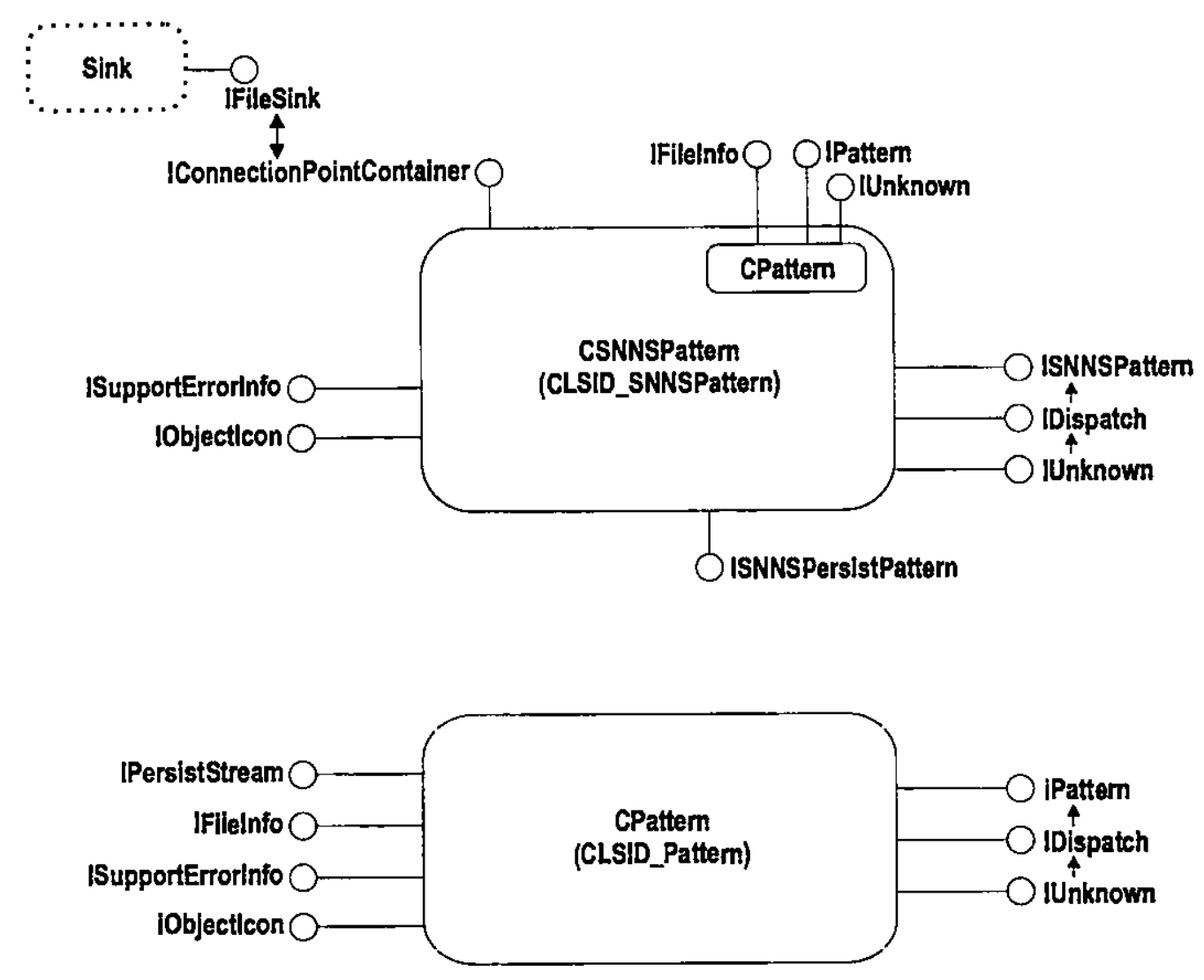

Figura 5.19: Os componentes SNNSPattern e Pattern.

\subsection{Modelo de Dados para Redes MLP e Visualizado- res}

A estrutura de dados utilizada no projeto original do Simulador Kipu associava as classes que representavam os elementos de uma Rede Neural (neurônios, camadas e a própria rede) com a classe responsável pelo desenho desta rede na interface gráfica. Para quebrar este vínculo, a classe template IObjectViewerImpl foi criada como base de classes especialmente destinadas a tratar da visualização de determinados modelos de Redes Neurais. Estas classes comunicam-se com as classes que representam a Rede Neural e obtêm as informações necessárias, como número e disposição dos neurônios e conexōes, para desenhá-la em uma janela.

A classe template IObj ectViewer utiliza a biblioteca de classes VTK (Visualization Toolkit) (Schroeder et al., 1997) (VTK, 2000), que oferece recursos para criar desenhos em três dimensões e manipular a visualização com operações de rotação, translação e zoom. 
Para o modelo MLP, ou seja, redes que implementam a interface IMLNeuralNetwork, a classe núcleo CMLNViewer implementa métodos específicos para desenhar a Rede Neural em treinamento, e publica-os através da interface IObjectViewer. Esta classe ainda está em fase de desenvolvimento.

As classes responsáveis pela visualização de uma Rede Neural foram convencionalmente chamadas de Visualizadores (ou Viewers), e estão sendo implementadas como uma DLL separada, permitindo ao usuário utilizá-los ou não.

O Visualizador funciona como uma máquina fotográfica, capturando o estado da Rede Neural em um determinado momento e utilizando este estado para desenhá-la na interface gráfica. Desta forma, o Visualizador não influencia no treinamento da Rede Neural, podendo ser inclusive desabilitado. A interação entre Visualizador e Rede Neural é transparente para o usuário.

A utilização do Visualizador como um componente independente torna a estrutura de dados da Rede Neural mais enxuta e totalmente dedicada ao seu treinamento e utilização. A Figura 5.20 apresenta a estrutura de dados criada para representar uma Rede Neural MultiCamadas, ilustrando a interação entre as classes CMLNeuralNetwork, CMLLayer e CNeuron.

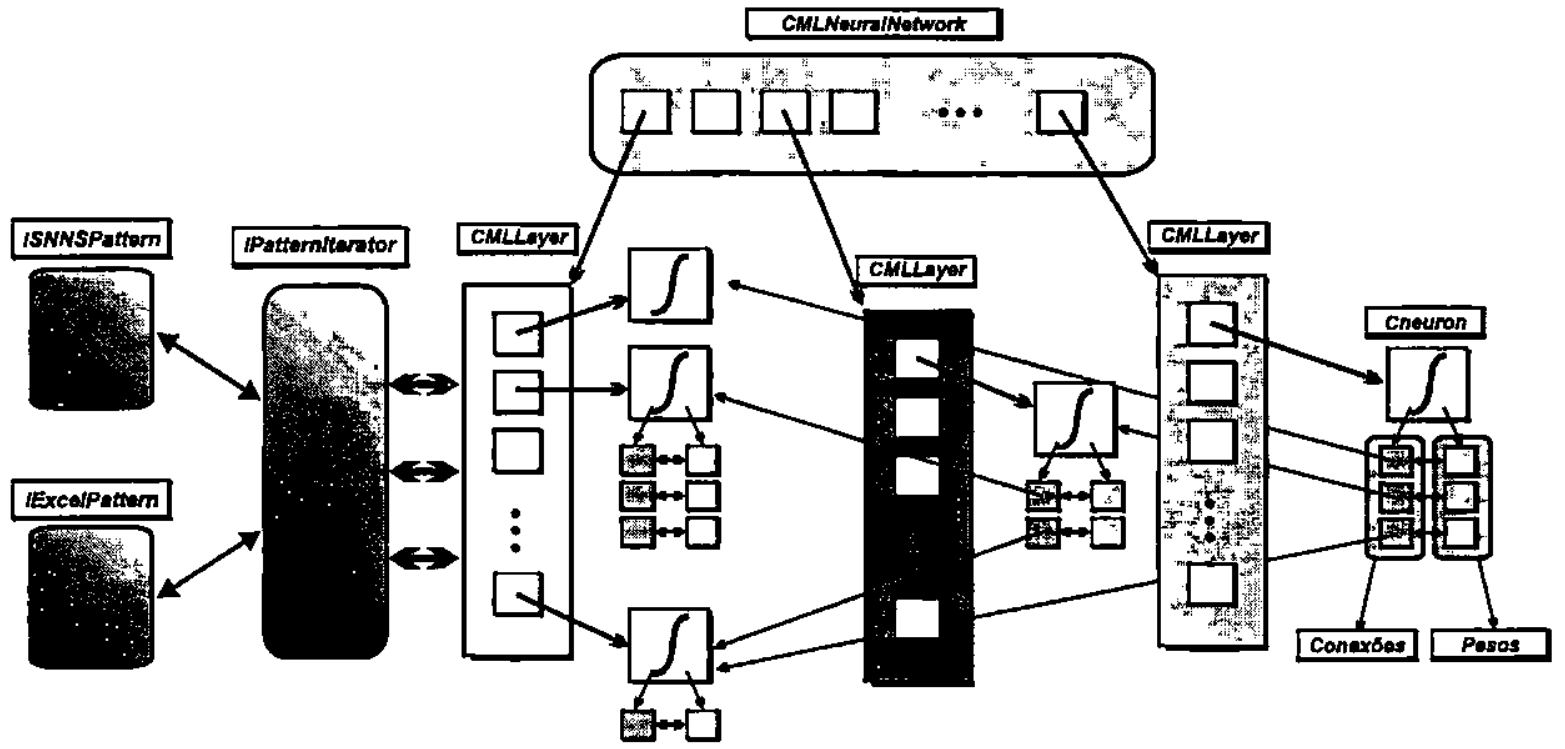

Figura 5.20: Estrutura de dados representando uma Rede Neural Multi-Camadas.

As classes CMLNeuralNetwork e CMLLayer são derivadas da classe template CFastArray. Objetos destas classes são vetores de ponteiros à camadas e neurônios, respectivamente. A 
classe CNeuron possui membros do tipo CFastArray para armazenar os vetores de ponteiros a outros neurônios e de pesos associados a estas conexões.

\subsection{O Repositório de Dados}

Durante o processo de simulação, vários dados podem ser compartilhados entre os componentes do Kernel. Para uniformizar e facilitar o controle de concorrência sobre estes dados, o Kernel implementa o componente CKipuRepository.

Este componente é definido como Singleton, isto é, existe apenas uma instância deste componente em todo o escopo do programa. Desta forma, sempre que uma funçāo pedir a criação de uma instância, esta só será criada se nenhuma instância tiver sido criada. Caso já exista esta instância, ela é retornada à função que pediu a criação.

O CKipuRepository é composto de um grupo de vetores destinados a armazenar um tipo específico de dados: Redes Neurais, Algoritmos, Padrões, Iteradores de Padrões (Pattern Iterators), Visualizadores e até Camadas e Neurônios, caso seja necessário. No caso de Redes Neurais, Padrões, Camadas e Neurônios, é armazenado um ponteiro ao componente criado: INeuralNetwork*, IPattern*, ILayer* e INeuron*.

Como Iteradores de Padrões, Algoritmos e Visualizadores são criados durante o processo de simulação, apenas os identificadores das classes dos componentes suportados pelo simulador são armazenados, ou seja, seu CLSID. O CLSID é o identificador único da classe que se pretende instanciar através de uma interface COM. Este identificador é composto por um valor de 128 bits registrado no sistema operacional.

Os vetores que armazenam ponteiros e identificadores de classes são definidos em uma classe template chamada CRepository, que na verdade é composta de dois vetores: um para armazenar os dados desejados e o outro para armazenar referências para janelas que devem ser notificadas caso hajam alterações nos dados armazenados.

As notificações dizem respeito à inserção, modificação e remoção de elementos no repositório, e devem ser enviadas a determinadas janelas do programa para que estas alterem o seu estado. Um exemplo seria a inserção de um novo conjunto de padrões, onde uma janela 
que apresenta uma lista dos padrões carregados no repositório deve ser notificada para ser atualizada, apresentando o novo padrão carregado.

$\mathrm{Na}$ Seção 5.1.2 foi comentado que um Algoritmo Construtivo apresenta ao usuário uma lista de algoritmos de treinamento que podem ser agregados a ele. Estes algoritmos de treinamento possuem seus CLSIDs registrados no repositório. Quando um Algoritmo Construtivo é criado, sua janela de parâmetros é registrada no repositório para receber notificaçōes sobre os algoritmos registrados. O repositório envia a esta janela uma lista de todos os algoritmos registrados, além de notificações de inclusão e remoção dos mesmos. Cabe ao Algoritmo Construtivo filtrar quais algoritmos do repositório podem ser apresentados ao usuário de acordo com o seu mapa interno de interfaces. Esta operação de troca de informações entre o repositório e um componente é uniformemente aplicada em vários pontos do Simulador, facilitando o controle interno do Kernel e a interface gráfica com o usuário.

Como a inserção, modificação e remoção de elementos podem partir de qualquer parte do programa, inclusive de threads diferentes, é importante ressaltar que o repositório possui um controle de concorrência para evitar deadlocks ou inconsistência nos dados.

O repositório também é capaz de armazenar informaçōes sobre seu estado no registro do sistema operacional, como quais conjuntos de padrões estavam carregados quando o Simulador foi fechado. Assim, quando o Simulador é reiniciado, este estado é lido do registro e apresentado ao usuário como se a execução do Simulador não tivesse sido encerrada.

O repositório é criado no início da execução do Simulador, permanecendo na memória até que este seja fechado.

\subsection{O Controlador}

Vários elementos envolvidos no processo de treinamento foram apresentados. Destes, os mais relevantes são a Rede Neural em treinamento e o algoritmo de treinamento selecionado. Outros elementos importantes são o Visualizador e os parâmetros escolhidos para o algoritmo de treinamento.

Durante o processo de treinamento, todos estes elementos precisam freqüentemente trocar 
informações entre si. Para vinculá-los, um objeto chamada de Controlador (ou Controller) é criado, armazenando um ponteiro para cada um destes quatro elementos. Estes elementos, por sua vez, armazenam um ponteiro ao Controller. Assim, qualquer elemento do treinamento pode acessar eficientemente outro elemento. A Figura 5.21 ilustra a posição de intermediador assumida pelo Controller.

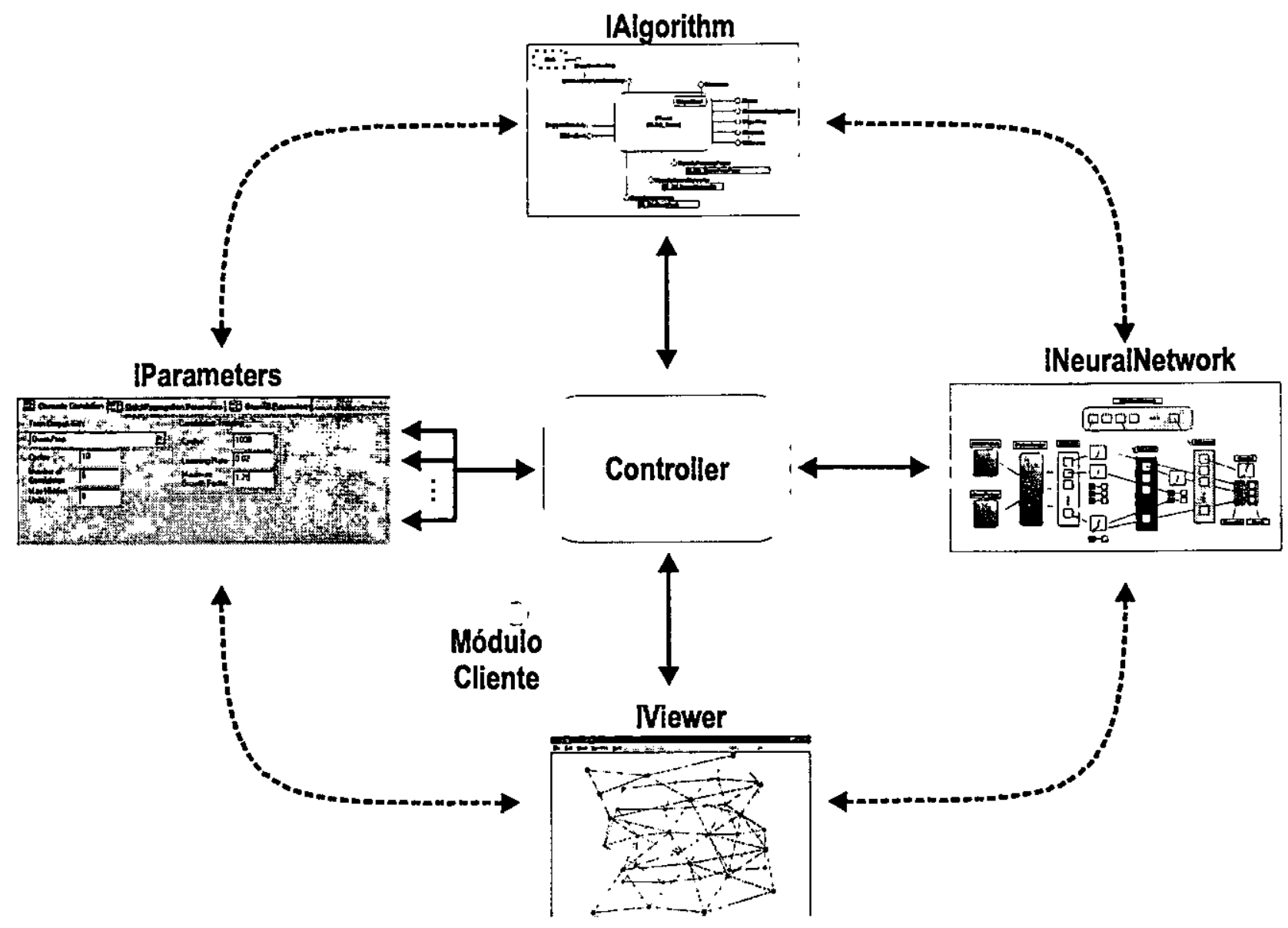

Figura 5.21: Relacionamento entre o Controller e os demais componentes.

Outros elementos que também são necessários durante a simulação também são referenciados pelo Controller, como o canal de comunicação entre o Kernel e o módulo cliente, e no caso de redes MLP, a classe responsável pelo teste da Rede Neural resultante do treinamento.

\subsection{Conexão entre Componentes}

Muitas vezes, um componente precisa enviar eventos ou mensagens a outros componentes. Por exemplo, o treinamento de uma Rede Neural executada em uma thread precisa manter 
atualizados os dados do gráfico de treinamento contido em outra thread. Como os componentes COM não apresentam detalhes de implementação em suas interfaces, a comunicação entre objetos do Kernel e do Simulador é feita através de canais especializados chamados Connection Points (ou Pontos de Conexão), já mencionados na Seção 4.2.5.

Em vários pontos do projeto esta comunicação é necessária. Os pontos de conexão mais importantes são criados para:

- Enviar eventos do Kernel ao Simulador sempre que necessário.

- Manter o usuário atualizado sobre o andamento do treinamento.

- Manter o usuário atualizado sobre o andamento da leitura de conjunto de padrões.

Quando a arquitetura da Rede Neural é alterada por um Algoritmo Construtivo, o Simulador é notificado para atualizar o desenho da Rede Neural. Outras notificações constantes são as trocas de mensagens indicando início ou término de treinamento.

Para que estas notificações sejam enviadas de maneira eficiente a partir de qualquer ponto do Kernel, o Controller mantém um ponteiro ao sink do Simulador.

\subsection{O Módulo Cliente}

Uma vez definido o Kernel, o programa cliente (ou Simulador) que utiliza os componentes COM mencionados nas seções anteriores foi implementado. Este programa é um executável Windows que utiliza classes MFC (Microsoft Foundation Class) com suporte à ATL (Active Template Library) para acessar componentes COM.

A janela principal do Simulador é um gerenciador de elementos, onde Redes Neurais, Padrões e Algoritmos podem ser disponibilizados para utilização. Para cada Rede Neural criada ou carregada no gerenciador, este disponibiliza em uma nova thread um treinador, ou Trainer, que apresenta os recursos necessários para manipular e visualizar o tipo de Rede Neural em uso. A Figura 5.22 apresenta a janela principal do Simulador com uma lista de algoritmos de treinamento disponíveis e a janela do Trainer com a topologia da Rede Neural em treinamento. 

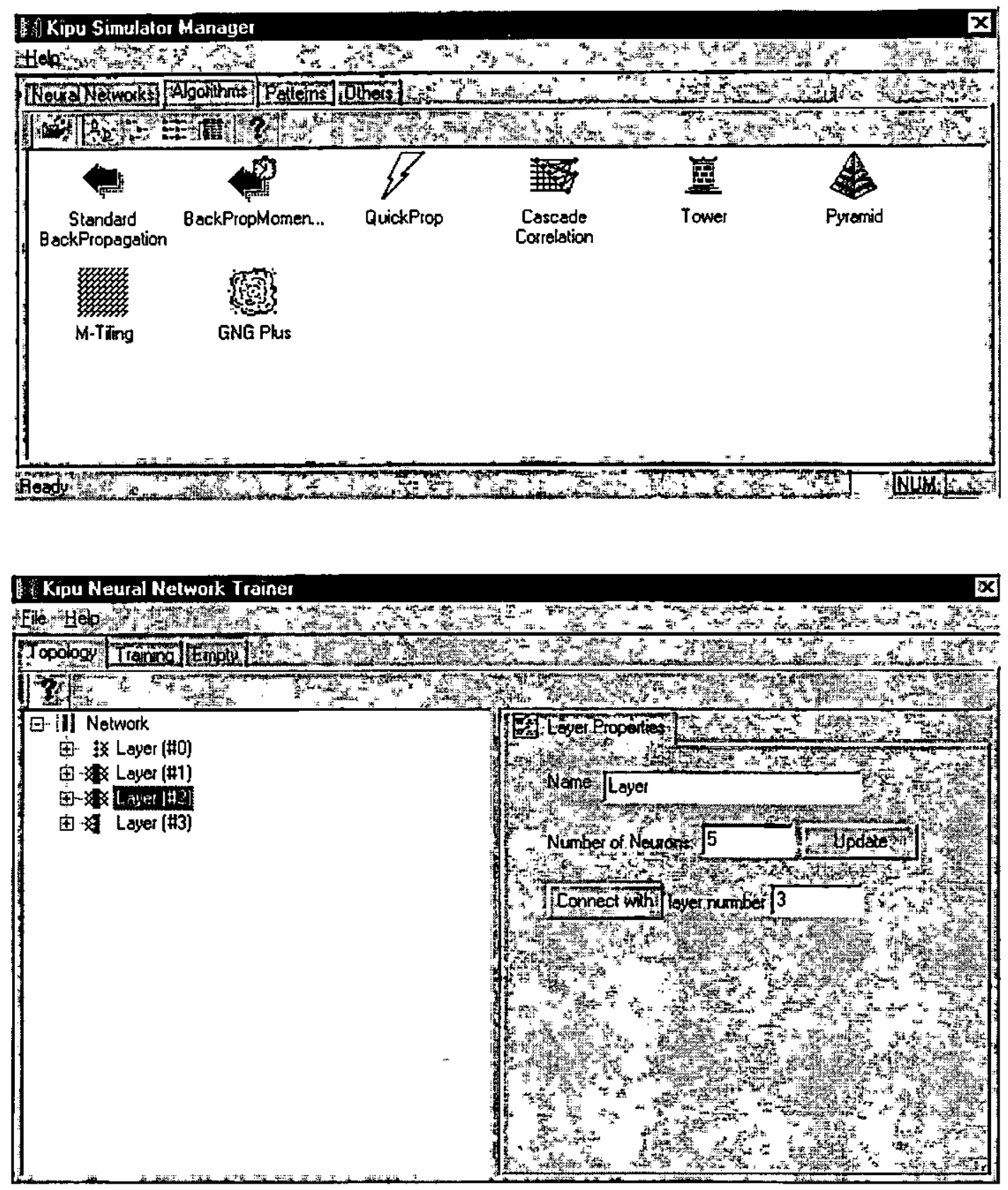

Figura 5.22: Janelas do módulo cliente.

O Trainer apresenta ao usuário três informações sobre a Rede Neural: Topologia, Treinamento e Resultado. Estas informaçōes são apresentadas através de property pages (páginas de propriedade), muito comuns em aplicações Windows, onde o usuário pode fornecer e receber várias informações de maneira direta e formatada.

A property page responsável pela Topologia apresenta uma estrutura hierárquica da Rede Neural através de uma árvore, onde a raiz é a Rede Neural em uso e seus outros nós são camadas e neurônios. Quando um destes nós é selecionado, uma ou mais property pages 
específicas a este componente são carregadas para edição das características do elemento. Através da property page carregada, propriedades como número de camadas e neurônios, funções de ativação e inicialização de pesos, ou atributos mais simples como o nome do componente, podem ser alterados. A janela do Trainer, ilustrada na Figura 5.22, apresenta a property page de uma das camadas. Esta página é determinada pelo componente MLLayer, visto na Seção 5.2.2, e carregada em tempo de execução pela aplicação cliente.

A property page do Treinamento disponibiliza uma lista de algoritmos de treinamento carregados no Repositório e que são suportados pela Rede Neural em uso. Uma vez selecionado o algoritmo desejado, o Trainer cria uma instância deste algoritmo e carrega uma ou mais property pages implementadas pelo mesmo. No caso dos Algoritmos Construtivos discutidos no Capítulo 3, além das páginas específicas ao algoritmo, são carregadas também as páginas do algoritmo de treinamento selecionado. Por exemplo, um algoritmo como o Cascade Correlation que pretende utilizar o back-propagation para alterar seus pesos, carrega suas páginas e as páginas do back-propagation. A página de Treinamento também é responsável pelo controle do treinamento, exibindo os controles para o início e término do treinamento e o gráfico do erro da Rede Neural.

As informações do Resultado de uma Rede Neural podem ser apresentadas em uma ou mais property pages. Como este trabalho concentrou-se em problemas de classificação, apenas uma página é carregada. Esta página permite ao usuário testar o desempenho da Rede Neural com um conjunto de padrões inéditos, fornecendo tanto a soma do erro quadrático e o erro quadrático médio, quanto o número e porcentagem de padrões corretamente classificados, incorretamente classificados e padrões não reconhecidos. Estas porcentagens são obtidas através de uma regra como a 402040 (Zell, 1995), ou determinando limites de valores para considerar um neurônio como ativado ou desativado. Para problemas de regressão, uma nova página de teste pode ser facilmente incluída no componente, contendo regras de avaliação de desempenho mais apropriadas.

O Trainer foi implementado de maneira a não precisar de nenhum detalhe sobre a Rede Neural ou algoritmo em utilização. Isto é possível devido ao fato de todas as property pages específicas à Rede Neural ou ao algoritmo serem definidas pelos seus próprios componentes e implementadas junto ao Kernel. Assim, o Trainer trata-se apenas de um recipiente preenchido por componentes do Kernel. Este mecanismo permite a total flexibilidade do Simulador 
em relação a novos modelos e algoritmos, sendo totalmente transparente para o Trainer.

\subsection{Considerações Finais}

Este Capítulo apresentou os motivos que levaram à reformulação do projeto do Simulador Kipu. O principal motivo foi a sua adequação às necessidades surgidas durante o desenvolvimento deste trabalho. A reformulação enfocou, principalmente, a modularidade e independência dos diversos elementos envolvidos no treinamento e utilização de Redes Neurais.

Cada um destes elementos foi definido como um componente COM, de maneira que seu acesso passou a ser controlado por uma ou mais interfaces. Uma interface é a definição de um conjunto de funções semanticamente relacionadas que são implementadas pelo componente. Em COM, uma interface comporta-se como uma classe base puramente virtual, onde suas classes derivadas redeclaram seus métodos e adicionam a implementação mais adequada.

O encapsulamento de funcionalidade em componentes acessados através de interfaces torna o modelo COM um sistema aberto e extensível. Aberto no sentido de que qualquer objeto pode fornecer uma implementação de uma interface definida e desenvolver uma aplicação que utilize esta interface, e extensível no sentido de que interfaces novas ou incrementadas podem ser definidas sem mudanças nas aplicações existentes.

O próximo passo na remodelação do Simulador foi a definição de uma nova hierarquia de classes, onde qualquer modelo ou algoritmo para Redes Neurais possa ser facilmente adicionado. Para permitir que esta adição ocorra intuitivamente, classes abstratas foram criadas através de templates. Estas classes implementam funções comuns a qualquer algoritmo de treinamento ou Rede Neural, de maneira que um novo algoritmo ou Rede Neural será representado por uma classe derivada destas classes template.

Os Algoritmos Construtivos apresentados no Capítulo 3 também foram definidos como componentes COM, permitindo que qualquer algoritmo de treinamento derivado do backpropagation possa ser agregado em tempo de execução para modificar os pesos da Rede Neural em treinamento.

Os componentes foram disponibilizados em uma DLL chamada Kernel, podendo ser utiliza- 
dos em qualquer aplicação com suporte ao modelo COM. Substituindo o antigo Simulador Kipu, sua nova versão é uma aplicação cliente que, ao utilizar os serviços desta DLL, não precisa conhecer os detalhes de implementação dos componentes, bastando gerenciá-los de acordo com as instruções do usuário. Outras aplicações também podem ser criadas para utilizar os recursos presentes no Kernel. Estas novas aplicações podem inclusive se limitar a algum modelo de Rede Neural ou algoritmo específico. 


\section{Capítulo 6}

\section{Experimentos}

Os experimentos apresentados neste capítulo são os primeiros de uma seqüência que tem como objetivo comparar o desempenho das Redes Neurais Construtivas em diferentes domínios de aplicações envolvendo Reconhecimento de Padrões.

Os conjuntos de padrões descritos nas Seções 6.1 e 6.2 pertencem a repositórios públicos e foram agrupados e documentados no benchmark Proben1 (Prechelt, 1994). Estes conjuntos foram normalizados e convertidos para o padrão SNNS (Zell, 1995).

Os resultados obtidos são dispostos em tabelas contendo a média e o desvio padrão da porcentagem de padrões corretamente e incorretamente classificados e de padrōes não reconhecidos.

Estas médias foram calculadas sobre três treinamentos para cada algoritmo, onde cada treinamento utilizou um conjunto de padrōes obtido a partir do embaralhamento dos padrões do conjunto original. O conjunto obtido do embaralhamento dos padrões foi dividido em subconjuntos de Treinamento, Validação e Teste, de acordo com as instruções do Proben1.

O critério adotado para determinar a correta classificação de um padrão foi a regra 402040. Esta regra especifica que para o estado de um neurônio ser considerado como ativado, seu valor de saída deve ser superior a 0.6 , enquanto que um valor inferior a 0.4 indica o estado desativado. Valores de saída entre 0.4 e 0.6 indicam um estado indeterminado.

O padrão é considerado corretamente classificado quando as seguintes condições são observadas na camada de saída: 
1. Apenas um neurônio está ativado.

2. Os demais neurônios estão desativados.

3. Os neurônio ativado corresponde à classe desejada.

Quando o neurônio ativado não corresponde à classe desejada, o padrão é considerado incorretamente classificado. Um padrão não reconhecido é aquele que ativa mais de um neurônio, não ativa nenhum neurônio ou gera um estado indeterminado em algum dos neurônios.

Os parâmetros selecionados para os algoritmos de treinamento foram obtidos a partir de execuções preliminares dos experimentos e correspondem aos parâmetros que resultaram em menor média para a taxa de erro de generalização, determinada pelo subconjunto de Validação.

Outros resultados, como a soma quadrática do erro da rede e o número conexões ajustadas, também foram considerados para a comparação destes algoritmos.

\subsection{Conjunto de Padrões Diabetes}

Este conjunto de dados foi inicialmente gerado pelo National Institute of Diabetes and Digestive and Kidney Diseases e fornecido ao UCI Machine Learning Database em maio de 1990 .

São 768 padrões contendo 8 atributos de entrada destinados a caracterizar a presença ou não de diabetes em um paciente do sexo feminino. Destes, 500 padrões representam indivíduos saudáveis. Os 268 padrões restantes representam indivíduos com diabetes. Os atributos de entrada são números reais e seu significado é apresentado na Tabela 6.1 .

Este conjunto de dados foi escolhido para fazer parte destes experimentos devido à grande dificuldade da correta classificação de grande parte dos padrões. Esta dificuldade é devida à falta de vários valores nos a.tributos de entrada, representados com o valor zero, o que torna este problema um desafio a qualquer modelo de Rede Neural. 


\begin{tabular}{|c|l|c|}
\hline Atributo & Descriçāo & Média \\
\hline 1 & Número de gestações & $3.8 \pm 3.4$ \\
\hline 2 & $\begin{array}{l}\text { Nível de glicose no plasma após 2 horas em um teste } \\
\text { oral de tolerância à glicose }\end{array}$ & $120.9 \pm 32.0$ \\
\hline 3 & Pressão sangǘnia diastólica $(\mathrm{mm} \mathrm{Hg})$ & $69.1 \pm 19.4$ \\
\hline 4 & Prega cutânea do tríceps (mm) & $20.5 \pm 16.0$ \\
\hline 5 & Nível de insulina no soro após 2 horas $(\mathrm{mu} \mathrm{U} / \mathrm{ml})$ & $79.8 \pm 115.2$ \\
\hline 6 & Índice de massa corporal (peso em kg/(altura em $\mathrm{m})^{2}$ ) & $32.0 \pm 7.9$ \\
\hline 7 & Função de disposição genética a diabetes & $0.5 \pm 0.3$ \\
\hline 8 & Idade (anos) & $33.2 \pm 11.8$ \\
\hline
\end{tabular}

Tabela 6.1: Estatística do conjunto de dados Diabetes.

\subsubsection{Resultados Obtidos pelo Tower}

$\mathrm{O}$ algoritmo Tower foi executado em conjunto com três algoritmos de treinamento: backpropagation, back-propagation momentum e quick-propagation. As Tabelas 6.2, 6.3 e 6.4 apresentam as médias da precisão de classificação (\%) obtidas utilizando os três algoritmos de treinamento, respectivamente.

\begin{tabular}{|l|c|c|c|}
\hline & Treinamento & Validação & Teste \\
\hline Corretos & $78,30 \pm 2,184$ & $70,49 \pm 3,468$ & $68,06 \pm 1,084$ \\
\hline Incorretos & $10,85 \pm 0,986$ & $18,58 \pm 1,591$ & $21,35 \pm 4,166$ \\
\hline Não reconhecidos & $10,85 \pm 2,760$ & $10,94 \pm 3,646$ & $10,59 \pm 4,045$ \\
\hline
\end{tabular}

Tabela 6.2: Resultados do Algoritmo Tower treinado com back-propagation.

\begin{tabular}{|l|c|c|c|}
\hline & Treinamento & Validação & Teste \\
\hline Corretos & $80,30 \pm 1,285$ & $78,30 \pm 4,045$ & $74,31 \pm 2,105$ \\
\hline Incorretos & $19,53 \pm 1,194$ & $21,53 \pm 3,978$ & $24,83 \pm 3,545$ \\
\hline Não reconhecidos & $0,17 \pm 0,300$ & $0,17 \pm 0,301$ & $0,87 \pm 1,503$ \\
\hline
\end{tabular}

Tabela 6.3: Resultados do Algoritmo Tower treinado com back-propagation momentum.

Nos três casos, o algoritmo foi limitado a inserir no máximo três camadas para evitar a especialização das redes sobre o conjunto de treinamento. Assim, 6 neurônios e 60 conexões foram inseridos ao todo, com 20 conexões sendo treinadas por ciclo. 


\begin{tabular}{|l|c|c|c|}
\hline & Treinamento & Validação & Teste \\
\hline Corretos & $68,23 \pm 4,688$ & $68,92 \pm 1,674$ & $64,24 \pm 3,348$ \\
\hline Incorretos & $14,06 \pm 1,584$ & $15,63 \pm 2,270$ & $17,19 \pm 3,932$ \\
\hline Não reconhecidos & $17,71 \pm 6,157$ & $15,45 \pm 3,943$ & $18,58 \pm 5,059$ \\
\hline
\end{tabular}

Tabela 6.4: Resultados do Algoritmo Tower treinado com quick-propagation.

Os algoritmos de treinamento foram configurados para executar 3000 ciclos antes do algoritmo Tower inserir uma camada, e executar mais 3000 ciclos após a última camada ser inserida. A taxa de treinamento foi de 0,01 para os três algoritmos de treinamento, com taxa de momentum igual a 0,00001 para o algoritmo back-propagation momentum.

\subsubsection{Resultados Obtidos pelo Pyramid}

A mesma configuração escolhida para o algoritmo Tower foi utilizada no algoritmo Pyramid. As Tabelas 6.5, 6.6 e 6.7 apresentam os resultados obtidos com o uso em conjunto dos mesmos três algoritmos de treinamento.

\begin{tabular}{|l|c|c|c|}
\hline & Treinamento & Validação & Teste \\
\hline Corretos & $62,50 \pm 3,315$ & $64,06 \pm 1,312$ & $60,16 \pm 5,525$ \\
\hline Incorretos & $13,02 \pm 0,737$ & $10,68 \pm 1,105$ & $14,06 \pm 0,736$ \\
\hline Não reconhecidos & $24,48 \pm 2,578$ & $25,26 \pm 2,207$ & $25,78 \pm 4,789$ \\
\hline
\end{tabular}

Tabela 6.5: Resultados do Algoritmo Pyramid treinado com back-propagation.

\begin{tabular}{|l|c|c|c|}
\hline & Treinamento & Validação & Teste \\
\hline Corretos & $71,09 \pm 2,345$ & $67,60 \pm 1,541$ & $62,40 \pm 4,258$ \\
\hline Incorretos & $16,67 \pm 1,904$ & $27,19 \pm 3,221$ & $23,96 \pm 2,183$ \\
\hline Não reconhecidos & $12,24 \pm 2,014$ & $5,21 \pm 3,578$ & $13,65 \pm 3,058$ \\
\hline
\end{tabular}

Tabela 6.6: Resultados do Algoritmo Pyramid treinado com back-propagation momentum.

Os parâmetros estabelecidos foram os mesmos do algoritmo Tower, pois estes algoritmos são baseados no mesmo conceito, diferenciando-se apenas pelo número de conexões inseridas.

Foram inseridos 6 neurônios e um total de 84 conexões, sendo que a cada ciclo foram treinadas de 16 a 28 conexões. 


\begin{tabular}{|l|c|c|c|}
\hline & Treinamento & Validação & Teste \\
\hline Corretos & $78,25 \pm 4,041$ & $62,74 \pm 2,465$ & $62,09 \pm 2,765$ \\
\hline Incorretos & $11,58 \pm 2,739$ & $28,77 \pm 2,187$ & $28,91 \pm 2,420$ \\
\hline Não reconhecidos & $10,17 \pm 3,437$ & $8,49 \pm 2,476$ & $9,00 \pm 2,689$ \\
\hline
\end{tabular}

Tabela 6.7: Resultados do Algoritmo Pyramid treinado com quick-propagation.

\subsubsection{Análise dos Resultados}

Aparentemente, o resultado dos Algoritmos Construtivos apresentou um desempenho abaixo do esperado. Porém, ao observar o erro quadrático médio (MSE), este desempenho considerado baixo ainda foi, para a Rede Tower treinada com o algoritmo back-propagation padrão, superior ao de Redes Neurais convencionais, como mostra o resultado publicado em Proben1. A Tabela 6.8 compara o erro quadrático médio dos Algoritmos Construtivos com o publicado em Proben1.

\begin{tabular}{|l|l|c|}
\hline & Treinada com & MSE \\
\hline MLP 8-4-4-2 & back-propagation & $0,1466 \pm 0,01066$ \\
\hline Tower & back-propagation & $0,1080 \pm 0,00431$ \\
\hline Tower & backprop momentum & $0,1962 \pm 0,01229$ \\
\hline Tower & quick-propagation & $0,1650 \pm 0,02349$ \\
\hline Pyramid & back-propagation & $0,1607 \pm 0,00976$ \\
\hline Pyramid & backprop momentum & $0,2279 \pm 0,02984$ \\
\hline Pyramid & quick-propagation & $0,1582 \pm 0,00952$ \\
\hline
\end{tabular}

Tabela 6.8: Erro quadrático médio (MSE).

A topologia da rede MLP na primeira linha da Tabela 6.8 foi escolhida como a de melhor generalização entre as outras topologias experimentadas no Proben1. A Tabela 6.9 apresenta os resultados obtidos com esta rede.

\begin{tabular}{|l|c|c|c|}
\hline & Treinamento & Validação & Teste \\
\hline Corretos & $69,97 \pm 2,105$ & $72,74 \pm 3,468$ & $67,53 \pm 1,972$ \\
\hline Incorretos & $15,28 \pm 0,398$ & $14,93 \pm 1,591$ & $18,40 \pm 2,869$ \\
\hline Não reconhecidos & $14,76 \pm 1,734$ & $12,33 \pm 2,106$ & $14,06 \pm 0,902$ \\
\hline
\end{tabular}

Tabela 6.9: Resultados do Algoritmo back-propagation aplicado em uma Rede Neural 8-44-2. 
Um resultado interessante observado neste experimento foi que, apesar do erro quadrático médio apresentado pelo algoritmo Tower em conjunto com o algoritmo back-propagation ser inferior ao apresentado pelo mesmo algoritmo em conjunto com o algoritmo back-propagation momentum, sua precisão de classificação para os conjuntos de teste e validação foi superada por este último.

Comparando a precisão de classificação dos conjuntos de teste, pode-se observar que o algoritmo Tower apresentou um desempenho superior ao algoritmo Pyramid. O melhor desempenho deste algoritmo também é observado no menor número de conexões inseridas e pesos modificados (60 do Tower contra 84 do Pyramid).

\subsection{Conjunto de Padrões Gene}

Este conjunto de dados, também conhecido como Primate splice-junction gene sequences with associated imperfect domain theory, foi construído a partir do repositório de dados Genbank 64.1 (genbank.bio.net) em janeiro de 1992.

Splice-junctions são pontos em uma seqüência de DNA em que DNA "supérfluo"é romovido durante o processo de criação de proteína em organismos mais desenvolvidos. O problema apresentado por esta base de dados é, dada uma seqüência de DNA, reconhecer os limites entre exons (as partes da seqüência de DNA que são mantidas após a quebra desta seqüencia) e introns (as partes da seqüência que são cortadas). Este problema consiste em duas subtarefas: reconhecer limites exon/intron (pontos de EI), e reconhecer limites intron/exon (pontos de IE). Na comunidade biológica, limites IE são denominados acceptors, enquanto limites EI são denominados donors.

Os padrões de entrada consistem originalmente de uma seqüência de 60 caracteres representando as posições de nucleotídios ( $\mathrm{A}, \mathrm{G}, \mathrm{T}$ e $\mathrm{C})$, sendo classificados em uma entre três categorias: EI, IE ou nenhum.

Do total de 3190 padrões, 767 (25\%) representam pontos EI, $768(25 \%)$ pontos IE e I587 (50\%) não caracterizam um splice-junction. Os 15 padrões que apresentam ambigüidade na seqüência de DNA não foram considerados no treinamento. 


\begin{tabular}{|c|c|}
\hline Nucleotídio & Entrada \\
\hline C & $-1-1$ \\
\hline A & -11 \\
\hline G & $1-1$ \\
\hline T & 11 \\
\hline
\end{tabular}

Tabela 6.10: Mapeamento dos padrōes de entrada.

A conversão deste conjunto de dados para valores numéricos, fornecida pelo Proben1, foi o mapeamento para uma representação com par de entradas para cada nucleotídio, como ilustra a Tabela 6.10.

\subsubsection{Resultados Obtidos pelo Tower}

Diferente do experimento anterior, com este conjunto de padrōes o algoritmo Tower foi executado em conjunto com apenas os algoritmos de treinamento back-propagation e quickpropagation. Os experimentos preliminares executados com o algoritmo back-propagation momentum apresentaram grandes variações tanto na precisão de classificação como no erro quadrático médio. Portanto, foi decidido que novas tentativas com parâmetros de treinamento diferentes devem ser executadas antes de apresentar qualquer resultado conclusivo. As Tabelas 6.2 e 6.3 apresentam as médias da precisão de classificação (\%).

\begin{tabular}{|l|c|c|c|}
\hline & Treinamento & Validação & Teste \\
\hline Corretos & $85,03 \pm 0,777$ & $71,03 \pm 1,666$ & $71,84 \pm 2,720$ \\
\hline Incorretos & $1,47 \pm 0,284$ & $5,67 \pm 0,881$ & $5,34 \pm 0,811$ \\
\hline Não reconhecidos & $13,50 \pm 1,004$ & $23,30 \pm 0,787$ & $22,82 \pm 2,406$ \\
\hline
\end{tabular}

Tabela 6.11: Resultados do Algoritmo Tower treinado com back-propagation.

\begin{tabular}{|l|c|c|c|}
\hline & Treinamento & Validação & Teste \\
\hline Corretos & $72,65 \pm 0,419$ & $66,46 \pm 1,956$ & $66,79 \pm 2,694$ \\
\hline Incorretos & $3,07 \pm 0,528$ & $4,87 \pm 1,14 \vdots$ & $5,30 \pm 0,550$ \\
\hline Não reconhecidos & $24,29 \pm 0,536$ & $28,67 \pm 0,838$ & $27,91 \pm 2,407$ \\
\hline
\end{tabular}

Tabela 6.12: Resultados do Algoritmo Tower treinado com quick-propagation. 
O algoritmo Tower foi limitado a inserir no máximo duas camadas. Em experimentos rodados com inclusão de mais camadas foi observado não apenas perda de generalização mas também aumento do erro do treinamento.

O algoritmo inseriu 6 neurônios e 738 conexões. A cada ciclo, 369 conexões tiveram seus pesos modificados.

Os algoritmos de treinamento foram configurados para executar 5000 ciclos com taxa de treinamento de 0,0001 antes da inserção de novas camadas, e executar mais 5000 ciclos após a última camada ser inserida.

\subsubsection{Resultados Obtidos pelo Pyramid}

Os experimentos utilizando o algoritmo Pyramid mantiveram a mesma configuração da seção anterior. As Tabelas 6.13 e 6.14 apresentam os resultados obtidos.

\begin{tabular}{|l|c|c|c|}
\hline & Treinamento & Validação & Teste \\
\hline Corretos & $82,51 \pm 3,457$ & $67,92 \pm 2,956$ & $68,25 \pm 2,700$ \\
\hline Incorretos & $2,60 \pm 1,323$ & $12,74 \pm 2,015$ & $12,32 \pm 1,457$ \\
\hline Não reconhecidos & $14,89 \pm 1,038$ & $19,34 \pm 1,836$ & $19,43 \pm 1,885$ \\
\hline
\end{tabular}

Tabela 6.13: Resultados do Algoritmo Pyramid treinado com back-propagation.

\begin{tabular}{|l|c|c|c|}
\hline & Treinamento & Validação & Teste \\
\hline Corretos & $70,99 \pm 3,265$ & $67,45 \pm 2,983$ & $65,57 \pm 1,516$ \\
\hline Incorretos & $1,57 \pm 1,109$ & $2,52 \pm 1,822$ & $2,67 \pm 0,982$ \\
\hline Não reconhecidos & $27,44 \pm 1,373$ & $30,03 \pm 2,674$ & $31,76 \pm 1,745$ \\
\hline
\end{tabular}

Tabela 6.14: Resultados do Algoritmo Pyramid treinado com quick-propagation.

O algoritmo Pyramid inseriu 6 neurônios e 756 conexões, alterando a cada ciclo de 360 a 378 pesos. Os parâmetros dos algoritmos de treinamento foram os mesmos utilizados pelo algoritmo Tower. 


\subsubsection{Análise dos Resultados}

Como nos experimentos com o conjunto de dados Diabetes, o erro quadrático médio dos experimentos descritos nesta seção foram comparados com os obtidos por uma rede MLP de topologia fixa treinada com o algoritmo back-propagation, utilizando os parâmetros publicados em Proben1.

\begin{tabular}{|l|l|c|}
\hline & Treinada com & MSE \\
\hline MLP 120-2-3 & back-propagation & $0,0612 \pm 0,00895$ \\
\hline Tower & back-propagation & $0,0448 \pm 0,00038$ \\
\hline Tower - & quick-propagation & $0,1020 \pm 0,00307$ \\
\hline Pyramid & back-propagation & $0,1292 \pm 0,00525$ \\
\hline Pyramid & quick-propagation & $0,1108 \pm 0,00924$ \\
\hline
\end{tabular}

Tabela 6.15: Comparação entre o MSE de cada configuração.

A topologia da rede MLP na primeira linha da Tabela 6.15 foi escolhida como a de melhor generalização entre as outras topologias experimentadas no Proben1. A Tabela 6.16 apresenta os resultados obtidos com esta rede.

\begin{tabular}{|l|c|c|c|}
\hline & Treinamento & Validação & Teste \\
\hline Corretos & $78,31 \pm 4,059$ & $75,02 \pm 3,212$ & $75,70 \pm 5,282$ \\
\hline Incorretos & $2,04 \pm 0,935$ & $2,94 \pm 1,404$ & $3,70 \pm 0,509$ \\
\hline Não reconhecidos & $19,65 \pm .3,136$ & $22,04 \pm 1,939$ & $20,60 \pm 4,904$ \\
\hline
\end{tabular}

Tabela 6.16: Resultados do Algoritmo back-propagation aplicado em uma Rede Neural 120$2-3$.

Comparando os algoritmos Tower e Pyramid, um melhor desempenho do algoritmo Tower pode ser observado, com a diferença de que neste caso, o algoritmo de treinamento utilizado foi o back-propagation. Entretanto, apesar do erro quadrático médio da Rede Tower ser inferior do que o da rede MLP com topologia fixa, a Rede Tower não conseguiu superar a precisão de classificação da rede MLP sobre os conjuntos de validação e teste. 


\section{Capítulo 7}

\section{Conclusão}

Este trabalho destacou cinco modelos de Redes Neurais Construtivas. Estes modelos diferem de Redes Neurais convencionais por permitir que novos neurônios e conexões sejam adicionados durante a fase de treinamento. A adição de novos elementos em uma Rede Neural Construtiva é controlada por seu Algoritmo Construtivo, que executa uma avaliação do desempenho da Rede Neural em um determinado momento do treinamento e insere novos neurônios e conexões de acordo com um critério específico. Os pesos das novas conexões são então alterados por um algoritmo de treinamento, como o algoritmo back-propagation ou uma de suas variações.

Os modelos construtivos estudados neste trabalho foram agrupados em quatro grupos que se caracterizam pelo método de avaliação do desempenho da Rede Neural em treinamento:

- Redes que avaliam a precisão de classificação.

- Redes que avaliam a presença de classificação incorreta.

- Redes que avaliam a correlação entre a ativação de um neurônio e a função de erro dos neurônios de saída.

- Redes que avaliam o critério de fidelidade de uma camada.

A abordagem oferecida pelos Algoritmos Construtivos possui a vantagem de apresentar a possibilidade de se automatizar o processo de determinação da topologia. Porém, como as 
pesquisas envolvendo estes algoritmos são recentes, grande parte dos resultados publicados envolvendo Redes Neurais Construtivas são obtidos de conjuntos de dados artificiais.

A motivação inicial deste trabalho foi a execução de uma série de experimentos utilizando as Redes Neurais Construtivas mencionadas. Os experimentos irão permitir uma melhor comparação do desempenho destas Redes Neurais em problemas reais de Reconhecimento de Padrões.

Entretanto, para que a comparação seja realmente imparcial, estes experimentos precisam ser realizados em um ambiente homogêneo, onde os algoritmos trabalhem sobre o mesmo modelo de dados e não dependam de otimizações de estrutura de dados e código normalmente encontradas em suas implementações originais.

O Simulador Kipu, inicialmente desenvolvido para a criação e treinamento de Redes Neurais Construtivas, foi adotado para a execução dos experimentos. Porém, durante a revisão do seu projeto, foi detectada a necessidade de alterações para desvincular certos elementos e permitir a inclusão de novos modelos e algoritmos de forma mais intuitiva.

Um novo projeto do Simulador Kipu foi desenvolvido, onde todos os seus elementos foram definidos como componentes COM (Component Object Model), permitindo assim a maior modularidade e flexibilidade na sua utilização.

A facilidade na inclusão de novos modelos e algoritmos para Redes Neurais foi alcançada através da definição de uma hierarquia de classes, onde as classes base são templates que contêm as operações comuns a qualquer tipo de objeto, como uma Rede Neural ou algoritmo de treinamento.

Outro aspecto fundamental no novo projeto foi a separação do Simulador Kipu em dois módulos: cliente e servidor. O módulo servidor é a coleção de componentes COM que implementam a funcionalidade dos Algoritmos Construtivos citados neste trabalho. Este módulo também contém o algoritmo de treinamento back-propagation e algumas de suas variações, além dos componentes para a manipulação de conjuntos de padrões. $O$ módulo cliente é a aplicação final que utiliza os serviços disponibilizados no módulo servidor para controlar o processo de treinamento de Redes Neurais sem, no entanto, depender diretamente da implementação destes serviços. 
O módulo servidor, ou Kernel, foi implementado como uma DLL (Dynamic Link Library), porém algumas partes foram implementadas em DLLs separadas, como é o caso do Visualizador de Redes Neurais comentado na Seção 5.3. Similarmente, novas modificações no Kernel podem ser implementadas em novas DLLs, sem influenciar a implementação dos componentes existentes.

Duas bibliotecas de classes foram utilizadas na implementação destes módulos. A biblioteca ATL (Active Template Library) contém um conjunto de classes próprio para a criação de componentes COM e foi utilizada no desenvolvimento do Kernel. O módulo cliente foi implementado utilizando a biblioteca MFC (Microsoft Foundation Class), que contém um extenso conjunto de classes para a criação de aplicações Windows.

O Capítulo 6 apresenta uma parcela dos experimentos planejados para a comparação do desempenho dos Algoritmos Construtivos em aplicações reais de Reconhecimento de Padrões. Nestes primeiros experimentos já é possivel perceber uma tendência no comportamento dos Algoritmos Construtivos, onde estes nem sempre conseguem atingir um valor de erro quadrático médio (MSE) melhor do que o de uma Rede Neural com topologia fixa treinado com o algoritmo back-propagation. Um possível motivo para esta diferença é que como no treinamento de Redes Neurais Construtivas, os pesos das conexões anteriormente inseridas permanecem inalterados após a inclusão de um novo neurônio ou camada. Assim, enquanto em uma Rede Neural convencional todos os pesos são alterados, em uma Rede Neural Construtiva apenas os pesos vinculados às conexões da camada de saída voltam a ser alterados.

Deve ser observado contudo, que o valor do erro quadrático médio é independente da precisão de classificação de uma Rede Neural. Nos experimentos apresentados na Seção 6.1, a Rede Neural Tower apresentou melhor precisão de classificação do que a Rede Neural com topologia fixa.

Nos experimentos do Capítulo 6, apenas dois Algoritmos Construtivos foram utilizados, percebendo-se um melhor desempenho do algoritmo Tower sobre sua variação Pyramid. Esta melhora deve-se principalmente ao melhor nível de generalização do algoritmo Tower, observado na precisão de reconhecimento nos conjuntos de validação e teste. 


\subsection{Contribuições}

O maior resultado obtido por este trabalho foi a hierarquia de classes e o desenvolvimento dos componentes descritos no Capítulo 5. A hierarquia e os componentes não compōem apenas um simulador de Redes Neurais, mas constituem um verdadeiro framework de aplicação para trabalhos em Redes Neurais. Uma definição simples de framework de aplicaçāo (Kruglinski et al., 1998) é:

Uma coleção integrada de componentes de software orientados a objetos que oferecem o necessário para a criação de uma aplicação genérica.

O termo framework neste trabalho é devido ao fato da hierarquia proposta não caracterizar um projeto fixo, e sim um ponto de referência para a implementação de qualquer aplicação que utilize um modelo de Rede Neural e \ou um algoritmo de treinamento. Este ponto de referência também existe para a implementação de novos modelos de Redes Neurais e algoritmos, fornecendo uma diretriz para a adição destes novos modelos e algoritmos no framework existente.

Os componentes COM desenvolvidos neste trabalho, por manterem a maior parte de sua funcionalidade em classes template base, servem como ponto de partida para a criação de novos componentes que reaproveitem esta funcionalidade. No caso de um componente cujas características não permitam este reaproveitamento, o desenvolvedor é orientado a separar as funcionalidades comuns a possíveis variações deste componente em novas classes template, evitando a especialização do código e permitindo ao framework continuar flexível e expansível. Outra contribuição deste trabalho foi a publicação de dois artigos em congressos internacionais. Estes artigos apresentam resultados obtidos da execução das primeiras versões dos Algoritmos Construtivos mencionados neste trabalho.

- Pattern Recognition Using Constructive Algorithms. Proceedings of the International Joint Conference on Neural Networks (Printed in CD-ROM). Washington, DC. 1999.

- Credit Assessment Using Constructive Neural Networks. Proceedings of the International Conference on Computational Inteligence and Multimedia Applications. New Delhi, India. 1999. 
A integração de softwares dedicados ao treinamento de Redes Neurais com uma aplicação final normalmente apresenta uma barreira de comunicação e dependência de implementação entre estas partes. O uso do Component Object Model neste trabalho contribuiu com a apresentação de conceitos de independência e comunicação de objetos que facilitam a integração do Simulador Kipu (ou outro aplicativo que utilize o framework) com aplicações externas.

\subsection{Dificuldades Encontradas}

A grande dificuldade encontrada no decorrer deste trabalho foi a remodelação do projeto do Simulador Kipu. Esta dificuldade concentrou-se no aprendizado e correta utilização do COM. Este modelo apresenta vários novos detalhes sobre a criação e utilização de seus componentes e, no caso do projeto do Simulador Kipu, várias funcionalidades que não possuem documentação, ou não aparecem em outros projetos, tiveram de ser implementadas, como por exemplo, a importação de property pages criadas em ATL em uma aplicação criada em MFC.

Outra dificuldade que acompanhou a revisão dos Algoritmos Construtivos e a inclusão de alguns algoritmos de treinamento, foi a omissão de detalhes de implementação na descrição destes algoritmos em seus artigos científicos. Estes detalhes, na maioria das vezes, só foram percebidos ao analisar o código criado pelo próprio autor dos artigos.

\subsection{Trabalhos Futuros}

Como mencionado anteriormente, os experimentos apresentados no Capítulo 6 são apenas os primeiros de um planejamento que envolve os outros Algoritmos Construtivos discutidos neste trabalho e outros conjuntos de dados representando diferentes domínios de aplicação de Reconhecimento de Padrões.

Assim que estes experimentos estiverem concluídos, pretende-se disponibilizar seus resultados em um relatório técnico a ser publicado pelo Instituto de Ciências Matemáticas e de Computação - USP. O resumo dos resultados será formatado em artigos submetidos a congressos ou revistas científicas. 
Outro relatório técnico, já em andamento, irá detalhar as particularidades de implementação do framework. Este relatório tem como objetivo permitir que as pesquisas envolvendo Redes Neurais, especialmente as realizadas no Laboratório de Inteligência Computacional Labic, possam tirar proveito do resultado alcançado por este trabalho, além de encorajar a continuidade do desenvolvimento do framework. 


\section{Referências}

Abernethy, R. (1999). COM/DCOM Unleashed. Sams Publishing.

Beale, R. and Jackson, T. (1990). Neural Computing: an Introduction. Adam Hilder.

Berthold, M. R. and Diamond, J. (1995). Boosting the performance of RBF networks with dynamic decay adjustment. In Proceedings of the 1994 Conference: Advances in Neural Information Processing Systems, volume 7, pages 521-528. MIT Press.

Braga, A., de Carvalho, A., and Ludermir, T. (2000). Redes Neurais Artificiais: Teoria e Aplicaçôes. LTC (Livros Tecnicos e Cientificos).

Carvalho, A., Fairhurst, M. C., and Bisset, D. L. (1997). Combining boolean neural architectures for image recognition. Connection Science, 9(4):405-418.

de Sousa, H. C. and de Carvalho, A. (1999a). Credit assessment using constructive neural networks. In IEEE Computer Press, editor, Proceedings of the International Conference on Computational Intelligence and Multimedia Applications., pages 40-44.

de Sousa, H. C. and de Carvalho, A. (1999b). Pattern recongnition using constructive algorithms. In INNS, editor, Proceedings of the International Joint Conference on Neural Networks. Printed in CDROM.

Fahlman, S. (1988). An empirical study of learning speed in back-propagation networks. Technical Report. School of Computer Science, Carnegie Mellon University., (CMUCS-88-162).

Fahlman, S. and Lebiere, C. (1991). The cascade correlation learning archtecture. Technical Report.

Frean, M. (1989). The upstar algorithm: a method for constructing and training feedfoward neural networks. Technical Report. 
Gallant, S. I. (1990). Perceptron-based learning algorithms. IEEE Transactions on Neural Networks, 1(2):179-191.

Halgamuge, S. (1997). Self-evolving neural networks for rule-based data processing. IEEE Transaction on Signal Processing, 45(11).

Haykin, S. (1999). Neural Networks: a Comprehensive Foundation. Prentice Hall.

Holland, J. (1975). Adaptation in Natural and Artificial Systems. The University of Michigan Press.

Karnin, E. D. (1990). A simple procedure for pruning back-prapagation trained neural networks. IEEE Transactions on Neural Networks, 1(2):239-242.

Kruglinski, D. J., Wingo, S., and Shepherd, G. (1998). Programing with Visual C++. Microsoft Press.

Kwok, T.-Y. and Yeung, D.-Y. (1997). Objective functions for training new hidden units in constructive neural networks. IEEE Transactions on Neural Networks, 8(5):1131-1148.

Lippmann, R. P. (1987). An introduction to computing with neural networks. IEEE Acoustics Speech and Signal Processing Magazine, 4(2):4-22.

Lippmann, R. P. (1992). An Introduction to Computing with Neural Nets., pages 13-31. In (Mehra and Wah, 1992).

Mehra, P. and Wah, B. W., editors (1992). Artificial Neural Networks: Concepts and Theory. IEEE Computer Society Press.

Microsoft (1995). The COM Core Technology Specification. http://www.microsoft.com/. Oja, E. and Kohonen, T. (1992). The Subspace Learning Algorithm as a Formalism for Pattern Recognition and Neural Networks., pages 13-31. In (Mehra and Wah, 1992).

Parekh, R., Yang, J., and Honavar, V. (1996). MTiling - a constructive neural network learning algorithm for multi-category pattern classification. In Proceedings of the World Congress on Neural Networks'g6, pages 182-187, San Diego.

Parekh, R., Yang, J., and Honavar, V. (1997a). Constructive neural networks learning algorithms for multi-category real-valued pattern classification. http://www.cs.iastate.edu/ honavar/aigroup.html. 
Parekh, R., Yang, J., and Honavar, V. (1997b). Pruning strategies for the M-Tiling constructive learning algorithm. In Proceedings of the IEEE/INNS International Conference on Neural Networks. ICNN'97, pages 1960-1965.

Parekh, R., Yang, J., and Honavar, V. (1998). Constructive neural networks learning algorithms for pattern classification. http://www.cs.iastate.edu/ honavar/aigroup.html.

Prechelt, L. (1994). Proben1 - a set of neural network benchmark problems and benchmarking rules. Fakultät füt Informatik. Universität Karlsruhe. Technical Report, number $21 / 94$.

Refenes, A.-P. (1995). Neural Networks In The Capital Markets. Wiley.

Ribeiro, J. and Vasconcelos, G. C. (1998). Verificação off-line de assinaturas baseada em uma arquitetura cascade-correlation autoassociativa. In Anais do V Simpósio Brasileiro de Redes Neurais, pages 305-310. Sociedade Brasileira de Computação.

Riedmiller, M. (1994). RPROP - description and implementation details. Technical Report. Institut für Logik, University of Karlsruhe., (W-76128 Karlsruhe).

Rumelhart, D. E., Hinton, G. E., and Williams, R. J. (1986). Learning internal representations by error propagation. In Parallel Distributed Processing: Explorations in the Microstructure of Cognition, pages 45-76. MIT Press.

Russel, S. and Norvig, P. (1995). Artificial Intelligence: A Modern Approach. PrenticeHall.

Schroeder, W., Martin, K., and Lorensen, B. (1997). The Visualization Toolkit: An ObjectOriented Approach To 3D Graphics. Prentice Hall.

Shiffmann, W., Joost, M., and Werner, R. (1994). Optimization of the backpropagation algorithm for training multilayer perceptrons. Technical Report. Institute of Physics, University of Koblenz.

Smith, M. (1996). Neural Networks for Statistical Modeling. International Thomson Computer Press.

Squires, C. and Shavlik, J. (1991). Experimental analysis of aspects of the cascade correlation learning archtecture. Computer Science Department, University of Wisconsin Madison. Technical Report, number 91-1. August. 
Tenorio, M. F. and Lee, W. T. (1989). Self-organizing neural nets for the identification problem. In Advances in Neural Information Processing Systems, volume 1.

Trippi, R. R. and Turban, E. (1993). Neural Networks in Finance and Inv̈es̈tīng. Prōbus Publishing Company.

Vargas, E. C. (1998). Kipu: Um simulador para redes neurais construtivas. Tese de mestrado, ICMC-USP.

Vargas, E. C., de Sousa, H. C., and de Carvalho, A. C. F. (1998). Target recognition using constructive neural networks. In European Space Agency, editor, Image Processing Techniques - Proceēdings of the 2nd Latino-American Seminar on Radar Remote Sensing, volume 433, pages 83-88.

VTK (2000). The VTK home page. http://www.kitware.com/vtk.html.

Waldherr, S., Thrun, S., and Romero, R. (1998). A neural-network based approach for recognition of pose and motion gestures on a mobile robot. In IEEE Computer Press, editor, Proceedings of the Vth Brazilian Symposium on Neural Networks, pages 79-84.

Zell, A. (1995). SNNS - stuttgart neural network simulator user manual version 4.1. University of Stuttgart. Technical Report, number 6/95. 